\title{
SIMULAÇÃO COMPUTACIONAL COMO UMA FERRAMENTA DE AQUISIÇÃO DE CONHECIMENTO
}

\author{
Muriel de Oliveira Gavira
}

Dissertação apresentada à Escola de Engenharia de São Carlos da Universidade de São Paulo, como parte dos requisitos para obtenção do título de Mestre em Engenharia de Produção

ORIENTADOR: Prof. Titular João Vitor Moccellin 
Dedico esta dissertação

Aos meus amados pais Valdir e Tânia Márcia.

Ao meu querido esposo Jayme. 


\section{AGRADECIMENTOS}

A DEUS, por tudo que tenho e pela força para vencer os obstáculos.

Ao professor e orientador Prof. João Vitor Moccellin pela colaboração, orientações sábias e práticas e paciência durante o tempo de trabalho em conjunto.

Ao Prof. Renato Vairo Belhot, pela orientação e apoio.

Aos professores da banca examinadora por haverem aceitado a incumbência, por seu interesse e dedicação na tarefa de avaliar o conteúdo do texto e oferecer suas valiosas contribuições.

Aos colegas Jana e William do Laboratório de Dinâmica Industrial da Universidade Federal de São Carlos pela valorosa colaboração e sugestões.

Ao Programa de Pós-Graduação em Engenharia de Produção da Escola de Engenharia de São Carlos da Universidade de São Paulo, por me proporcionar esta oportunidade de aprendizado e por prover os recursos necessários ao desenvolvimento da pesquisa.

Aos professores que não pouparam esforços para nos proporcionar a oportunidade de atualizar e expandir nossos conhecimentos.

Aos funcionários da Área de Engenharia de Produção, que, de maneira paciente e profissional, atenderam todas as minhas solicitações técnicas e administrativas. 
À CAPES pelo apoio financeiro que viabilizou a realização deste trabalho.

A todos colegas de mestrado, pela amizade, pelo apoio e sugestões.

À minha família, por sempre estar ao meu lado, compartilhando tanto das alegrias quanto das tristezas, incentivando-me sempre.

Ao meu querido esposo Jayme pelo apoio, compreensão e companhia em todas circunstâncias. À minha sogra Neusa, pela atenção e apoio enquanto estive ausente.

A todos os amigos que compartilharam comigo os bons e maus momentos durante este período em São Carlos.

E a todos aqueles que de alguma forma contribuíram para a elaboração desse trabalho. 


\section{SUMÁRIO}

LISTA DE FIGURAS ..................................................................................................I

LISTA DE TABELAS ............................................................................................ III

LISTA DE ABREVIATURAS E SIGLAS.............................................................IV

RESUMO ....................................................................................................... V

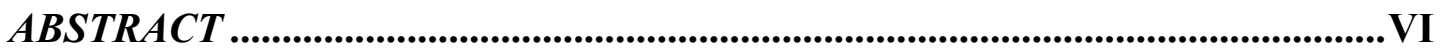

CAPÍTULO 1 INTRODUÇÃO................................................................................... 1

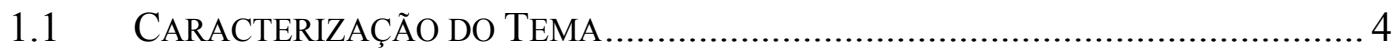

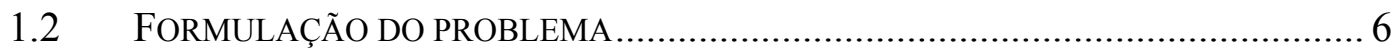

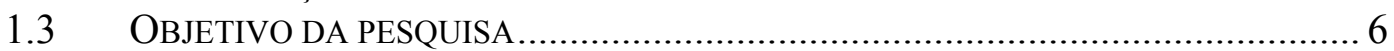

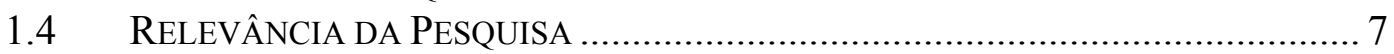

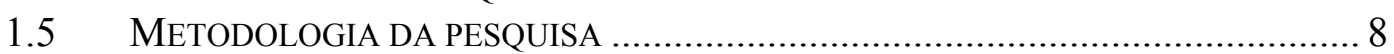

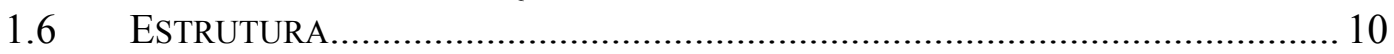

CAPÍTULO 2 O CONHECIMENTO ............................................................... 11

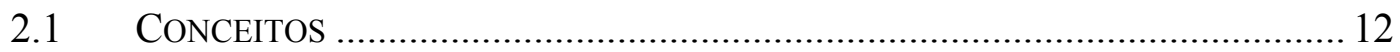

2.2 A EVOLUÇÃO DOS ASPECTOS DO CONHECIMENTO …................................ 15

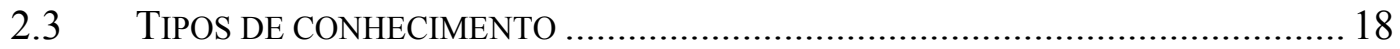

2.4 AQUISIÇÃO DE CONHECIMENTO......................................................... 20

CAPÍTULO 3 A PESQUISA OPERACIONAL .................................................. 24

3.1 A EVOLUÇÃO DA PESQUISA OPERACIONAL .............................................. 25

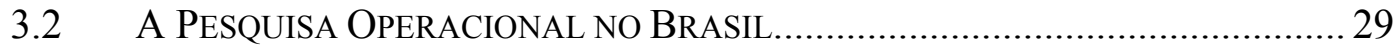

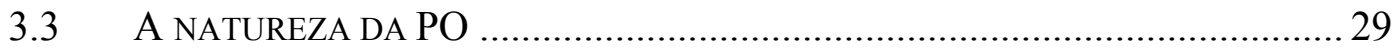

3.4 VANTAGENS DA UTILIZAÇÃo DA PESQUisa OPERACIONAL NO

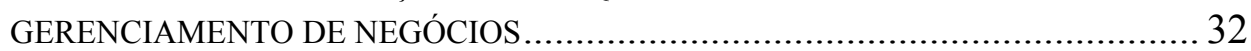

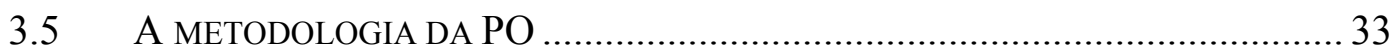

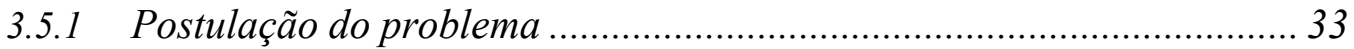

3.5.2 Construção do modelo ...................................................................... 34

3.5.3 Desenvolvimento analítico do modelo e obtenção dos dados................ 35

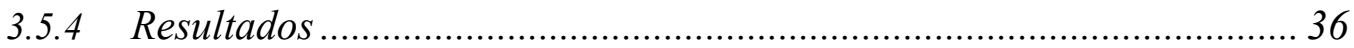

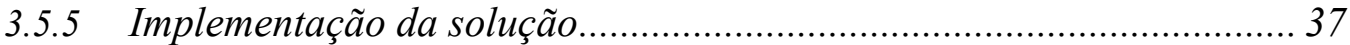

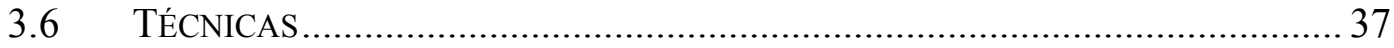

3.7 SimUlaÇ̃̃o DENTRO DA PESQUISA OPERACIONAL ...................................... 38

CAPÍTULO 4 CONCEITOS BÁSICOS SOBRE SIMULAÇÃO....................... 40

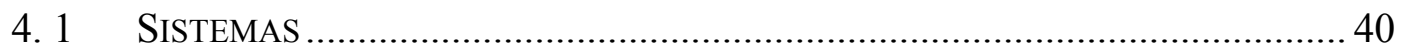


4.1.1 Componentes de um sistema ............................................................ 40

4.1.2 O estudo dos sistemas ................................................................... 41

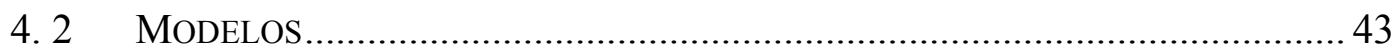

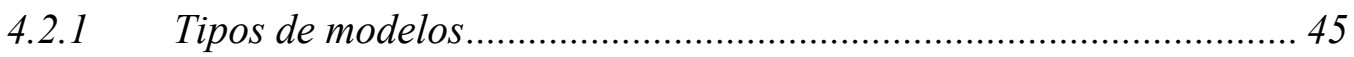

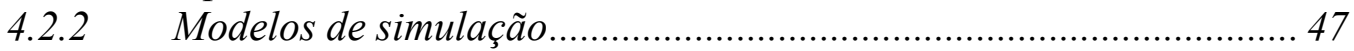

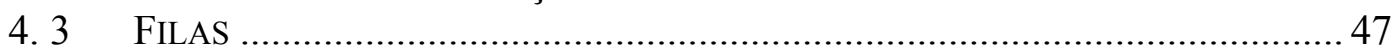

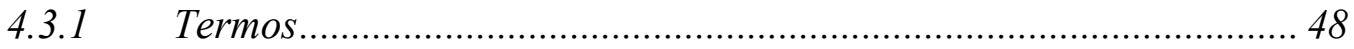

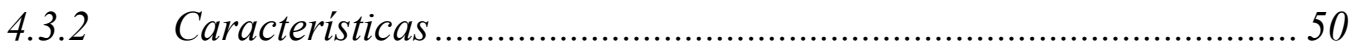

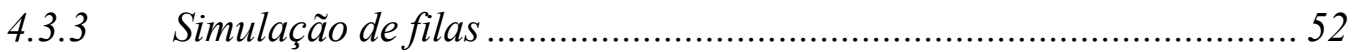

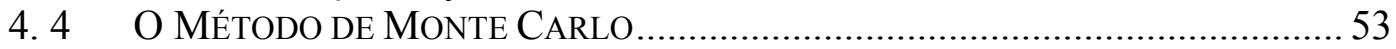

CAPÍTULO 5 A SIMULAÇÃO DE SISTEMAS ............................................55

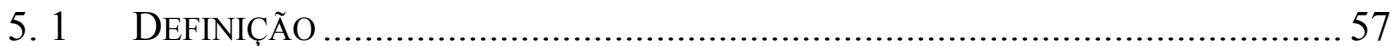

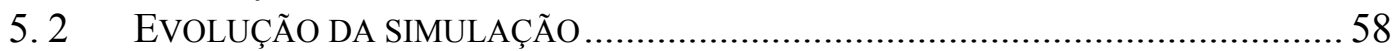

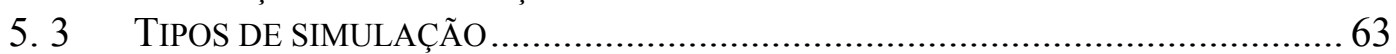

5.3.1 Simulação de sistemas dinâmicos de eventos discretos..................... 65

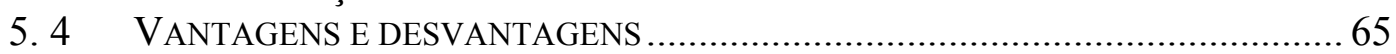

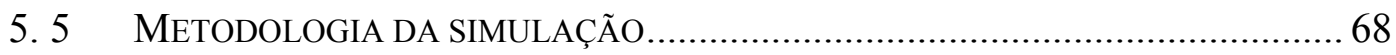

5.5.1 Formulação do problema e Planejamento do estudo ......................... 70

5.5.2 Coleta de dados e Definição do Modelo........................................... 71

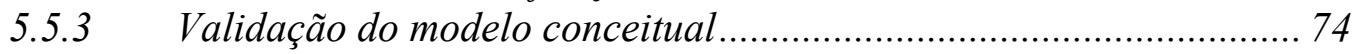

5.5.4 Construção do programa computacional e verificação...................... 74

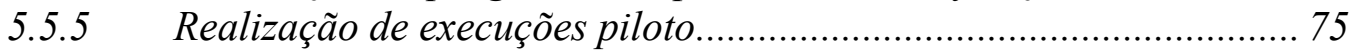

5.5.6 Validação do modelo programado ..................................................... 75

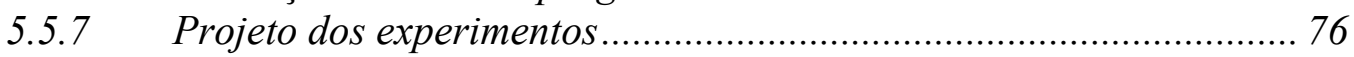

5.5.8 Realização das execuções de simulação ............................................. 77

5.5.9 Análise de Resultados ........................................................................ 77

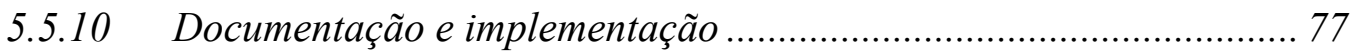

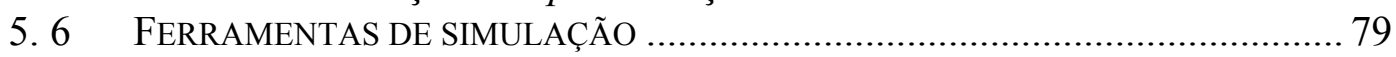

5.6.1 Linguagens de propósito geral ou linguagens de programação ....... 80

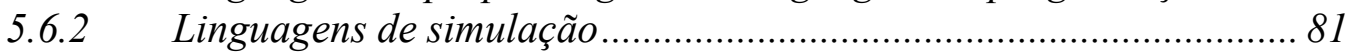

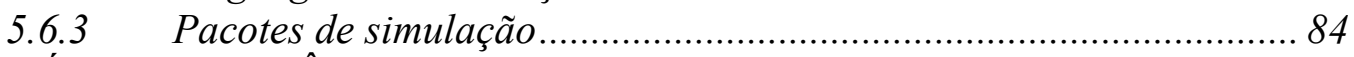

CAPÍTULO 6 DINÂMICA DE SISTEMAS _.................................................... 93

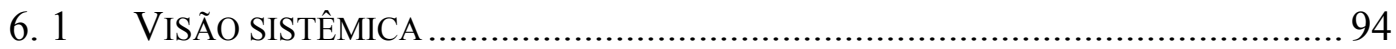

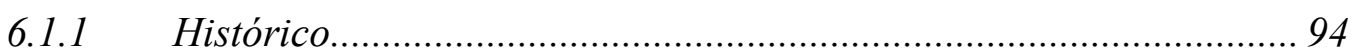

6.1.2 Características do Pensamento Sistêmico ............................................ 97

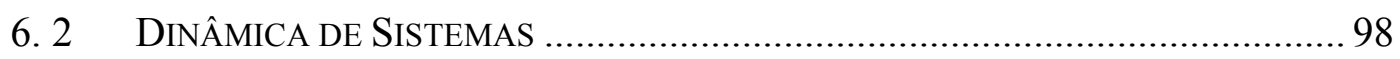

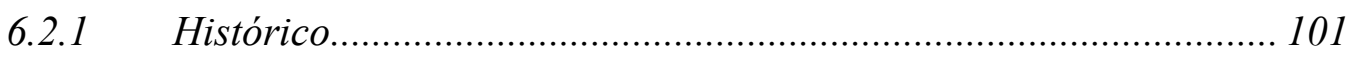

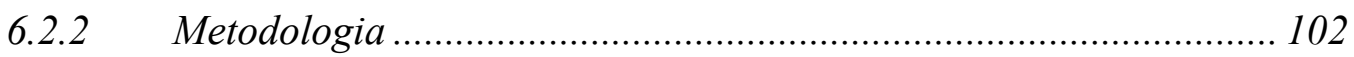

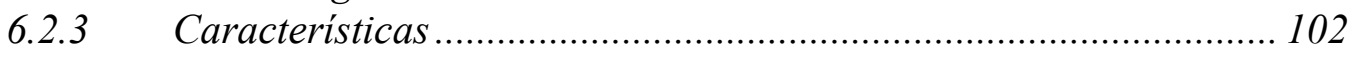

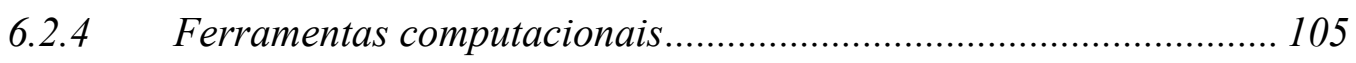

CAPÍTULO 7-DESENVOLVIMENTO DAS SIMULAÇÕES ....................... 107

7. 1 FORMULAÇÃO DO PROBLEMA E PLANEJAMENTO dO ESTUDO ..................... 108

7.1.1 Objetivo do estudo de simulação ................................................... 111

7.1.2 Questões a serem respondidas ....................................................... 111

7.1.3 Configurações do sistema a ser modelado ..................................... 112

7.1.4 Avaliadores de desempenho......................................................... 113 
7.1.5 Recursos computacionais utilizados ............................................. 114

7.1.6 Estrutura de tempo para o estudo e recursos requeridos................ 115

7. 2 COLETA DE DADOS E DEFINIÇÃO DO MODELO .............................................. 115

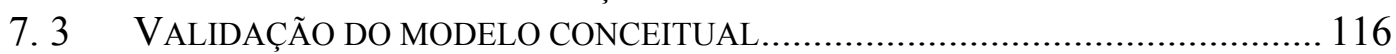

7. 4 CONSTRUÇÃO DO MODELO DE SIMULAÇÃO E VERIFICAÇÃO.........................116

7.4.1 PROGRAMAÇÃO DO MODELO NO PACOTE DE SIMULAÇÃO STELLA .............. 116

7.4.2 VERIFICAÇÃO DO PROGRAMA DE SIMULAÇÃO COMPUTACIONAL ................. 121

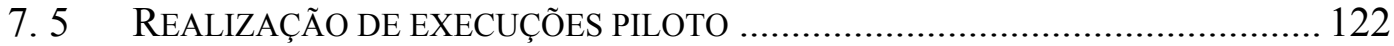

7. 6 VALIDAÇÃO DO MODELO PROGRAMADO ................................................. 122

7.6.1 COLETA DE INFORMAÇÕES E DADOS DE ALTA QUALIDADE NO SISTEMA .... 122

7.6.2 VALIDAÇÃO DA SAÍDA DO MODELO DE SIMULAÇÃO …................................ 122

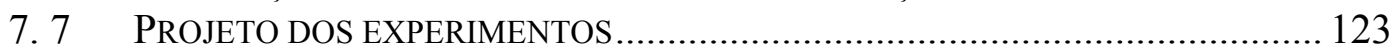

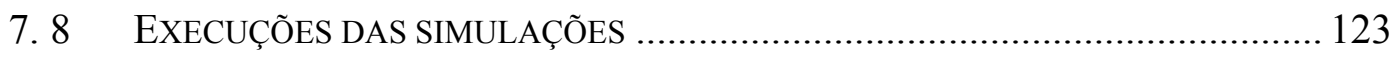

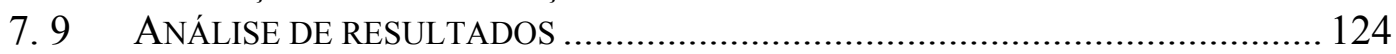

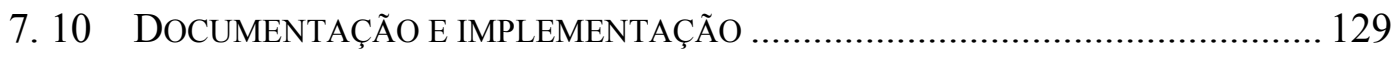

7. 11 CONSIDERAÇÕES SOBRE A AQUISIÇÃO DO CONHECIMENTO ........................ 129

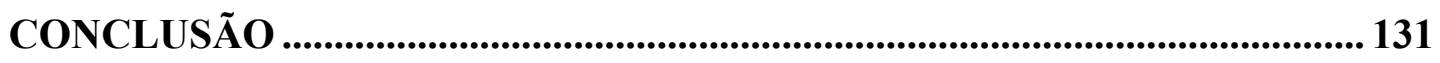

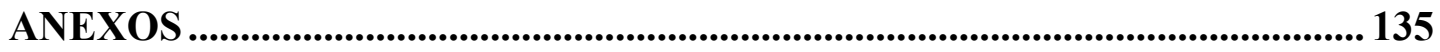

LISTA DOS MODELOS SIMULADOS E SEUS PARÂMETROS................... 136

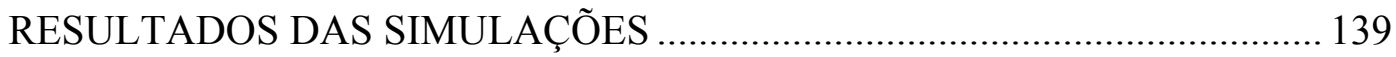

REFERÊNCIAS BIBLIOGRÁFICAS .......................................................... 142 


\section{LISTA DE FIGURAS}

FIGURA 01 - Ferramentas de aquisição do conhecimento ................................. 12

FIGURA 02 - Componentes dos processos de aprendizagem e memória ............ 12

FIGURA 03 - Modos de conversão do conhecimento ........................................ 21

FIGURA 04 - Metodologia da Pesquisa Operacional .......................................... 33

FIGURA 05 - Formas de estudo de um sistema ................................................ 42

FIGURA 06 - Processo simples de modelagem ................................................. 44

FIGURA 07 - Sistema básico de fila ............................................................... 48

FIGURA 08 - Estruturas básicas de modelos de fila de espera .......................... 51

FIGURA 09 - A evolução das ferramentas de simulação ...................................... 62

FIGURA 10 - Classificação dos modelos de simulação ......................................... 64

FIGURA 11 - Passos de um estudo de simulação ................................................. 69

FIGURA 12 - Modelagem com uma linguagem de propósito geral .................... 82

FIGURA 13 - Modelagem com uma linguagem geral de simulação .................... 83

FIGURA 14 - Camada superior do STELLA _................................................. 87

FIGURA 15 - Camada de construção do modelo do STELLA …........................ 87

FIGURA 16 - Camada de equações do STELLA …........................................... 88

FIGURA 17 - Barra de tarefas da camada de construção do modelo ................... 88

FIGURA 18 - Barra de tarefas da camada superior .......................................... 88

FIGURA 19 - Elementos utilizados na simulação em STELLA _......................... 89

FIGURA 20 - As principais ferramentas de aquisição do conhecimento ............. 94

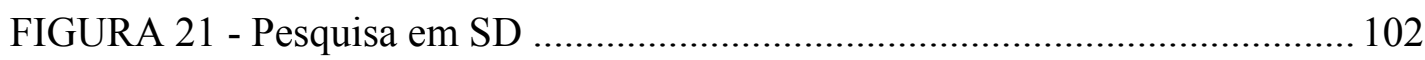

FIGURA 22 - Exemplo de estrutura de realimentação ....................................... 104

FIGURA 23 - Exemplo de uma estrutura de realimentação ................................ 104

FIGURA 24 - A fábrica de componentes plásticos ............................................ 109

FIGURA 25 - Análise do fluxo da fábrica de plásticos ..................................... 110 
FIGURA 26 - Modelo intermediário …............................................................. 117

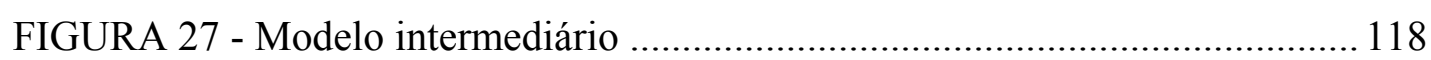

FIGURA 28 - Camada superior do modelo final ................................................. 119

FIGURA 29 - Camada de construção do modelo final ......................................... 120 


\section{LISTA DE TABELAS}

TABELA 01 - Investimentos em P\&D da indústria de telecomunicações ............. 03

TABELA 02 - Exemplos de componentes de um sistema ................................. 41

TABELA 03 - História do uso da simulação ........................................................ 60

TABELA 04 - Comparação das vantagens e desvantagens das linguagens .......... 84

TABELA 05 - Principais características do método analítico ............................... 95

TABELA 06 - Principais características do método sintético ................................ 96

TABELA 07 - Tempo médio de atendimento dos processos ................................ 110

TABELA 08 - Parâmetros estudados no modelo ..................................................... 111

TABELA 09 - Medidas de desempenho utilizadas .............................................. 114

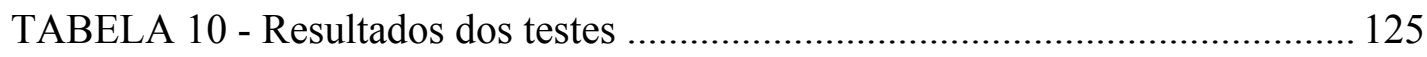




\section{LISTA DE ABREVIATURAS E SIGLAS}

$\begin{array}{ll}\text { GPSS } & \text { General Purpose Simulation System } \\ \text { ITA } & \text { Instituto Tecnológico da Aeronáutica } \\ \text { LDI } & \text { Laboratório de Dinâmica Industrial } \\ \text { MIT } & \text { Massachusetts Institute of Technology } \\ \text { MMC } & \text { Método de Monte Carlo } \\ \text { P\&D } & \text { Pesquisa e Desenvolvimento } \\ \text { PO } & \text { Pesquisa Operacional } \\ \text { PUC-RJ } & \text { Pontifícia Universidade Católica do Rio de Janeiro } \\ \text { SD } & \text { Dinâmicas de Sistemas (System Dynamics) } \\ \text { SOBRAPO } & \text { Sociedade Brasileira de Pesquisa Operacional } \\ \text { USP } & \text { Universidade de São Paulo }\end{array}$




\section{RESUMO}

GAVIRA, M. O. Simulação computacional como uma ferramenta de aquisição de conhecimento. São Carlos. 146p. Dissertação (Mestrado) - Escola de Engenharia de São Carlos, Universidade de São Paulo.

Nos últimos anos, a simulação computacional vem assumindo uma importância cada vez maior como ferramenta de aquisição de conhecimento. $\mathrm{Na}$ simulação desenvolvida nos primórdios da Pesquisa Operacional, os problemas eram resolvidos por meio da obtenção dos melhores resultados possíveis para cada parte individual do modelo. Entretanto, à medida que a complexidade dos problemas cresceu, surgiu a necessidade de se utilizar uma abordagem mais sistêmica e generalista. A simulação utilizou-se, inicialmente, de linguagens de programação geral, como o FORTRAN. Mas, à medida que a complexidade das observações e a capacidade dos recursos computacionais cresceram, surgiram os programas de simulação de propósito geral (como o GPSS) e os baseados na Dinâmica dos Sistemas (DYNAMO, STElla etc). Essa metodologia (Dinâmica dos Sistemas) faz uso do conceito de pensamento sistêmico para a resolução de problemas e para o estudo de sistemas. Nesse contexto, o presente trabalho tem como principal objetivo identificar e analisar os aspectos potenciais da simulação enquanto ferramenta de aquisição de conhecimento. Para atingir esse objetivo, aplica-se a simulação a um sistema de fila de uma fábrica de componentes plásticos.

Palavras-chave: Conhecimento; Simulação; Dinâmica de Sistemas. 


\begin{abstract}
GAVIRA, M. O. Computer simulation: a tool to acquiring knowledge. São Carlos. 146p. Dissertação (Mestrado) - Escola de Engenharia de São Carlos, Universidade de São Paulo.
\end{abstract}

In the last years, the computer simulation has become a vital tool in the development of several self-learning techniques, as well in the acquisition of knowledge in the engineering teaching and in the managerial training. The simulation used in the early years of the Operational Research boarded the potential problems by obtaining the best possible results for each part of the model. However, as the complexity of such problems increased, the need for more systemic and generalist approaches has also increased. Initially, the simulation was performed by general programming languages as FORTRAN. But, as the complexity of the observations and the capability of the computer resources increased, Simulation Languages (like GPSS) and Dynamic System Simulation Software (dynamo, STELLA etc) were developed. This methodology (“System Dynamics”) uses concepts of the systemic thought to solve problems and to analyze systems. In that context, the main objectives of this work are to identify and to analyze the potential aspects of the simulation based on System Dynamics when applied in the engineering teaching and in the managerial training.

Keywords: Knowledge; Simulation; System Dynamics. 


\section{CAPÍTULO 1 INTRODUÇÃO}

De acordo com DRUCKER (1994), a história ocidental sofre, periodicamente, uma grande transformação. Dentre essas transformações, pode-se citar as geradas pelo Renascimento e pela Revolução Industrial. Hoje, uma nova mudança, conhecida como Revolução da Informação, nos impulsiona à sociedade pós-capitalista. Essa nova sociedade tem visão de mundo, valores básicos, estrutura social e política, artes etc. muito diferentes da sociedade que a antecedeu (sociedade capitalista).

Pode-se dizer que essas transformações são decorrentes da modificação da forma de encarar e utilizar o conhecimento. Na Revolução Industrial, por exemplo, o conhecimento do artesão, que antes era restrito a ele, seus familiares e aprendizes, foi dividido entre várias pessoas. Mais tarde, esses conhecimentos, antes restritos às profissões artesanais, foram codificados de forma organizada e sistemática em manuais e livros e ensinado nas primeiras escolas técnicas.

Nenhuma das escolas técnicas do século dezoito visava a produção de novo conhecimento. O que elas fizeram foi reunir, codificar e publicar os conhecimentos empíricos dos artesãos ("mistério do artesanato"), da maneira como havia sido desenvolvido ao longo de milênios. Segundo DRUCKER (1994), as escolas converteram ciência em conhecimento, aprendizado em livros texto, mistérios em metodologia, fazer em conhecimento aplicado. Esses fatores foram essenciais para a Revolução Industrial - a transformação da sociedade por meio da tecnologia.

O surgimento da sociedade industrial gerou todos os mecanismos voltados para a produção de bens materiais. A sociedade pós-industrial, por sua vez, consolida-se na geração de serviços e na produção e transmissão de informações, através da experiência organizacional e de investimentos no desenvolvimento de tecnologia de ponta, na criação de grupos de especialistas, na implementação da produção modular, entre outros (SANTOS, 1990). 
Uma série de fatores acarretou a transição da sociedade industrial para a chamada sociedade pós-industrial ou do conhecimento. Dentre eles, pode-se citar: aumento da competitividade; diminuição do crescimento da produtividade; aumento da exigência dos consumidores; mudanças tecnológicas, políticas e ambientais etc. Essas mudanças, ocorridas principalmente no cenário competitivo, levaram as empresas a procurar saídas que lhes garantissem tomadas de decisão mais precisas e eficientes, de maneira a lhes proporcionar competitividade a longo prazo.

Segundo BARBOSA (1986), as transformações que possibilitaram essa nova realidade iniciaram-se na década de 50 e foram decorrentes, principalmente, do desenvolvimento dos recursos computacionais. O impacto da tecnologia da informática sobre a ciência vem se revelando considerável, pois esta deixa de ser vista como uma atividade "nobre", "sem finalidade preestabelecida", para ser um recurso gerador de riquezas. Isso advém da descoberta de que a coleta e o processamento adequado das informações é fator preponderante no sucesso de qualquer empreendimento.

DAVENPORT \& PRUSAK (1998) afirmam que o interesse das organizações pelo conhecimento teve início a partir da constatação de que o valor de mercado de diversas empresas, como a Microsoft e a Nokia, é muito maior de que seu patrimônio físico. O valor das ações dessas empresas incorpora fatores intangíveis, como o valor de suas marcas, a capacidade de inovação, o talento dos funcionários, as relações com os clientes etc. Assim, as empresas voltaram-se para a valorização do conhecimento a fim de entender, organizar e lucrar com seu valor intangível.

O aumento da preocupação das empresas com a aquisição de conhecimento e com a inovação é comprovado pelo comportamento dos investimentos em Pesquisa e Desenvolvimento (P\&D) da indústria de equipamentos de telecomunicações (considerada uma das principais "indústrias do conhecimento"). De acordo com a TABELA 01, pode-se notar que o investimento em P\&D das principais empresas do setor de telecomunicações vem aumentado de maneira consistente com o decorrer do tempo. Isso reflete, entre outras coisas, a preocupação dessas empresas com a aquisição de novos conhecimentos, os quais serão transformados em novos produtos, serviços e/ou processos produtivos. 
TABELA 01 - Investimentos em P\&D da indústria de telecomunicações (\% das vendas)

\begin{tabular}{l|c|c|c}
\hline Corporação & $\mathbf{1 9 7 5}$ & $\mathbf{1 9 8 0}$ & $\mathbf{1 9 8 5}$ \\
\hline NEC & 3,7 & 5,1 & 7,5 \\
\hline ATT/WE & 5,4 & 5,8 & 8,0 \\
\hline ITT & - & 7,4 & 9,2 \\
\hline ERICSSON & - & 6,1 & 8,3 \\
\hline SIEMENS & 8,4 & 9,6 & 9,8 \\
\hline NORTHERN & 4,8 & 6,8 & 10,0 \\
\hline PHILLIPS & 7,3 & 7,5 & - \\
\hline PLESSEY & 10,6 & 14,5 & 22,0 \\
\hline
\end{tabular}

Fonte: MACULAN (1992) ${ }^{1}$. Citado por FLEURY \& FLEURY (1995)

TERRA (1999), analisando o trabalho de THUROW ${ }^{2}$ (1997), seleciona vários dados e argumentos que corroboram a afirmação de que a importância econômica do conhecimento vem crescendo:

- Entre as doze maiores empresas americanas do início do século, dez eram empresas baseadas em recursos naturais; apenas uma dessas empresas sobreviveu até o final do século, a General Electric;

- Antes da primeira guerra, a Inglaterra empregava mais de 1 milhão de trabalhadores em suas minas de carvão ( $6 \%$ da força de trabalho do país); hoje, menos de 30 mil pessoas trabalham nestas mesmas minas;

- No final do século XIX, países ricos em recursos naturais, como Argentina e Chile, eram ricos, enquanto países sem recursos, como o Japão, estavam destinados a ser pobres;

- Corrigida a inflação geral, os preços dos recursos naturais caíram quase $60 \%$ entre meados dos anos 70 e meados dos anos 90;

- As decisões de localização dos investimentos industriais, principalmente pelas empresas multinacionais, têm dependido, cada vez mais, da existência de uma mão-de-obra qualificada;

- Os trabalhadores de fábricas costumavam ter baixíssima qualificação no início da industrialização; hoje, nos Estados Unidos, cerca de 16\% já possuem alguma educação de nível superior e 5\% chegam a se graduar.

\footnotetext{
1 MACULAN, A. M. As novas estratégias tecnológicas das multinacionais do setor de telecomunicações. Revista de Economia Política, v. 3, n. 2. 1992.

2 THUROW, L. C. O futuro do capitalismo: como as forças econômicas de hoje moldam o mundo de amanhã. Rio de Janeiro: Rocco, 1997.
} 
- Em 1990, o Ministério do Comércio Internacional e da Indústria do Japão elaborou uma lista dos setores de crescimento mais rápido nos anos $90 \mathrm{e}$ início do século XXI: microeletrônica, biotecnologia, indústrias da nova ciência de materiais, telecomunicações, fabricação de aviões civis, máquinas operatrizes e robôs, e computadores, todos setores "cerebrais", que poderiam estar localizados em qualquer parte do planeta;

- Estudos recentes mostram que as taxas de retorno sobre investimentos em qualificação são duas vezes superiores àquelas obtidas em investimentos em fábricas e equipamentos;

Assim, nessa nova sociedade, o conhecimento assume uma posição cada vez mais importante. Nas palavras de DRUCKER (1994, XV):

"Hoje o recurso realmente controlador, o "fator de produção" absolutamente decisivo, não é o capital, a terra ou a mão-de-obra. É o conhecimento. Ao invés de capitalistas e proletários, as classes da sociedade pós-capitalista são os trabalhadores do conhecimento e os trabalhadores em serviços".

O avanço na aquisição e transmissão de informações trouxe, e continuará trazendo, profundas modificações na aquisição e transmissão de conhecimentos, sendo que estes serão a principal força de produção da sociedade. A relação entre fornecedores e usuários do conhecimento, e o próprio conhecimento, tende e tenderá a assumir a forma de valor; o saber é e será produzido para ser vendido, e ele é e será consumido para ser valorizado numa nova produção.

\subsection{Caracterização do Tema}

Nessa nova era, a informação e o conhecimento assumem grande importância na preparação dos indivíduos e empresas ao entendimento e à adaptação à realidade. A simulação computacional é uma das ferramentas que podem ser utilizadas para a aquisição, organização e construção do conhecimento e da visão sistêmica. Esse 
recurso favorece a educação e o treinamento das pessoas e, conseqüentemente, sua adaptação às rápidas mudanças de nossa sociedade.

A simulação é uma das ferramentas que permite a diversos profissionais, entre eles o administrador e o engenheiro de produção, realizar as atividades a que se propõe. Através dela, eles podem adquirir capacidade de identificar, formular e solucionar problemas ligados às atividades de projeto, operação e gerenciamento do trabalho e de sistemas de produção de bens e/ou serviços.

Nesse contexto, o presente trabalho propõe-se a identificar e analisar os aspectos potenciais da simulação computacional, principalmente daquela baseada na metodologia de Dinâmica de Sistemas (System Dynamics), na aquisição de conhecimentos sobre um sistema de produção a ser estudado.

Este estudo baseia-se em algumas conclusões fundamentadas na literatura e nas experimentações realizadas a respeito da aquisição de conhecimento através da simulação. Os processos e mecanismos de aquisição, construção e gestão do conhecimento não serão detalhados, pois isto extrapolaria os objetivos deste trabalho.

Um estudo a respeito da simulação jamais estará completo e especializado, uma vez que esta técnica possui uma área de aplicação muito vasta, sendo impossível reunir, em um só trabalho, todos os seus aspectos. Os tópicos aqui abordados restringem-se a:

- Experiências com modelos lógicos matemáticos; não estão incluídos modelos físicos, analógicos, verbais etc.;

- Modelos de filas de espera;

- Experiências a serem executadas em computadores digitais;

- Experiências que se desenvolvem em longos períodos, sob condições dinâmicas e estocásticas, e cujas soluções não são necessariamente completas e analíticas.

As restrições impostas ao estudo aqui realizado não implicam na ineficiência dos aspectos ou modelos não incluídos; sua adoção visou permitir uma análise adequada da simulação computacional como uma ferramenta para a criação do conhecimento. 


\subsection{Formulação do problema}

Empresas de todos os setores vêem enfrentando uma forte competição. Esse fenômeno se deve a fatores como a globalização, aumento do grau de exigência e sofisticação de seus clientes, rápido avanço tecnológico, entre outros. Para superar essas dificuldades, as empresas necessitam de "profissionais do conhecimento" capacitados que as ajude a entender a dinâmica dos sistemas nos quais estão inseridas.

Segundo SENGE \& STERMAN (1994), o conhecimento desses profissionais é constituído de seu modelo interno da realidade, de seu conjunto de suposições que estrutura seu entendimento a respeito do ambiente de negócios e dos fatores críticos para seu sucesso; esse conhecimento é a base para o sucesso ou fracasso de uma organização. Quando o mundo muda, os administradores precisam se adaptar à nova realidade; para isso, precisam de ferramentas que possibilitem o teste de novos cenários antes que mudanças possam ocorrer.

Uma forma de permitir o aperfeiçoamento e a atualização desses profissionais é a simulação das variáveis que influenciam o meio onde vivem e trabalham e, assim, determinar como é essa influência, sua causa e, principalmente, as alternativas para a resolução de possíveis problemas.

O desafio é saber se a simulação é uma ferramenta eficiente, através da qual os tomadores de decisão, os trabalhadores do conhecimento, possam adquirir conhecimento, tanto sobre o sistema em que estão inseridos, quanto sobre seus subsistemas e ambiente. Essa ferramenta é capaz de criar novos conceitos sobre as complexas relações entre os elementos do sistema estudado? É adequada para a análise de diferentes cenários e políticas operacionais?

Assim, o enfoque da pesquisa pode ser resumido na seguinte questão:

Como a simulação computacional pode auxiliar na aquisição de conhecimento individual sobre um determinado sistema?

\subsection{Objetivo da pesquisa}

O objetivo principal desta pesquisa é demonstrar a aplicação prática da simulação, em particular daquela baseada na metodologia de Dinâmica de Sistemas, 
como um método de aquisição de conhecimento. Para tanto, um problema de dimensionamento de fila em uma fábrica de componentes plásticos foi estudado por meio de um pacote de simulação. Os resultados e o processo foram comparados com o propósito de demonstrar o potencial de aplicação desse método na aquisição de conhecimento.

Como objetivo secundário, tem-se a revisão bibliográfica sobre a simulação e sobre a aquisição de conhecimento individual.

\subsection{Relevância da Pesquisa}

A partir da década de 50, a sociedade entrou numa nova fase, denominada por diversos autores de era da informação, cujo principal recurso estratégico é o conhecimento.

Segundo KLEIN (1998), "hoje a informação pura e simples já não garante um diferencial competitivo". Para assegurar um lugar no futuro, as organizações precisam aprender a transformar as informações em conhecimento, e utilizá-lo para obter novos resultados, diversificar mercados e satisfazer os seus clientes.

O investimento em novas tecnologias de produto ou processo é alto e arriscado. Contudo, é essencial, para a sobrevivência das organizações, o uso de recursos que garantam a eficácia e a viabilidade econômica de novas tecnologias, a um baixo custo e, principalmente, com pequeno ou nenhum risco (LEPIKSON, 1998). Uma das alternativas para alcançar tal objetivo é a implementação de simulações computacionais para estudo de sistemas organizacionais.

A simulação permite a transformação de informações em conhecimento, o qual será aplicado no processo de tomada de decisões. Num mundo globalizado e turbulento, tal ferramenta se mostra eficiente na tarefa de propiciar ao indivíduo a oportunidade de aprender a pensar e a tomar decisões de forma rápida e eficiente.

Além disso, essa ferramenta, estimula a análise crítica de dados, a formulação de perguntas e a descoberta de respostas, a visão sistêmica, entre outros. 


\subsection{Metodologia da pesquisa}

O presente estudo é classificado como pesquisa científica aplicada, uma vez que tem como objetivo a geração de conhecimentos para aplicação prática dirigida à solução de problemas específicos (SILVA \& MENEZES, 2001).

De acordo com FERRARI (1974), este tipo de pesquisa está vinculada ao valor prático ou pragmático de um tema. Ainda segundo ele, apesar da finalidade prática da pesquisa, ela "pode contribuir teoricamente com novos fatos para o planejamento de novas pesquisas, ou mesmo para a compreensão teórica de certos setores do conhecimento".

Do ponto de vista dos procedimentos de levantamento de dados, o estudo é baseado na pesquisa bibliográfica e de laboratório.

Segundo ARANTES ${ }^{3}$ (1971, p.9), citada por FACHIN (2001, p.125), a pesquisa bibliográfica constitui o "ato de ler, selecionar, fichar, organizar e arquivar tópicos de interesse para a pesquisa em pauta".

A pesquisa bibliográfica foi realizada com a finalidade de conhecer as contribuições científicas sobre os conceitos aqui empregados (entre eles conhecimento, simulação, visão sistêmica etc.).

De acordo com FACHIN (2001), todo tipo de estudo deve ser apoiado e respaldado por uma pesquisa bibliográfica ampla e cuidadosa, mesmo que se baseie em uma pesquisa de laboratório ou de campo.

A pesquisa de laboratório, por sua vez, refere-se a experiências limitadas a um recinto fechado e condicionado a certas manipulações (FERRARI, 1974). Essas experiências requerem instrumentos próprios como, no caso do presente estudo, um pacote de simulação e um computador.

TRIPODI (1981) caracteriza a pesquisa de laboratório como estudos experimentais nos quais o investigador cria uma situação isolada, num ambiente artificial e com variáveis hipotéticas. As relações entre as variáveis são examinadas

\footnotetext{
3 ARAntes, T. F. Pesquisa bibliográfica nas ciências biomédicas. São Paulo: Faculdade de Odontologia - USP. Revista n.XIII, 1971.
} 
pela manipulação destas e pelo controle da potencial influência das variáveis extrínsecas à hipótese testada.

Esse tipo de pesquisa oferece a vantagem de se controlar a cronologia da pesquisa, desde o instante inicial. Através dela, é possível verificar situações de causa e efeito; por exemplo, se a causa for aumentada, constata-se que houve aumento do efeito etc. (FACHIN, 2001).

Segundo FERRARI (1974), apesar das características citadas anteriormente, essa pesquisa não deixa de ter suas exigências, que derivam de três fontes: da instrumentação, dos objetivos e da manipulação do instrumental para alcançar os objetivos previstos. A instrumentação refere-se aos recursos (equipamentos, espaço físico etc.) que serão utilizados. Esses recursos oferecem ao cientista a precisão e ampliação necessárias.

O objetivo direciona todos os passos e esforços na pesquisa de laboratório; é ele que contém a meta a ser atingida. Por sua vez, o experimento de laboratório é definido como a criação de uma situação na qual manipulam-se certas variáveis para atingir uma determinada meta.

Assim, a pesquisa (simulações) foi realizada com base em uma metodologia de simulação. Essa metodologia, baseada no método científico, foi sugerida por LAW \& KELTON (2000), e possui os seguintes passos: formulação do problema, planejamento do estudo, coleta de dados, definição do modelo, validação do modelo conceitual, construção e verificação do programa computacional, realização de execuções piloto, validação do modelo programado, projeto dos experimentos, realização das execuções de simulação, análise de resultados e documentação e implementação.

Os recursos computacionais utilizados na pesquisa foram disponibilizados pelo Laboratório de Simulação e Jogos do Departamento de Engenharia de Produção (Escola de Engenharia de São Carlos/Universidade de São Paulo). Para a fase de construção do programa computacional, até a fase de realização de execuções, foi utilizado o pacote de simulação STELLA. 


\subsection{Estrutura}

A estrutura deste trabalho inclui, além da introdução, sete capítulos.

Os capítulos de dois a seis referem-se à revisão bibliográfica referente aos principais conceitos tratados no estudo. $\mathrm{O}$ capítulo dois apresenta a conceituação de conhecimento, sua relação com a aprendizagem e com a informação e suas características, evolução, classificação e formas de aquisição.

No terceiro capítulo aborda-se a Pesquisa Operacional e a origem da simulação computacional; são apresentados aspectos relacionados à sua evolução, natureza e metodologia, além de se contextualizar a simulação como um ramo da Pesquisa Operacional.

Alguns conceitos básicos necessários ao entendimento adequado da simulação e do estudo aqui realizado são introduzidos no capítulo quarto. São eles: sistema, modelo, filas e Método de Monte Carlo.

No quinto capítulo retoma-se, de maneira mais profunda, a discussão sobre a simulação; são tratados os aspectos relacionados à sua definição, evolução, classificação, vantagens e desvantagens, metodologia e ferramentas.

A evolução, características e ferramentas da visão sistêmica e da Dinâmica dos Sistemas, dois conceitos fundamentais para o processo de aquisição do conhecimento, são apresentados no sexto capítulo.

Já no capítulo sete apresenta-se o desenvolvimento das simulações e a análise dos resultados. Descreve-se a pesquisa laboratorial desenvolvida com base em uma metodologia de simulação e trata-se com detalhes de todos os passos executados durante o estudo. Para tanto, a pesquisa utilizou-se de um problema de fila de espera de uma fábrica de componentes plásticos.

No oitavo capítulo traz-se as conclusões finais, baseadas nas pesquisas bibliográfica e laboratorial aqui realizadas. 


\section{CAPÍTULO 2 O CONHECIMENTO}

A preocupação com o conhecimento não é algo novo. Contudo, seu reconhecimento como um elemento fundamental na constituição das pessoas e organizações e a exploração de seu potencial como uma vantagem competitiva sustentável para organizações e países, são fenômenos recentes. Só recentemente as empresas se deram conta da importância da aquisição e gerenciamento do conhecimento para um melhor desenvolvimento de suas atividades.

As empresas se viram obrigadas a adotar essa posição frente à necessidade de inovação, melhoria qualidade de produtos e processos e aumento de produtividade. Essa necessidade é decorrente de fatores como: globalização, aumento de competição, aumento da exigência dos consumidores, melhoria das comunicações e transportes etc.

De acordo com GEUS (1997), o início da década de 50 do século XX é o momento de transição da sociedade baseada no capital para a sociedade baseada no conhecimento. Segundo ele, o conhecimento passou a ser o elemento mais escasso, e as organizações vencedoras serão aquelas que souberem aplicá-lo e transformá-lo adequadamente em produtos e serviços.

Este capítulo destina-se ao estudo desse novo diferencial entre pessoas, empresas e países, que é o conhecimento. A simulação será utilizada neste trabalho com o fim de testar sua capacidade de auxílio à aquisição do conhecimento. Conforme se observa na FIGURA 01, três conceitos serão utilizados: a simulação, a visão (ou pensamento) sistêmica, e a metodologia da Dinâmica de Sistemas. Estes dois últimos serão tratados com mais detalhes no Capítulo 6.

Neste trabalho será considerada apenas a aquisição de conhecimento individual. Os aspectos relacionados ao conhecimento organizacional não serão abordados por fugirem do objetivo do trabalho. 


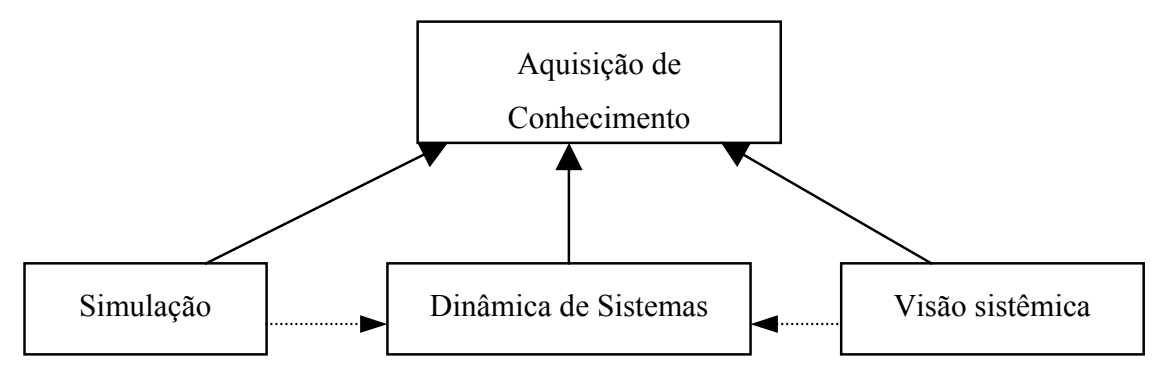

FIGURA 01 - Ferramentas de aquisição do conhecimento consideradas no trabalho Fonte: Elaborada pelo autor

Aquele que constrói e experimenta um modelo de simulação adquire conhecimento a respeito da metodologia de simulação e também do sistema modelado. Nesta pesquisa, serão tratados apenas os conhecimentos adquiridos sobre o sistema modelado.

Assim, o conhecimento a ser aqui estudado refere-se aos diversos tipos de conhecimentos relacionados ao sistema estudado, e não à técnica de simulação em si.

A fim de se fornecer requisitos para um melhor entendimento do estudo aqui realizado, a próxima seção se encarregará de conceituar alguns termos importantes, tais como conhecimento, dado, informação, aprendizagem, aquisição do conhecimento, tipos de conhecimento etc.

\subsection{Conceitos}

O conceito de conhecimento está intimamente ligado ao de aprendizagem. $\mathrm{Na}$ verdade, a aprendizagem abrange o conhecimento; segundo FLEURY \& FLEURY (1995, p. 23) "o processo de aprendizagem refere-se à aquisição de conhecimentos e habilidades e o de memória ao de retenção desses conhecimentos". A FIGURA 02 fornece um melhor entendimento a respeito da aprendizagem e sua abrangência.
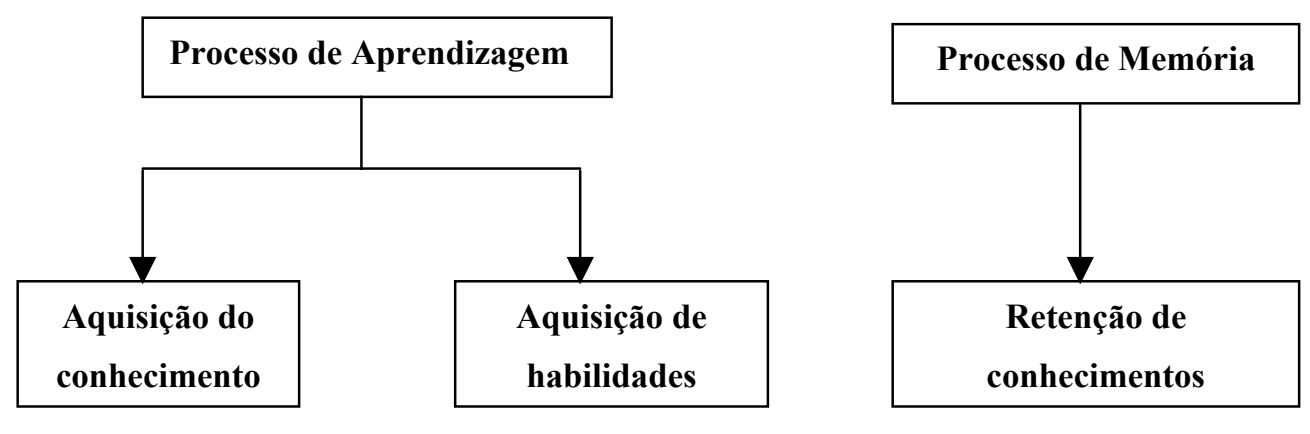

FIGURA 02 - Componentes do processo de aprendizagem e do processo de memória Fonte: Elaborada pelo autor 
Enfoca-se aqui apenas a parte do processo de aprendizagem referente à aquisição de conhecimentos.

O conhecimento também está intrinsecamente relacionado a dois outros termos: dados e informação. Apesar disso, esses três não podem ser considerados sinônimos, e entendê-los é essencial para a realização bem-sucedida de qualquer trabalho ligado ao conhecimento.

Segundo DAVENPORT \& PRUSAK (1998, p.2), dados são "um conjunto de fatos distintos e objetivos, relativos a eventos". Em organizações, dados são descritos como registros estruturados de transações. Os dados, por si só, têm pouco valor, uma vez que descrevem apenas parte do que aconteceu, não fornecem julgamento, interpretação, ou qualquer base sustentável para tomada de ação. Eles são matériaprima para a criação da informação.

As informações, por sua vez, são dados dotados de relevância e propósito (DRUCKER, 1994). A informação tem como objetivo modificar o modo como se vê algo; exerce influência sobre julgamentos e comportamentos.

Segundo NONAKA \& TAKEUCHI (1997), a informação proporciona um novo ponto de vista para a interpretação de eventos ou objetos; ela lança luz sobre conexões inesperadas e torna visíveis significados antes invisíveis.

É o significado que confere a diferença entre dado, informação e conhecimento. Dados tornam-se informação quando seu criador lhes acrescenta significado (DAVENPORT \& PRUSAK, 1998). Subseqüentemente, quando se acrescenta significado à informação, ela se torna conhecimento. Assim, o conhecimento é algo mais amplo, profundo e rico do que dados ou informações.

O filósofo Richard Rorty (1988) traz uma definição clássica da filosofia para conhecimento: "Conhecer é representar cuidadosamente o que é exterior à mente".

Já NONAKA \& TAKEUCHI (1997, p.63) adotam a definição tradicional de conhecimento como uma "crença verdadeira justificada", porém a complementam com a observação de que este é "um processo humano dinâmico de justificar a crença pessoal com relação à "verdade"”".

Outra definição de conhecimento, mais ampla, é dada por DAVENPORT \& PRUSAK (1998, p. 6): conhecimento é uma mistura fluida de experiência condensada, valores, informação contextual e visão experimental, a qual proporciona uma 
estrutura para a avaliação e incorporação de novas experiências e informações. Ele tem origem e é aplicado na mente dos conhecedores. Nas organizações, ele costuma estar embutido não só em documentos ou repositórios, mas também em rotinas, processos, práticas e normas organizacionais.

Ainda segundo esses autores, para que a informação se transforme em conhecimento, ela precisa ser trabalhada. Tal transformação ocorre através de quatro questões:

- Comparação: de que forma as informações relativas a esta situação se relacionam com outras situações conhecidas?

- Conseqüências: que implicações estas informações trazem para as decisões e tomadas de ação?

- Conexões: quais as relações deste novo conhecimento com o conhecimento já acumulado?

- Conversação: o que outras pessoas pensam da informação?

NONAKA \& TAKEUCHI (1997) fazem três observações referentes às semelhanças e diferenças entre conhecimento e informação:

- O conhecimento, ao contrário da informação, diz respeito a crenças e compromissos. O conhecimento é função de uma atitude, perspectiva ou intenção específica;

- O conhecimento, ao contrário da informação, está relacionado à ação;

- O conhecimento, como a informação, diz respeito ao significado.

Acredita-se que a simulação computacional seja uma ferramenta satisfatória para desempenhar essas formas de conversão de informação em conhecimento, atendendo em especial às três primeiras questões há pouco enunciadas.

Cada vez mais, o conhecimento é considerado um fator valioso para pessoas e empresas. Uma das razões disso, no ponto de vista do autor, é que o conhecimento está próximo da ação; o conhecimento de uma técnica, método ou forma de trabalho pode ser uma vantagem competitiva significativa em um mercado cada vez mais exigente. 
TERRA (1999) faz uma relação das características do conhecimento sob uma perspectiva individual:

- é um processo ativo e laborioso, que envolve todos os sentidos do corpo;

- envolve um indissociável processo mental e emocional;

- processa-se, em grande medida, no subconsciente; daí a importância da intuição e do conhecimento tácito;

- resulta da resolução de tensões e liberação de angústias;

- depende das experiências, tentativas e erros de cada indivíduo;

- é um processo social que depende da interação com outros;

- inclui a capacidade de combinar diferentes entradas e perspectivas e compreender relações complexas, por meio de um permanente processo de reformulação dos modelos mentais e mapas cognitivos;

- está associado a mudanças de comportamento: existência de oportunidades para autodesenvolvimento, incentivo à autenticidade e estímulo à explicitação de modelos mentais.

O exame da literatura leva à crença de que o conhecimento individual pode ser adquirido através de vários caminhos, dentre os quais pode-se citar a experimentação (simulação, jogos empresariais, estudos de caso etc.) e a absorção de conhecimentos de outros indivíduos (livros, artigos, vídeos etc.).

\subsection{A evolução dos aspectos do conhecimento}

FLEURY \& FLEURY (1995), DRUCKER (1994) e LANDES (1998) fazem revisões históricas semelhantes quanto às característica e à importância do conhecimento no decorrer do tempo. Uma síntese dessa revisão é descrita a seguir.

Não há quem duvide da importância do conhecimento para os seres humanos, desde os tempos mais remotos. Desde a pré-história, a inteligência e o conhecimento fizeram a diferença no processo evolucionário humano. Aqueles que detinham melhores conhecimentos de caça e proteção se destacavam sobre os demais. Assim surgiu o homo sapiens, o qual, por possuir melhores conhecimentos, acabou por sobrepujar e dominar seus "concorrentes" contemporâneos. 
Nos tempos do artesanato, os conhecimentos sobre produtos e processos eram integrados numa única pessoa. $\mathrm{O}$ artesão conhecia (e fazia) todos os aspectos de seus produtos; ele projetava, desenhava, obtinha as ferramentas, produzia, vendia etc. Geralmente, contavam com o auxílio de aprendizes. À medida que estes aprendiam com o mestre-artesão, garantia-se a continuidade do ofício e dos conhecimentos e habilidades a eles associados.

Com o passar do tempo e evolução das formas de organização social, essa estrutura foi-se alterando. Os conhecimentos e as habilidades necessários à produção foram gradualmente separados e entregues a diferentes pessoas. Era o início da divisão do trabalho, que proporcionou um grande aumento na produtividade das operações e uma gradual separação do projeto do produto e do processo em relação à produção propriamente dita.

Ao mesmo tempo, o conhecimento acarretou um aumento da expectativa de vida da população, devido a fatores como maior higiene pessoal (criação de roupas feitas de tecidos laváveis e produção em massa de sabão), maior oferta de alimentos (desenvolvimento de transportes mais rápidos e eficientes e de melhores técnicas agrícolas), progressos na área médica etc.

Após a Revolução Industrial, a valorização do conhecimento individual se tornou evidente com a intensa importação de especialistas por países que pretendiam desenvolver ou expandir suas atividades industriais. Esses trabalhadores eram muito experientes, possuíam o conhecimento; por isso eram tão apreciados. Além disso, os países enviavam agentes treinados para observar, relatar e aliciar artesãos experientes.

Outro fato histórico que impulsionou a divulgação de conhecimentos foi o surgimento das Escolas e Universidades de ciência e tecnologia, as quais se propunham a treinar pessoal e criar a base da autonomia intelectual. Os franceses foram, nesse quesito, os pioneiros, com sua Ecole Polytechnique, inaugurada em 1794. A partir dessa surgiram, em diversos países, as escolas locais profissionalizantes e as escolas industriais especializadas, entre outras.

Segundo LANDES (1998), a confiança na educação formal para a difusão do conhecimento técnico e científico teve importantes conseqüências. Em primeiro 
lugar, envolveu quase sempre instrução em matérias abstratas e teóricas, que se prestavam a uma variedade de aplicações. Em segundo lugar, abriu caminho para novos ramos de conhecimento de grande potencial econômico.

Por volta 1880, surgiu a "Administração Científica", quando Frederick Winslow Taylor procurou substituir o empirismo que reinava na organização dos processos de produção por procedimentos sistemáticos de análise, que utilizavam algumas informações relacionadas a experimentos científicos. Era a aplicação do conhecimento na melhoria das técnicas de trabalho e produção.

A aplicação da metodologia de Taylor resultou numa completa separação entre planejamento e execução das tarefas. Com essa separação, os operários estariam teoricamente isentos da necessidade de qualquer conhecimento sobre processo e produto; a função de reunir, classificar e administrar os conhecimentos seria atribuída à gerência. Para Taylor, assim como para Ford, a contribuição do trabalhador era analisada de um ponto de vista mecânico, como uma peça.

Com os métodos de Taylor, e de autores com abordagens semelhantes, o conhecimento mudou de significado, começando a ser aplicado a ferramentas, processos e produtos.

Nos últimos anos, tem-se vivido uma situação na qual o conhecimento, que era fragmentado e isolado, precisa ser integrado, não apenas em termos individuais, mas também em termos organizacionais e interorganizacionais. No entanto, não basta integrar o conhecimento; é preciso estabelecer uma dinâmica de contínua aprendizagem, uma postura de aprender a aprender.

Muitos fatores levam à necessidade do estudo do conhecimento. Segundo DAVENPORT \& PRUSAK (1998), a percepção e realidade de um mundo competitivo globalizado constituem uma das energias dessa expansão. Outros fatores são as rápidas mudanças e a crescente competição por consumidores, os quais, cada vez mais sofisticados, levaram as empresas a buscar uma vantagem sustentável para se distinguir em seus mercados. Essa vantagem sustentável pode ser proporcionada pelo emprego adequado do conhecimento (tanto individual quanto organizacional e interorganizacional) 


\subsection{Tipos de conhecimento}

Segundo FACHIN (2001), por relacionar-se com o mundo de diferentes formas, o indivíduo utiliza-se de diversos tipos de conhecimento e através deles evolui e faz evoluir o meio em que vive, trazendo contribuições para a sociedade.

Diversos autores sugerem classificações para o conhecimento. As classificações de FACHIN (2001), FERRARI (1974) e POLANYI (1966) foram utilizadas para se montar uma classificação geral, mais adequada ao contexto desta pesquisa. Essa classificação é explicada a seguir:

- Conhecimento filosófico: conduz a uma reflexão crítica sobre os fenômenos e possibilita informações coerentes. Objetiva o desenvolvimento funcional da mente, procurando educar o raciocínio. Ele oferece às ciências de todas as áreas seus princípios, enquanto $\mathrm{o}$ conhecimento científico (a ser abordado mais adiante) oferece à filosofia novos dados, tornando seus princípios gerais passíveis de novas descobertas. Esse conhecimento, segundo FERRARI (1974), é valorativo (faz ponderar), racional, sistemático, infalível, não verificável e exato;

- Conhecimento teológico ou religioso: é produto da parte do intelecto do indivíduo relacionado à fé. Implica na crença de que as verdades tratadas são infalíveis, indiscutíveis, por serem reveladas pelo mistério oculto ou sobrenatural. É um conhecimento sistemático do mundo como obra de um criador divino e cujas evidências não são verificadas. Apresenta respostas para questões que o ser humano não pode responder. Não importa qual é a crença; importa, porém, sua fé;

- Conhecimento empírico: aquele que se adquire independentemente de estudos, de pesquisas, de reflexões ou de aplicações de métodos. Esse conhecimento é resultado de suposições e de experiências pessoais conseguidas na vida cotidiana e, comumente, ao acaso; é fundamentado apenas em experiências vivenciadas ou transmitidas de pessoa para pessoa. Também pode proceder de experiências causais, por meio de 
erros e acertos, sem a fundamentação dos postulados metodológicos. É prático, porém limitado, pois se processa segundo os conhecimentos adquiridos nas ações anteriores, sem nenhuma relação científica, metódica ou teórica. Esse conhecimento é a estrutura para se chegar ao conhecimento científico; é a base fundamental do conhecer.

- Conhecimento científico: caracteriza-se pelo acolhimento metodológico e sistemático dos fatos da realidade sensível. Preocupa-se com a abordagem sistemática dos fenômenos (objetos), tendo em vista seus relacionamentos e as noções básicas de causa e efeito. Geralmente, o conhecimento científico se prende aos fatos, significando que ele possui uma referência empírica; ele se vale dos testes empíricos para formular soluções aos problemas colocados e apoiar suas próprias declarações. Ele procura alcançar a verdade dos fatos (objetos), independentemente da escala de valores e das crenças dos cientistas; resulta de pesquisas metódicas e sistemáticas da realidade. Este é o tipo de conhecimento mais explorado no presente trabalho.

Em um mesmo indivíduo, vários tipos de conhecimento podem existir simultaneamente. Por exemplo, um cientista pode ser também crente participante de sua religião ou pode estar engajado dentro de uma orientação filosófica; isso tudo sem deixar de lado seus conhecimentos provenientes do senso comum. $\mathrm{O}$ fato de diversas formas de conhecimento persistirem concomitantemente não acarreta conflitos, devido à extração seletiva em diversas situações (FERRARI, 1974).

Segundo FACHIN (2001), a literatura sobre metodologia mostra que o conhecimento científico é adquirido pelo método científico e, sem interrupção, pode ser submetido a testes para aperfeiçoar-se mediante as situações enfrentadas. As simulações computacionais a serem realizadas neste trabalho seguirão uma metodologia de simulação (LAW \& KELTON, 2000) baseada no método científico.

Outra classificação do conhecimento é sugerida por POLANYI (1966), que divide o conhecimento em tácito e explícito. O conhecimento tácito é pessoal, informal, específico ao contexto e, assim, difícil de ser formulado, visualizado e 
comunicado; ele é o conhecimento pessoal enraizado na experiência individual e envolve crenças pessoais, intuição, emoções, perspectivas e valores.

Já o conhecimento explícito (ou codificado) refere-se àquele transmissível em linguagem formal e sistemática. Pode ser facilmente comunicado e compartilhado de várias formas (textos, palestras, fórmulas, teorias etc.), além de poder ser processado e armazenado eletronicamente. Segundo o mesmo autor, esse tipo de conhecimento representa apenas uma pequena parte do conjunto de conhecimentos como um todo. Essa concepção fica evidente em sua frase: "Podemos saber mais do que podemos dizer" (POLANYI, 1966, p.4).

NONAKA \& TAKEUCHI (1997) segmentam o conhecimento tácito em duas dimensões: técnica e cognitiva. A dimensão técnica abrange uma capacidade informal e de difícil definição, normalmente designada pelo termo know-how. Como exemplo, tem-se um artesão que desenvolve seu trabalho com habilidade, mas não consegue descrever os princípios técnicos e científicos do que sabe.

A dimensão cognitiva aborda esquemas, modelos mentais, crenças e percepções; ela reflete a imagem que o indivíduo tem da realidade e sua visão de futuro. Apesar de não poderem ser articulados com facilidade, esses modelos (imagens) implícitos moldam a forma como se percebe o mundo.

Os elementos cognitivos centram-se, principalmente, no que JOHNSON-LAIRD ${ }^{4}$ (1983) chama de modelos mentais, nos quais os seres humanos criam modelos do mundo, estabelecendo e manipulando analogias em suas mentes. Assim, os modelos mentais podem ser esquemas, paradigmas, perspectivas, crenças e pontos de vista; eles ajudam os indivíduos a perceberem e definirem seu mundo (NONAKA \& TAKEUCHI, 1997).

\subsection{Aquisição de conhecimento}

A aquisição de conhecimento está relacionada ao desenvolvimento de novos conceitos e métodos e à identificação de idéias, habilidades e relacionamentos (DIBELLA \& NEVIS, 1999).

\footnotetext{
${ }^{4}$ JOHNSON-LAIRD, P. N. Mental models. Cambridge: Cambridge University Press, 1983.
} 
Segundo NONAKA \& TAKEUCHI (1997), na epistemologia ${ }^{5}$ tradicional o conhecimento é derivado da separação do sujeito e do objeto; as pessoas, como sujeitos da percepção, adquirem conhecimento através da análise dos objetos externos. Sob esse ponto de vista, o conhecimento é uma adequação do sujeito ao objeto; o sujeito tem seus meios de conhecimento, e o objeto se revela para ele conforme tais meios. De maneira distinta, POLANYI (1966) afirma que as pessoas geram conhecimento ao se envolverem com os objetos; adquirem conhecimentos criando e organizando ativamente suas próprias experiências. Para ele, saber algo é criar sua imagem ou padrão através da integração tácita de detalhes; grande parte do conhecimento é fruto do esforço voluntário das pessoas de lidar com o mundo.

NONAKA \& TAKEUCHI (1997) propõem que o conhecimento é criado (adquirido) por meio da interação entre o conhecimento tácito e o conhecimento explícito. Eles estabelecem quatro modos diferentes de conversão do conhecimento (ver FIGURA 03):

- de conhecimento tácito em conhecimento tácito: socialização;

- de conhecimento tácito em conhecimento explícito: externalização;

- de conhecimento explícito em conhecimento explícito: combinação;

- de conhecimento explícito em conhecimento tácito: internalização.

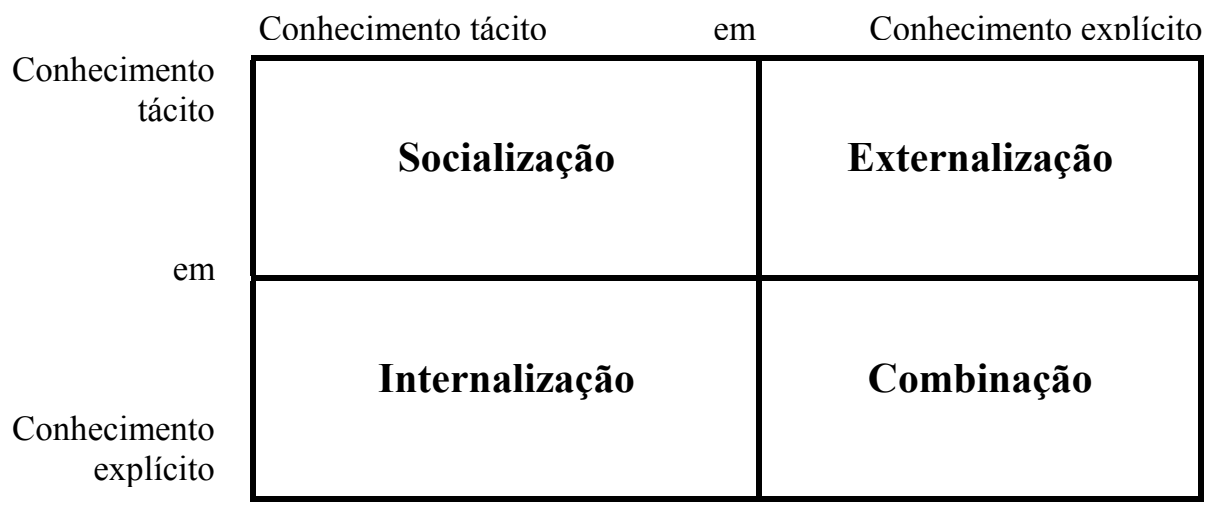

FIGURA 03 - Modos de conversão do conhecimento

Fonte: NONAKA \& TAKEUCHI (1997)

\footnotetext{
${ }^{5}$ Segundo NONAKA \& TAKEUCHI (1997), epistemologia é o estudo dos fundamentos filosóficos do conhecimento.
} 
Os modos de conversão que se inserem no contexto deste trabalho são o de conhecimento tácito em conhecimento explícito (externalização), o de conhecimento explícito em conhecimento explícito (combinação) e o de conhecimento explícito em conhecimento tácito (internalização). Esses três modos de conversão serão explicados a seguir, tendo como base a proposta de NONAKA \& TAKEUCHI (1997).

\section{Conhecimento tácito em conhecimento explícito: externalização}

A externalização é um processo no qual o conhecimento tácito se torna explícito, expresso na forma de modelos, metáforas, analogias, conceitos ou hipóteses. Esse modo de conversão do conhecimento é a chave para a criação do conhecimento, pois gera conceitos novos e explícitos a partir do conhecimento tácito.

NONAKA \& TAKEUCHI (1997) afirmam que as maneiras mais eficientes de se realizar essa conversão são: metáfora, analogia e modelo. A metáfora é uma forma de perceber ou entender algo intuitivamente, através da criação de uma imagem simbólica composta de outros elementos; em outras palavras, faz com que a pessoa entenda determinado problema relacionando-o com uma situação ou objeto conhecido. Através dela, pode-se entender conceitos abstratos pelo uso de imagens de elementos concretos.

A analogia destaca o caráter comum a duas coisas diferentes. A associação entre coisas ou fatos através da analogia é realizada pelo pensamento racional e concentra-se nas semelhanças entre elas. O modelo, por sua vez, é normalmente criado a partir de metáforas; nele, são representados os conceitos explícitos, não devendo haver contradições. Todos os conceitos e proposições devem ser expressos em linguagem sistemática e lógica.

A partir dessas definições, pode-se assumir que um modelo de simulação de um sistema é uma forma de converter conhecimento tácito em codificado, já que as atividades de reflexão, discussão, dedução, indução etc. inerentes à modelagem proporcionam o conhecimento do sistema (aquisição de conhecimento sobre o sistema modelado).

\section{Conhecimento explícito em conhecimento explícito: combinação}

A combinação é um processo de sistematização de conceitos em um sistema de conhecimento; ela envolve a combinação de diferentes conjuntos de 
conhecimento explícito. As pessoas trocam e combinam conhecimentos através de meios como documentos, reuniões, conversas, redes de comunicação computadorizadas etc. A reconfiguração das informações existentes através da classificação, do acréscimo, da combinação e da categorização do conhecimento explícito pode levar a novos conhecimentos. O treinamento formal nas escolas normalmente assume essa forma.

\section{Conhecimento explícito para conhecimento tácito: internalização}

Internalização é o processo de inclusão do conhecimento explícito no conhecimento tácito; está intimamente relacionada ao "aprender fazendo". As experiências, incluindo aquelas adquiridas nos outros modos de conversão, são internalizadas no conhecimento tácito dos indivíduos sob a forma de modelos mentais ou conhecimento técnico.

$\mathrm{Na}$ internalização, faz-se necessária uma verbalização e diagramação do conhecimento sob forma de documentos, manuais, histórias orais, vídeos etc.

A simulação computacional de sistemas envolve esses três modos de conversão de conhecimentos. Num primeiro momento, a externalização se sobressairá, pois o conhecimento tácito será transformado em explícito através da realização do modelo. Depois, a combinação e a internalização serão utilizadas para transferir os conhecimentos adquiridos para documentos apropriados e para a própria pessoa que simula.

Adquirir novos conhecimentos não é uma questão apenas de instruir-se com os outros ou com livros, mas também aprender através da prática, da experimentação, da interação intensiva entre o sujeito e seu objeto de estudo. Esta última forma de aquisição de conhecimento pode ser representada pela simulação de sistemas, onde o conhecimento a respeito de determinado sistema é adquirido através da análise de diversos cenários. 


\section{CAPÍTULO 3 A PESQUISA OPERACIONAL}

Nos últimos anos, as empresas começaram a enfrentar constantes mudanças no seu modo gerencial, ocasionadas, em especial, pelo(a):

- Aumento das exigências dos consumidores em relação à variedade e qualidade dos produtos e serviços, qualidade do atendimento, confiabilidade e rapidez de entrega etc.;

- Aumento da automação, fazendo com que as máquinas substituam o homem em trabalhos repetitivos e alienantes. As pessoas passam, então, a ser responsáveis pelos trabalhos que exigem raciocínio e criatividade;

- Abertura da economia e globalização, fazendo com que as empresas busquem satisfazer seus clientes enfrentando concorrentes do mundo todo.

Deste modo, dentre as principais medidas adotadas pelas empresas para se sobressair frente a seus concorrentes e obter lucro por um longo período, tem-se a utilização de novas formas de gestão, novas técnicas de apoio à gestão e, principalmente, a busca pelo aprimoramento de suas operações. Uma abordagem importante de apoio à análise e ao aprimoramento de operações é a Pesquisa Operacional (PO).

Em muitas situações gerenciais, a intuição e as experiências não proporcionam informação suficiente para as decisões; nesse momento, uma análise mais profunda torna-se indicada para a solução de problemas. Essa análise pode ser realizada pela PO, já que seu objetivo principal, segundo MACHLINE (1975), é a criação de modelos adequados à tomada racional de decisões.

O crescimento no uso das técnicas de pesquisa operacional em empresas industriais e de serviços comprova, primeiramente, o esforço de seus gestores para 
manterem suas empresas firmes no mercado e, depois, a eficiência dessa abordagem e de suas técnicas.

Uma das técnicas mais utilizadas pela Pesquisa Operacional, muito útil na resolução de problemas complexos e que possuem alta dose de aleatoriedade, é a simulação (estudada no capítulo cinco).

Este capítulo tem como objetivo caracterizar a Pesquisa Operacional e discorrer sobre sua evolução, metodologia e técnicas.

\subsection{A evolução da Pesquisa Operacional}

A evolução da pesquisa operacional pode ser dividida em três fases distintas: antes da Segunda Guerra Mundial, quando as aplicações eram isoladas; durante a Segunda Guerra, com fins puramente militares; e no período pós-guerra, como instrumento gerencial.

De acordo com HILLIER \& LIEBERMAN (1988), a revolução industrial trouxe ao mundo um notável crescimento no tamanho e complexidade das organizações. Essa revolução proporcionou um aumento na divisão do trabalho e das responsabilidades nas empresas. Os resultados foram excelentes, mas junto com eles surgiram problemas.

Dentre esses problemas encontra-se, por parte dos segmentos organizacionais, a perda da visão do objetivo organizacional e de como as atividades das organizações devem interagir para atingi-lo. Outro problema relacionado é a alocação dos recursos disponíveis entre as várias atividades de maneira eficaz. Esses problemas, bem como a necessidade de solucioná-los, proporcionaram um incentivo a estudos científicos que hoje podemos relacionar com a pesquisa operacional.

Evidentemente, esses estudos não possuem todas as características da PO, mas permitem a observação de alguns pontos importantes. Dentre esses estudos, estão os trabalhos de (ELLENRIEDER, 1971):

- Arquimedes: físico e matemático que idealizou a defesa da cidade de Siracusa, descobrindo novas armas e táticas;

- Frederick W. Lanchester: inglês que lidou com o problema de traduzir complexas estratégias militares em fórmulas matemáticas; 
- Thomas Alva Edison: durante a Primeira Guerra Mundial, utilizou um tabuleiro de jogo tático para determinar rotas e outras técnicas que permitissem aos navios mercantes escapar aos submarinos inimigos. Técnicas semelhantes foram utilizadas, nessa mesma guerra, pelo Comando Geral Prussiano;

- Frederick W. Taylor: iniciou uma série de estudos objetivando o aumento da eficiência de determinadas operações industriais. Taylor denominou seus métodos de "administração científica" e os descreveu num livro editado em 1911 (“The Principles of Scientific Management”). A Taylor seguiram-se outros pesquisadores com contribuições à administração organizacional: Gantt, Gilbreth, Stewart etc.

- Horace C. Levinson: na década de 1930, iniciou a aplicação da análise científica de dados e deduziu, baseado nos mesmos, problemas de comércio. Seus trabalhos consistiam em estudos de hábitos de compras dos clientes, respostas à propaganda etc.

De acordo com ELLENRIEDER (1971), os antecedentes citados seriam, nos dias de hoje, considerados estudos de Pesquisa Operacional, apesar dessa designação não ser utilizada naquela época. Além disso, devemos reconhecer que toda ciência ou técnica sempre tem pioneiros que a elas não são unidos. Dessa maneira, encara-se a Pesquisa Operacional como algo novo, nascido no início da Segunda Guerra Mundial e consolidada, organizada e sistematizada em um processo que continua até hoje.

Durante a Segunda Guerra Mundial, diante de problemas operacionais (de natureza logística, tática e de estratégia militar) e de alocação de recursos escassos, a gerência militar inglesa solicitou a diversos cientistas a aplicação de uma abordagem científica para a solução desses problemas.

Segundo ACKOFF \& SASIENI (1977), no período de vinte anos compreendido entre o fim da Primeira Guerra Mundial e o início da Segunda, a tecnologia militar desenvolveu-se tão rapidamente que não foi absorvida pela tática e pela estratégia.

Assim, em agosto de 1940, o Chefe do Comando Antiaéreo da Grã-Bretanha solicitou a colaboração do professor P. M. S. Blackett, prêmio Nobel de Física da 
Universidade de Manchester, para estudar, inicialmente, a coordenação dos equipamentos de radar.

Blackett, então, reuniu uma equipe com treino científico. Essa equipe ficou conhecida como "Anti-Aircraft Command Research Group", e tinha a característica de ser interdisciplinar, pois incluía fisiologistas, físico-matemáticos, astrofísicos, oficiais militares, topógrafos, físicos gerais, matemáticos, entre outros. Alguns grupos incluíam também cientistas sociais (ELLENRIEDER, 1971).

De acordo com MEDEIROS (2000), as equipes de cientistas trabalharam em problemas como:

- Detecção de navios e submarinos pelo radar;

- Relação entre o peso de bombas e os sinistros;

- Ações aéreas anti-submarinas;

- Dimensionamento ótimo dos comboios;

- Lançamento aéreo de minas;

- Manobras de navios para evitar kamikazes;

- Precisão dos bombardeios;

Esses cientistas não fizeram mais do que aplicar o método científico, que já conheciam, aos problemas que lhes foram sendo colocados. Desenvolveram então a idéia de criar modelos matemáticos, apoiados em dados e fatos, que lhes permitissem perceber os problemas em estudo e simular e avaliar o resultado hipotético de estratégias ou decisões alternativas.

Os êxitos das equipes de pesquisa sobre operações influenciaram a expansão de seu método na Grã-Bretanha e, logo, no Canadá, na Austrália e nos Estados Unidos. A expansão da então chamada Pesquisa Operacional abrangia não somente outros países, como também áreas fora da aplicação militar (ELLENRIEDER, 1971).

Esses grupos de cientistas e a sua nova metodologia de abordagem dos problemas se transferiram para as empresas que, após a guerra, se viram também confrontadas com problemas de decisão de grande complexidade. Suas técnicas passaram a ser aplicadas a problemas de gerenciamento de atividades produtivas, o que permitiu grande economia no uso dos meios de produção e popularizou o seu uso nessa área de conhecimento. 
Ao longo dos anos, a teoria e as aplicações da PO se diversificaram, fazendo dela um campo em franca expansão, cujas aplicações abrangem indústria, comércio, serviços e setores governamentais. Especificamente, as áreas de expressiva importância estratégica que mais utilizam a pesquisa operacional são aquelas ligadas a energia, gestão industrial, gestão da qualidade, administração de operações, logística, finanças, marketing, planejamento e gestão de serviços, informação etc. além de inúmeras outras, civis e militares.

Após a Segunda Guerra, a Pesquisa Operacional para Administração dirigiuse a problemas como (MEDEIROS, 2000):

- Programação da produção;

- Controle de estoque;

- Programação de vendas;

- Problemas de Transportes;

- Manutenção e substituição de equipamentos;

- Estudos de mercado;

- Planejamento de atividades quaisquer;

- Investimentos;

A partir dos anos 50, foram criadas inúmeras associações ligadas à PO, como a "Operations Research Society of América”, fundada nos Estados Unidos em 1953, ou a Federação Internacional de Associações de Pesquisa Operacional, criada em 1957. Revistas técnicas começaram a surgir em vários países, assim como cursos e programas em pesquisa operacional.

Apesar dos resultados obtidos pela Pesquisa Operacional durante a Segunda Guerra Mundial terem sido muito importantes para o sucesso das operações no conflito, eles foram limitados pela complexidade dos cálculos envolvidos. Somente após a disponibilização de métodos computacionais, o potencial da PO foi mais bem aproveitado. Dentre as técnicas de pesquisa operacional que mais se desenvolveram com o avanço dos métodos computacionais, está a simulação.

Hoje em dia, o potencial da Pesquisa Operacional é tão grande, que costumase dizer que ela é "uma solução à procura de um problema" (SELLITTO, 2000). 


\subsection{A Pesquisa Operacional no Brasil}

Segundo a Sociedade Brasileira de Pesquisa Operacional (SOBRAPO), a PO surgiu no Brasil quando professores da Universidade de São Paulo (USP), Instituto Tecnológico da Aeronáutica (ITA) e Pontifícia Universidade Católica do Rio de Janeiro (PUC-RJ), com formação no exterior, criaram, nos anos 50, os primeiros cursos de graduação que incluíam disciplinas de PO (como o de Engenharia da Produção); tais disciplinas foram também incluídas em cursos já existentes, como os de Economia, Engenharia, Matemática e Estatística.

A partir de 1960, a criação de cursos de pós-graduação na área de PO e a aquisição dos primeiros computadores multiplicaram as possibilidades de sua aplicação. Várias empresas começaram a utilizar a PO, estreitando um proveitoso relacionamento com as Universidades. O primeiro exemplo desta relação foi o da PUC-RJ com as empresas SOCIL e Anhangüera, para o desenvolvimento de programas de minimização de custo de rações para animais, através da Programação Linear (uma das principais técnicas da PO).

Contudo, os principais setores a empregar técnicas de PO, na época, foram os de siderurgia (CSN, Cia. Vale do Rio Doce), eletricidade (Cia Nacional de Energia Elétrica), transportes (FRONAPE), petróleo (PETROBRÁS, ESSO) e telecomunicações, além de grandes projetos e obras estatais.

Uma das primeiras aplicações da Programação Linear no Brasil foi feita em 1955, na Refinaria Presidente Bernardes (Cubatão-SP), para determinar a proporção ideal de produtos acabados a serem obtidos na refinação, a fim de maximizar o lucro (MACHLINE, 1975).

Em função de todos esses estudos e aplicações, foi criada, em 1968, a Sociedade Brasileira de Pesquisa Operacional.

Na década seguinte, a PO se consolidou no país através de um maior interesse das empresas e um maior contingente de profissionais habilitados na área, permitindo a formação de grupos próprios para atuar na solução de problemas táticos e no planejamento estratégico dessas empresas.

\subsection{A natureza da PO}

Não existe um consenso entre os autores quanto à definição mais apropriada a ser atribuída à Pesquisa Operacional, ou mesmo se esta pode ser definida. 
ACKOFF \& SASIENI (1977) apresentam uma definição que leva a uma compreensão inicial da natureza da PO. Eles consideram PO como a aplicação do método científico, por equipes interdisciplinares, a problemas que dizem respeito ao controle de sistemas organizados (homem-máquina), com a finalidade de obter as soluções que melhor satisfaçam aos objetivos da organização como um todo.

As características essenciais que podem ser obtidas dessa definição, segundo os autores, são: a) a orientação para sistemas (ou para sua direção), b) o emprego de equipes interdisciplinares e c) a aplicação do método científico a problemas de controle.

Para HERMAN \& MAGEE $^{6}$, citados por ELLENRIEDER (1971, p.8):

"O primeiro ponto a destacar é que a Pesquisa Operacional é o que seu nome indica: pesquisa sobre operações. Envolve, porém, uma visão particular das operações e, ainda mais importante, uma classe particular de pesquisa. As operações são consideradas como uma única entidade. O objetivo do estudo não é o equipamento utilizado, nem a predisposição dos participantes, nem as propriedades físicas do "produto final", mas a combinação de todos esses fatores em conjunto, considerados como um processo econômico. E as operações, assim concebidas, são submetidas à análise através dos processos mentais e dos métodos que estão associados com os trabalhos de pesquisa dos físicos, químicos e biólogos - tudo o que veio a ser chamado de "método científico"."

Segundo ELLENRIEDER (1971), essa definição provém dos especialistas da primeira época da pesquisa operacional (nascida com Blackett e seus contemporâneos), e se mostra relativamente tautológica, isto é, fala-se sempre o mesmo, apenas empregando-se diferentes termos. Para que ela se mostre mais explícita, há a necessidade de uma descrição da metodologia empregada.

Em síntese, esses especialistas tentavam, por meio de um processo de indução, achar um mecanismo que explicasse o fenômeno (que é chamado de modelo); logo, por um processo de dedução, procurava-se determinar qual seria o comportamento do fenômeno que mais convinha aos objetivos do momento. Tudo isso em termos quantitativos, com o estabelecimento do que se poderia chamar medida da efetividade do sistema ou da operação.

\footnotetext{
${ }^{6}$ HERMANN, C. C.; MAGEE J.F. Operations research for management. In: BURSK, E.C.; CHAPMAN, J.F. (Eds). New decision-making tools for managers. New York: The Mentor Executive Library, 1963.
} 
Mas, a definição mais comum e, por sua vez, uma das mais antigas, foi dada por KITTEL" ${ }^{7}$, citado por ELLENRIEDER (1971). Segundo KITTEL a "Pesquisa Operacional é o uso do método científico para prover os departamentos executivos de elementos quantitativos para tomar decisões com respeito a operações sob seu controle".

Outra definição concisa é a de EHRLICH (1985), que se refere à Pesquisa Operacional como: “... um conjunto de técnicas quantitativas com o intuito de auxiliar o processo de decisão dentro de uma filosofia de modelagem e, preferivelmente, de otimização".

Nas definições de ACKOFF \& SASIENI e de HERMANN \& MAGEE, observa-se a descrição do método e do procedimento de trabalho da PO como auxílio na compreensão do significado de Pesquisa Operacional.

Apesar de diferenças quanto à generalização ou particularização das definições, observa-se a mesma idéia central, as mesmas características em todas elas. Dentre essas características estão:

- Aplicação da PO a problemas relativos a como conduzir e coordenar as operações ou atividades dentro de uma organização;

- Amplitude de aplicações: tem sido aplicada nos negócios, nas indústrias, no governo, nos hospitais etc;

- Utiliza a abordagem do método científico;

- Ponto de vista organizacional;

- Sua meta é identificar o melhor curso de ações possível, tenta encontrar a solução melhor ou ótima para o problema;

- Utilização de equipes formadas por pessoas com diferentes experiências e habilidades.

De acordo com HEILLIER \& LIEBERMAN (1988), a contribuição da abordagem da pesquisa operacional deriva principalmente de:

- Estruturação da situação de vida real num modelo matemático, abstraindo os elementos essenciais para que possa ser buscada uma solução relevante para os objetivos do tomador de decisões;

\footnotetext{
${ }^{7}$ KITTEL, C. The nature and development of operations research. Science, p. 105-150, 1947.
} 
- Exploração da estrutura de tais soluções e desenvolvimento de procedimentos sistemáticos para obtê-los;

- Desenvolvimento de uma solução, incluindo, se necessário, a Teoria Matemática, que permita a obtenção de um valor ótimo para determinada medida desejada (ou possivelmente que compare cursos de ações alternativos através da avaliação de suas medidas).

\subsection{Vantagens da utilização da Pesquisa Operacional no gerenciamento de negócios}

Para uma dada situação, um modelo de pesquisa operacional pode oferecer a mesma solução a que um administrador experiente poderia chegar usando somente bases intuitivas. Por essa razão, os benefícios de se utilizar a PO têm que ser avaliados em termos de seu impacto de longo prazo no processo gerencial.

As qualidades inerentes a essa abordagem racional fazem dela um método válido que possui os seguintes benefícios (WAGNER, 1975):

- Ênfase na avaliação das interações e ramificações de todo o sistema de decisões alternativas. Intrínseco em uma abordagem de pesquisa de operações está a construção de um modelo que sintetiza os segmentos de um empreendimento que são afetados por uma decisão. Cada parte individual é construída pelo pessoal com maior conhecimento a respeito dos dados relevantes.

- Ímpeto para desenvolver uma gama completa de decisões alternativas. O número de possíveis ações que podem ser analisadas aumenta expressivamente pela aplicação dos métodos matemáticos e dos recursos computacionais.

- Foco na resolução de pontos críticos. A abordagem procede de maneira a estabelecer implicações da forma: "se a hipótese H é verdadeira e a ação A é realizada, então o resultado R irá ocorrer". O método promove uma comunicação interdepartamental. Como conseqüência, choques de opinião dentro de uma organização podem ser ordenados de acordo com determinado critério. 


\subsection{A metodologia da PO}

A PO utiliza, em determinados problemas, o chamado "método científico". Esse método consiste numa organização particular das atividades, orientada à solução do problema proposto.

Vários autores concordam que a metodologia da PO é baseada e dividida de acordo com o "método científico". Um exemplo é o diagrama abaixo (FIGURA 04), proposto por ELLENRIEDER (1971), o qual divide a metodologia nas seguintes fases: postulação do problema, estabelecimento do modelo, desenvolvimento analítico, obtenção de dados, resultados e implementação da solução.

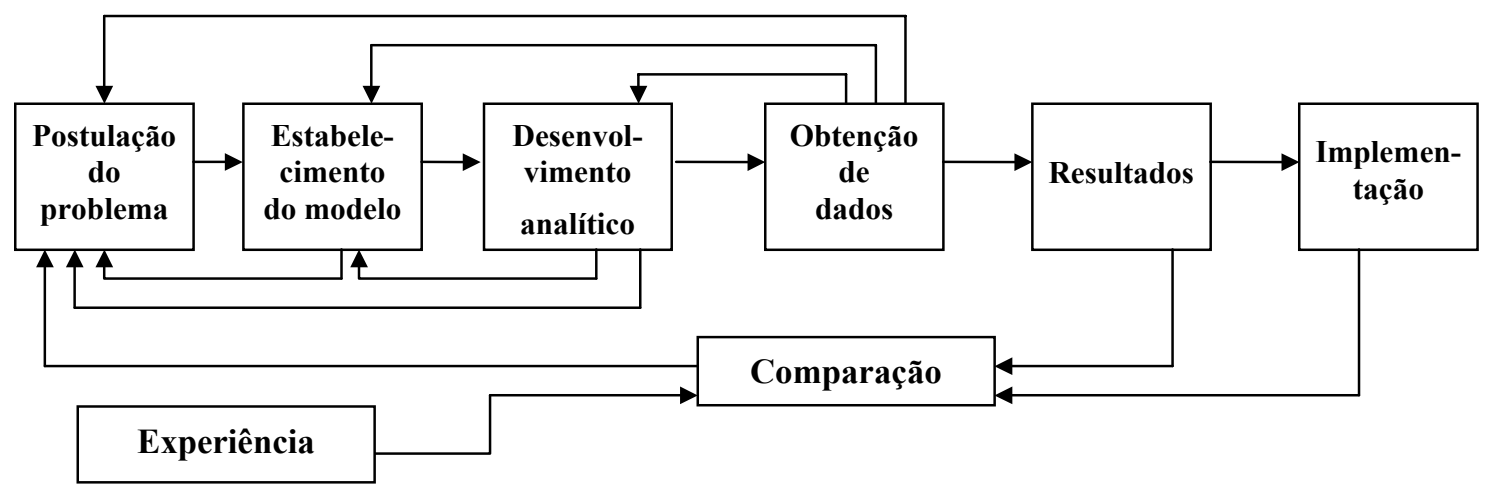

FIGURA 04 - Metodologia da Pesquisa Operacional

Fonte: ELLENRIEDER (1971)

O plano de ação elaborado por essa metodologia não deve ser encarado como uma série de etapas rígidas, e sim flexíveis. Isto significa que só após o término de cada etapa, avalia-se o que foi realizado e decide-se o que fazer a seguir.

A seguir as etapas da metodologia serão explicadas com mais detalhes de acordo com ACKOFF \& SASIENI (1977), ELLENRIEDER (1971), HILLIER \& LIEBERMAN (1988) entre outros.

\subsubsection{Postulação do problema}

Esta é a primeira fase, consistindo na definição do problema, a qual deve ser a mais precisa possível. Nessa definição, devem ser apontados os objetivos a serem alcançados, além das características das restrições do sistema e das diferentes 
variáveis existentes, bem como suas interligações. Quanto mais precisa a definição, mais facilitadas serão as outras etapas.

Os problemas cujas soluções mais utilizam as técnicas e princípios da PO são relativos a operações militares, táticas ou estratégicas, assim como a administração pública, econômica e industrial. Entretanto, em princípio, essas técnicas podem ser aplicadas a qualquer sistema.

\subsubsection{Construção do modelo}

Após observar o sistema e analisar o problema, constrói-se uma representação formal do sistema e de seu comportamento (modelo), isto é, deve-se conseguir expressar, de forma mais ou menos exata, a realidade através de um modelo. Esse modelo é, geralmente, matemático.

De acordo com ACKOFF \& SASIENI (1977) os modelos em PO assumem a forma de equações com diversos níveis de complexidade. Além disso, necessita-se, freqüentemente, de uma ou mais equações ou inequações para traduzir a condição de que algumas (ou todas) variações controladas só podem ser manipuladas dentro de limites.

Segundo os mesmos autores, uma conseqüência importante da aplicação da PO a uma grande variedade de problemas táticos é a verificação de que a maioria desses problemas pode ser representada por um pequeno número de problemas típicos. Como esses ocorrem com grande freqüência, desenvolveram-se técnicas para modelá-los e obter soluções a partir desses modelos. Tais problemas típicos são:

- Alocação;

- Estoque;

- Substituição ou reposição;

- Filas de espera;

- Seqüência e coordenação;

- Determinação de rotas;

- Situações de competição;

- Busca de informação; etc. 
Deste modo, o modelo é usado como uma simulação de uma situação presente ou futura e na avaliação da probabilidade de sua ocorrência, delimitando a área de ação e determinando o alcance de uma situação atual ou futura com um considerável nível de certeza.

Apesar da PO utilizar a construção de modelos para analisar fenômenos e obter informações dos mesmos, deve-se ressaltar que essa metodologia não é restrita a este tipo de aplicação. Hoje em dia, modelos são utilizados na construção de edifícios e fabricação de meios de transporte (maquetes), na contabilidade (modelo matemático de fluxos de capital) etc. Os modelos podem ser encontrados até mesmo na Renascença, em pinturas e esculturas, sem contar as pinturas rupestres na era préhistórica.

\subsubsection{Desenvolvimento analítico do modelo e obtenção dos dados}

Com o modelo em mãos, procura-se fazer um desenvolvimento analítico que leve à resolução do problema. Esse desenvolvimento consiste em manipular todas ou algumas das variáveis (controladas), de forma que determinada grandeza, expressando uma característica desejável do sistema (por exemplo, a medida de efetividade ou da utilidade), atinja um valor ótimo (ou suficientemente próximo deste). Resumindo, desenvolver analiticamente o modelo consiste na busca por um método capaz de calcular o valor das variáveis que influenciam na resolução do problema em foco.

A maneira como a manipulação das variáveis é feita depende da natureza do modelo. A solução pode ser extraída do modelo mediante experimentação (isto é, por simulação) ou mediante análise matemática. Em alguns casos, a análise matemática pode ser conduzida sem que se tenha qualquer idéia a respeito dos valores das variáveis (isto é, abstrata ou simbolicamente), mas em outros casos é necessário conhecer tais valores (isto é, concreta ou numericamente) (ACKOFF \& SASIENI, 1977).

Para alguns tipos de modelos, a matemática clássica fornece instrumentos perfeitamente adequados para a determinação dos melhores valores das variáveis controladas, desde que as restrições não sejam numerosas. Nos últimos anos, diversas técnicas matemáticas foram desenvolvidas e/ou aperfeiçoadas, fazendo com 
que problemas com numerosas restrições, intratáveis pelo uso de métodos clássicos, devido ao custo em tempo e dinheiro envolvido, possam ser abordados adequadamente. Dentre essas técnicas, encontram-se:

- Programação Linear;

- Programação Não-linear;

- Programação Inteira;

- Programação Dinâmica;

- Teoria das Filas;

- Simulação;

- Teoria dos Jogos, entre outras.

Caso o desenvolvimento analítico não seja possível, ou por ser muito difícil do ponto de vista teórico, ou por ter cálculos excessivamente complexos, deve-se fazer uma revisão do problema e do modelo; uma eventual simplificação deste último pode ser necessária, visando facilitar sua análise.

Se o desenvolvimento analítico for viável, isto é, se for encontrado um método de cálculo do valor das variáveis que leve ao ponto ótimo, passa-se à obtenção de dados. Nessa fase, tenta-se determinar o conjunto de dados necessários para se chegar à solução esperada. Os dados previstos para a resolução do modelo podem ou não ser passíveis de obtenção; se o segundo caso ocorre, pode haver a necessidade de uma reformulação dos passos anteriores.

Uma análise da validade dos dados e dos erros a eles associados é importante como forma de garantir a veracidade da solução a ser encontrada.

\subsubsection{Resultados}

Nesta etapa, faz-se uma comparação entre os resultados obtidos a partir do modelo e o comportamento efetivo do sistema. Se a solução obtida pelo modelo tiver um desempenho inferior ao da política ou procedimento que irá substituir pode-se, mais uma vez, refazer as etapas anteriores. No caso do resultado ser satisfatório, passa-se diretamente à implantação da solução obtida.

Porém, se as suposições que permitiram a construção do modelo forem válidas devido a simplificações em sua confecção ou aproximações realizadas no 
desenvolvimento analítico, podem aparecer resultados cujos valores não estejam em conformidade com a experiência. Nesse caso, faz-se necessária uma revisão das etapas anteriores à solução.

\subsubsection{Implementação da solução}

Após a análise dos resultados obtidos, faz-se a aplicação da solução indicada. É importante que sua viabilidade seja verificada e que haja um controle permanente no processo de aplicação. Às vezes, a aplicação prática da solução é inviável para o problema (devido a fatores restritivos), ou podem surgir situações em que a aplicação da solução indicada acarrete o surgimento de novos problemas cujas soluções sejam imprescindíveis para uma implementação adequada.

Além disso, o processo de implementação da solução preconizada pelo modelo pode exigir o controle constante das etapas anteriores, já que modificações significativas nos sistema e no meio ambiente ocorrem com relativa facilidade. Essa prática possibilita a obtenção de dados mais próximos da realidade.

\subsection{Técnicas}

Como visto anteriormente, um estudo de pesquisa operacional começa com a construção de um modelo conceitual simplificado do sistema a ser analisado. A partir daí, analisa-se o modelo como se o sistema fosse real. Por causa da necessidade de incorporação de dados numéricos e outros eventos objetivos, os modelos de PO são quase sempre matemáticos e, portanto, requerem uma análise que emprega os métodos matemáticos.

Otimização e incerteza são temas constantes nos estudos de PO. Segundo ECKER \& KUPFERSCHMID (1988), a necessidade de se fazer escolhas ótimas em situações de incerteza determina duas categorias principais de métodos matemáticos usados na pesquisa operacional:

- Otimização

- Programação linear;

- Programação inteira; 
- Programação não-linear;

- Programação dinâmica, entre outros.

- Probabilidade aplicada

- Teoria das filas

- Modelos de estoques

- Simulação de eventos discretos, entre outros.

Os métodos de otimização são também conhecidos como métodos de programação matemática, e os tópicos de probabilidade aplicada são usados na predição de resultados de uma seqüência de eventos incertos.

Os problemas reais de pesquisa operacional não vêm em pacotes prontos para uma análise matemática. As situações nas quais há maior dificuldade (e necessidade) de se aplicar a PO são justamente aquelas que possuem fatores difíceis de quantificar e medir, mecanismos complicados e/ou obscuros e problemas com caráter fortemente aleatório.

\subsection{Simulação dentro da Pesquisa Operacional}

A definição e os principais aspectos da simulação serão abordados no capítulo 5. Nesta seção, pretende-se auxiliar a compreensão da simulação como uma ferramenta da PO.

A partir dos primeiros estudos realizados pela Pesquisa Operacional, os problemas analisados cresceram em complexidade, exigindo, desta maneira, técnicas mais sofisticadas de análise. Assim, a simulação surgiu da carência por métodos de solução de problemas de natureza estatística ou estocástica.

Um dos métodos de simulação mais utilizados na $\mathrm{PO}$, para problemas e processos bem definidos, foi o método de Monte Carlo. Esse método consiste em reproduzir, em laboratório, o processo aleatório que gera o fenômeno estudado. Ele era especialmente útil quando a lei de probabilidade do processo era excessivamente complexa para se criar seu modelo matemático. A partir desse método, originou-se a chamada simulação probabilística (MACHLINE, 1975). 
Segundo HILLIER \& LIEBERMAN (1988), a simulação, dentro da Pesquisa Operacional, envolve a construção de um modelo que é, por natureza, predominantemente matemático. Mas, em lugar de descrever diretamente o comportamento geral do sistema, o modelo de simulação descreve a operação do sistema em termos dos eventos individuais de cada componente do sistema.

Ainda segundo os autores acima, no procedimento de simulação utilizado na PO, o sistema é subdividido em elementos cujos comportamentos possam ser preditos, pelo menos em termos das distribuições de probabilidade, para cada um dos possíveis estados do sistema e suas entradas. As inter-relações entre os elementos também são construídas dentro do modelo. A partir daí, combina-se os elementos em sua ordem natural e faz-se com que o computador apresente o efeito das interações. Após sua construção, o modelo é ativado (pela geração de dados de entrada), a fim de simular a operação real do sistema e registrar seu comportamento agregado. Repetindo-se isso para várias configurações alternativas de projeto e políticas de operação do sistema, e comparando seus desempenhos, as formas mais promissoras podem então ser identificadas.

Em decorrência do erro estatístico, é impossível garantir que a configuração que resulte no melhor desempenho simulado seja, de fato, a ótima; porém, se o experimento tiver sido projetado adequadamente, tal configuração estará bastante próxima da ideal.

Assim, poder-se-ia definir a simulação na PO como a realização de experimentos numéricos com modelos lógico-matemáticos (SALIBY, 1989).

Neste trabalho, a técnica simulação é aplicada, em seus diferentes aspectos, a um problema de fila de espera. Os conceitos de fila de espera e Método de Monte Carlo serão abordados com mais detalhes no capítulo quatro. 


\section{CAPÍTULO 4 CONCEITOS BÁSICOS SOBRE SIMULAÇÃO}

Antes da discussão sobre a simulação de sistemas propriamente dita, deve-se considerar alguns conceitos que estão intrinsecamente relacionados a ela e cuja discussão facilite seu entendimento. Por esse motivo, apresenta-se a seguir uma descrição dos principais conceitos adotados neste estudo: sistemas, modelos, filas e Método de Monte Carlo.

\section{1 Sistemas}

Um sistema pode ser definido, segundo BANKS et al. (1996), como um grupo de objetos que são reunidos em alguma interação ou interdependência regular, a fim de se alcançar algum propósito.

Através dessa definição, nota-se que um sistema é algo bastante relativo. Em determinado momento, uma coleção de objetos pode ser uma pequena parte de um sistema maior (subsistema), e em outro é considerada um sistema completo. Os limites do sistema são estabelecidos a fim de se definir o que será estudado e incluir neles apenas aqueles itens que são considerados mais importantes para os objetivos. A determinação desses limites depende do estudo realizado e dos objetivos a serem alcançados. Deste modo, o termo endógeno é usado para descrever atividades e eventos que ocorrem no sistema, e o termo exógeno é usado para descrever atividades e eventos do ambiente que afetam o sistema (BANKS et al., 1996).

\subsubsection{Componentes de um sistema}

De acordo com BANKS et al. (1996), para se compreender e analisar um sistema, alguns termos precisam ser definidos. Uma entidade é um objeto de interesse no sistema e um atributo é uma propriedade de uma entidade. Uma 
atividade representa um período de tempo de duração especificada; já um evento pode ser definido como uma ocorrência instantânea que pode mudar o estado do sistema. Se uma linha de produção está sendo estudada, os produtos poderão ser entidades, seus tempos de processamento poderiam ser um atributo, e a transformação dos produtos poderia ser uma atividade.

O estado de um sistema é outro componente que pode ser definido, segundo LAW \& KELTON (2000), como uma coleção de variáveis necessárias para descrever um sistema em determinado momento. No estudo de um banco, são possíveis variáveis de estado: o número de atendentes ocupados, o número de clientes esperando na fila ou sendo servidos e o tempo de chegada do próximo cliente. A TABELA 02 abaixo lista alguns exemplos dos componentes de um sistema.

TABELA 02 - Exemplos de componentes de um sistema

\begin{tabular}{l|l|l|l|l|l}
\hline \multicolumn{1}{c|}{ Sistema } & Entidades & \multicolumn{1}{|c|}{ Atributos } & Atividades & \multicolumn{1}{|c|}{ Eventos } & \multicolumn{1}{c}{ Variáveis de estado } \\
\hline Banco & Clientes & $\begin{array}{l}\text { Saldo da } \\
\text { conta } \\
\text { bancária }\end{array}$ & Depositar & $\begin{array}{l}\text { Chegada; } \\
\text { partida. }\end{array}$ & $\begin{array}{l}\text { Número de caixas } \\
\text { ocupados; número de } \\
\text { clientes esperando. }\end{array}$ \\
\hline Ferrovia & Viajantes & $\begin{array}{l}\text { Origem; } \\
\text { destino. }\end{array}$ & Viajar & $\begin{array}{l}\text { Chegada à } \\
\text { estação; } \\
\text { Chegada ao } \\
\text { destino. }\end{array}$ & $\begin{array}{l}\text { Número de viajantes } \\
\text { esperando em cada } \\
\text { estação; número de } \\
\text { viajantes em trânsito. }\end{array}$ \\
\hline Produção & Máquinas & $\begin{array}{l}\text { Velocidade; } \\
\text { taxa de } \\
\text { quebra. }\end{array}$ & Solda, Molde. & $\begin{array}{l}\text { Quebra } \\
\text { Ctatus das máquinas } \\
\text { (ocupada, ociosa ou } \\
\text { quebrada). }\end{array}$ \\
\hline Comunicações & Mensagem & $\begin{array}{l}\text { Duração; } \\
\text { destino. }\end{array}$ & Transmitir & $\begin{array}{l}\text { Chegada ao } \\
\text { destino }\end{array}$ & $\begin{array}{l}\text { Número esperando para } \\
\text { ser transmitido }\end{array}$ \\
\hline Estoques & Armazém & Capacidade & Remoção & Demanda & $\begin{array}{l}\text { Níveis dos estoques: } \\
\text { demandas acumuladas }\end{array}$ \\
\hline
\end{tabular}

Fonte: Adaptado de BANKS et al. (1996)

\subsubsection{O estudo dos sistemas}

LAW \& KELTON (2000) expõem a necessidade de se estudar os sistemas para tentar aferir algumas hipóteses sobre os relacionamentos entre os vários componentes 
ou para predizer o desempenho do sistema sob novas condições. Algumas das diferentes maneiras existentes para se estudar um sistema estão representadas no esquema abaixo (FIGURA 05) e explicadas a seguir:

- Experimento com o sistema real versus Experimento com um modelo

do sistema real: se for possível (e custo-efetivo) alterar o sistema fisicamente e então fazê-lo operar sob as novas condições, é provavelmente desejável assim proceder. Entretanto, tal situação raramente ocorre, porque um experimento poderia, com freqüência, ser muito caro ou desestabilizar o sistema. Além disso, o "sistema" poderia não existir, mas ainda assim haveria a necessidade de estudá-lo de acordo com várias propostas de configurações alternativas para observar como ele poderia ser construído. Por essas razões, é usualmente necessário construir um modelo como uma representação do sistema e estudá-lo como um substituto para o sistema real.

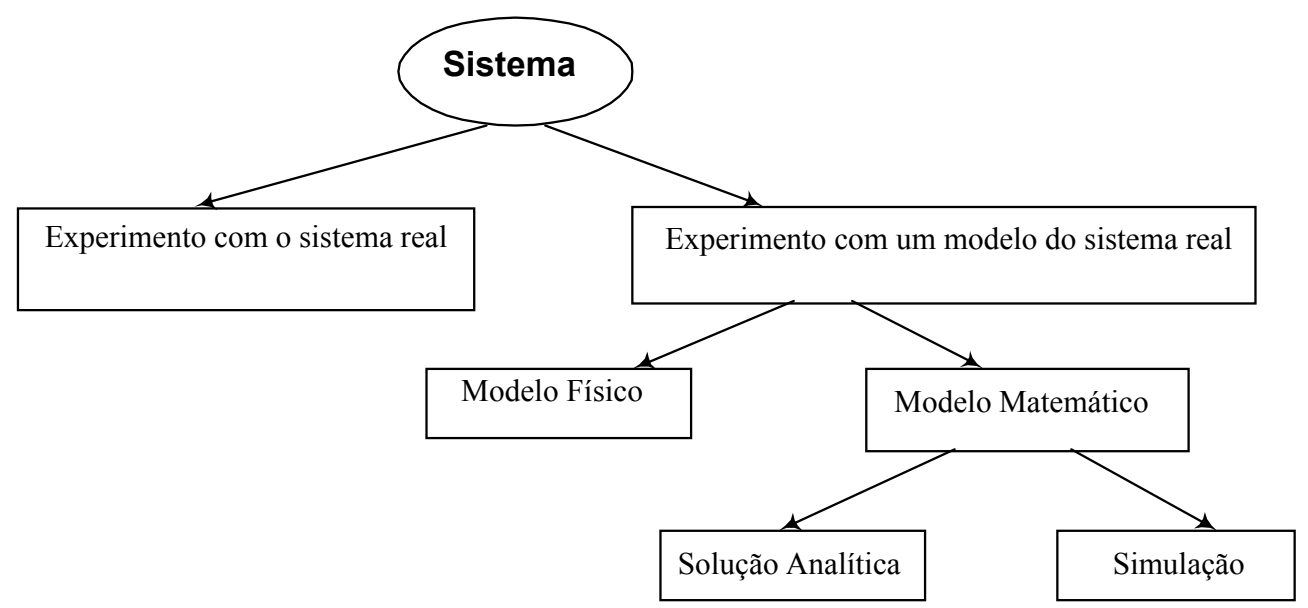

FIGURA 05 - Formas de estudo de um sistema Fonte: LAW \& KELTON (2000)

- Modelo físico versus Modelo matemático: os modelos físicos ou icônicos normalmente se parecem com o que eles representam, mas diferem no tamanho; são réplicas, geralmente de dimensões reduzidas. Como exemplo tem-se: fotografias, mapas, maquetes etc. Segundo ACKOFF \& SASIENI (1977), os modelos icônicos são freqüentemente específicos, concretos e difíceis de manipular para fins experimentais. Esses modelos normalmente não interessam aos pesquisadores operacionais e analistas de sistemas; a maioria 
dos modelos de interesse desses profissionais é matemático. Os modelos matemáticos (também chamados de abstratos ou simbólicos) usam símbolos em lugar de dispositivos físicos; eles representam um sistema em termos de relacionamentos lógicos e quantitativos, os quais são manipulados para se observar como o modelo reage, e então como o sistema reagiria. Um modelo de simulação é um tipo particular de modelo matemático.

- Solução analítica versus Simulação: uma vez construído, um modelo matemático deveria ser examinado a fim de se determinar como ele poderia ser utilizado na obtenção de respostas às questões de interesse a respeito do sistema que supostamente representa. Se o modelo é suficientemente simples, pode ser possível trabalhar com suas relações e quantidades para obter uma solução analítica. Se uma solução analítica para um modelo matemático é viável e computacionalmente eficiente, esta é, freqüentemente, a abordagem mais adequada. Porém, muitos sistemas são altamente complexos, dificultando qualquer possibilidade de soluções deste tipo. Nesse caso, o modelo deve ser estudado através da simulação, isto é, numericamente experimentado para as entradas em questão, com o objetivo de determinar como elas afetam as saídas e as medidas de desempenho do sistema.

Uma vez que se decidiu utilizar simulação para se estudar um modelo matemático, algumas ferramentas particulares devem ser examinadas para esse fim. É útil para esse propósito classificar os modelos de simulação e estudar as linguagens de simulação, conforme indicado no Capítulo 5.

\section{2 Modelos}

O item anterior tratou, entre outras coisas, do estudo de um sistema através de modelos físicos ou matemáticos. Mas o que é exatamente um modelo e qual sua classificação? Esta seção visa conceituar o termo modelo e apresentar uma breve discussão sobre sua classificação. 
"Um modelo é uma representação de um objeto, sistema ou idéia em alguma forma outra que não a própria entidade" (SHANNON, 1975, p.123).

FORRESTER (1961), discorrendo sobre modelos, diz que eles têm se tornado largamente aceitos como um meio de estudar fenômenos complexos e que seu valor provém da melhoria da nossa compreensão das características de comportamento do sistema real, compreensão essa mais efetiva do que aquela realizada pela observação do sistema em si. Um modelo, comparado ao sistema real que ele representa, pode lidar com informação a um baixo custo, além do conhecimento ser obtido mais rapidamente e em condições não observáveis na vida real.

A definição transcrita acima remete a uma característica fundamental da utilidade dos modelos: resumir o funcionamento do sistema num pequeno número de variáveis que permita sua apreensão pelo intelecto humano. A FIGURA 06 procura fornecer uma noção a respeito dos princípios utilizados no processo de modelagem.

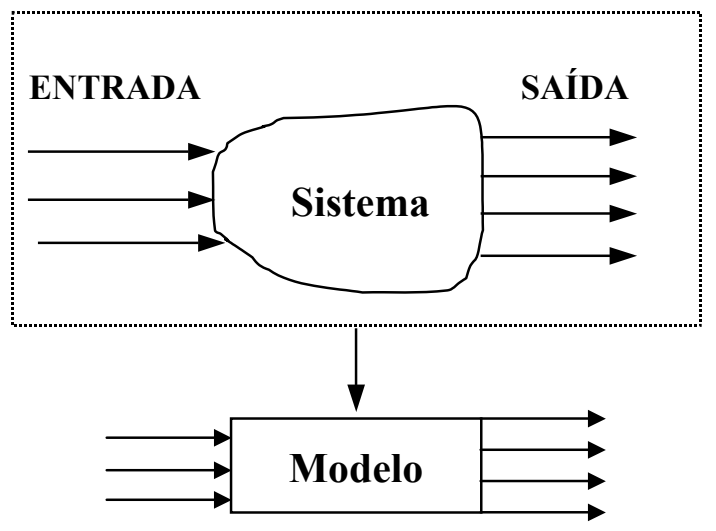

FIGURA 06 - Processo simples de modelagem Fonte: Adaptado de CASSANDRAS \& LAFORTUNE (1999)

Para se construir modelos e empregá-los para prever e explicar fenômenos com alto grau de precisão, é necessária uma seleção correta das variáveis mais significativas para se descrever o comportamento do sistema. A razão disso, segundo ACKOFF \& SASIENI (1977), é que, embora seja necessário um grande número de variáveis para prever um fenômeno com perfeita exatidão, um pequeno número de variáveis geralmente explica a maior parte dele. O ponto chave do processo de modelagem, evidentemente, é descobrir as variáveis certas e a relação entre elas.

Dessa maneira, a principal tarefa daquele que modela (modelador) um sistema deve ser decidir, com base nos objetivos estabelecidos, quais elementos do 
sistema incluir no modelo e, dessa forma, instituir suas fronteiras e nível de detalhamento. Dependendo do modelador e de seu objetivo, um mesmo sistema pode ter modelos com maior ou menor nível de detalhamento e com diferentes características.

\subsubsection{Tipos de modelos}

Uma breve classificação de modelos de sistemas foi apresentada na seção 4.1.3 (modelos físicos versus matemáticos). Várias outras classificações de modelos são sugeridas por diversos autores, entre eles CASSANDRAS \& LAFORTUNE (1999), BANKS et al. (1996), SOARES (1990), EHRLICH (1985), FORRESTER (1961) etc. A seguir, apresenta-se uma síntese dessas classificações.

\section{Linear ou não-linear}

Os modelos são lineares quando o sistema que representam segue uma lei linear, ou seja, independente do nível em que esteja, sempre haverá a mesma resposta da variável endógena a uma variável independente ou exógena. Modelos não-lineares são aqueles em que o relacionamento das variáveis endógenas e exógenas não se dá através de relações lineares.

\section{Estático ou dinâmico}

Um modelo estático representa um sistema em um ponto particular no tempo ou um sistema no qual o tempo simplesmente não desempenha um papel importante; modelos de Monte Carlo são exemplos de modelos de simulação estáticos. Modelos dinâmicos representam sistemas à medida que eles evoluem ao longo do tempo.

\section{Estável ou instável}

Modelos dinâmicos podem ser estáveis ou instáveis. Nos primeiros, sempre se volta à condição inicial após algum distúrbio. Já os modelos instáveis representam sistemas que, depois de ativados, tendem a desenvolver a sua amplitude de movimentação e, conseqüentemente, a se afastar sobremaneira de sua condição inicial. 


\section{Discretos ou contínuos}

As alterações nas variáveis de estado do sistema podem ser contínuas ou discretas no tempo. Um modelo de mudança discreta (chamado de modelo de sistema de eventos discretos) é aquele em que as variáveis se modificam discretamente em pontos específicos do tempo simulado. Um modelo de mudança contínua é aquele em que as variáveis podem variar continuamente ao longo do tempo simulado.

\section{Determinísticos ou estocásticos}

Modelos que não contêm variáveis aleatórias são classificados como determinísticos; esses têm um conjunto conhecido de entradas que resultarão em um único conjunto de saídas. Um modelo estocástico tem uma ou mais variáveis aleatórias como entrada; essas entradas levam a saídas aleatórias, as quais podem apenas ser consideradas como estimativas das verdadeiras características de um modelo.

\section{Modelos analíticos ou modelos de simulação}

Esta é uma classificação na qual os modelos são divididos de acordo com os métodos utilizados na obtenção dos resultados numéricos. Assim, modelos analíticos são definidos como aqueles cuja estrutura é formada por uma série de equações matemáticas, através das quais o comportamento do sistema pode ser obtido pela atribuição de valores aos parâmetros do modelo e a solução das equações. Modelos de simulação podem ser definidos como aqueles representados por uma estrutura matemática/lógica, que pode ser exercitada de forma a mimetizar o comportamento do sistema. Através do experimento (simulação), várias observações são realizadas para dar subsídio às várias conclusões sobre o sistema.

ACKOFF \& SASIENI (1977) afirmam que na Pesquisa Operacional procura-se, sempre que possível, estabelecer modelos simbólicos, porque são mais fáceis de manipular e produzem, quase sempre, resultados mais exatos que os modelos icônicos.

Neste estudo, são considerados os modelos de simulação de sistemas dinâmicos de eventos discretos, em particular os modelos de fila de espera. 


\subsubsection{Modelos de simulação}

Segundo SOARES (1990), os modelos são uma descrição dos sistemas e, apesar de serem construídos dependentes do problema a resolver, requerem uma estrutura organizada qualquer. Uma linguagem (ou pacote) para simulação fornece uma destas estruturas, e é sua compilação que vai traduzir a descrição do sistema em uma forma aceitável por um sistema de computação.

Esta pesquisa está direcionada ao estudo de sistemas descritos através de modelos - apoiados em uma estrutura fornecida por um pacote de simulação - que, ao serem exercitados num computador, fornecerão subsídios para que decisões relacionadas com a resolução de problemas, referentes a estes sistemas, possam ser tomadas.

\section{3 Filas}

Uma vez que este trabalho baseia-se no estudo de um sistema de fila, é importante que se apresente sua conceituação e principais características.

A Teoria das Filas é uma técnica da Pesquisa Operacional que utiliza conceitos de processos estocásticos e de matemática aplicada para analisar o fenômeno de formação de filas e suas características. Essa teoria foi desenvolvida de modo a resolver problemas de congestionamento e dimensionamento de instalações.

Sistemas de filas ou de linhas de espera são muito comuns. Como exemplo, tem-se as filas de clientes em um banco, bens incompletos esperando processamento e passageiros esperando num ponto de ônibus. Qualquer sistema que é caracterizado por elementos sujeitos a espera por um serviço podem ser conceituados como sistemas de fila (WATSON, 1981).

A fila é formada por aqueles elementos esperando na linha para receber o serviço. Já o sistema de fila inclui a fila, o servidor e qualquer elemento que esteja sendo servido naquele momento. Por exemplo, em um supermercado, os clientes esperando na linha constituem a fila; e a(s) fila(s), o(s) cliente(s) que está(ão) sendo servido(s) e o(s) atendente(s) formam o sistema de fila (ver FIGURA 07). 


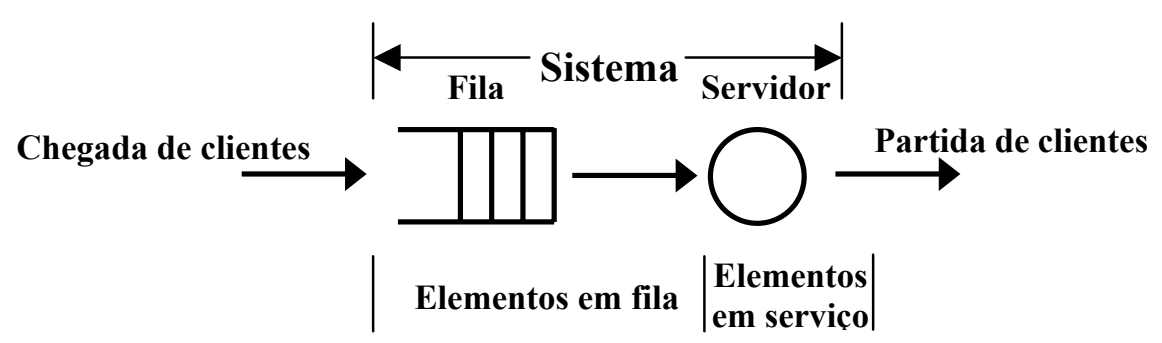

FIGURA 07 - Sistema básico de fila

Fonte: Elaborada pelo autor

De maneira geral, uma fila resulta da falta de programação do sistema, pois se fosse possível organizar as chegadas e os serviços, seria possível evitar completamente a espera dos clientes. Mas, na maioria dos sistemas, é impossível programar as filas, pois as chegadas e os serviços são geralmente aleatórios.

De acordo com MACHLINE (1975), os problemas de filas normalmente estão relacionados com o congestionamento de clientes e com a ociosidade dos servidores. O congestionamento em filas de espera pode ser criado porque há muitos clientes chegando para serem servidos em instalações de serviço inadequadas (a taxa de chegada excede a taxa de serviço). Um tempo longo de espera causa a desistência de clientes e então, para alguns sistemas, perda de rendimentos. Instalações de serviço podem estar ociosas (esperando por clientes) porque pode haver um excessivo número de unidades de serviço e/ou as instalações existentes podem ter uma taxa total de serviço que excede a taxa de chegada.

A situação mais ideal é um sistema de fila balanceado que tende a um equilíbrio; nesses casos as instalações de serviço esperam temporariamente por clientes e clientes esperam temporariamente pelo serviço.

\subsubsection{Termos}

Apresenta-se a seguir alguns termos básicos relacionados à Teoria de Filas (SHAMBLIN \& STEVENS, 1974):

- Cliente: unidade de chegada que requer atendimento. Os clientes podem ser pessoas, máquinas, peças etc.

- Fila (linha de espera): número de clientes esperando atendimento. Normalmente, a fila não inclui o cliente que está sendo atendido. 
- Canal de atendimento: processo ou sistema que realiza o atendimento do cliente. Pode ser um canal múltiplo ou único.

- Taxa de chegada: a taxa (clientes por períodos de tempo) segundo a qual os clientes chegam para serem atendidos. O pressuposto referente à distribuição deste valor tem grande efeito sobre o modelo matemático. $\mathrm{O}$ pressuposto típico que será utilizado neste texto é o de que a taxa de chegada está aleatoriamente distribuída conforme a distribuição de Poisson. $O$ valor médio da taxa de chegada é $\lambda$.

- Taxa de atendimento: a taxa (clientes por período de tempo) segundo a qual um canal de atendimento pode efetuar o atendimento requerido pelo cliente. Esta é a taxa que poderia ser atingida se o canal de atendimento não ficasse ocioso. A distribuição deste valor é igualmente importante na determinação do grau de complexidade matemática. Salvo indicação em contrário, supõe-se que a taxa de atendimento está distribuída aleatoriamente conforme um processo de Poisson.

- Prioridade: critério de decisão sobre a ordem de atendimento. O pressuposto mais comum é o de que quem chegou primeiro será atendido primeiro.

- Tamanho da população: tamanho do grupo que fornece os clientes. Se houver apenas alguns clientes potenciais, a população será finita. Se houver um número grande de clientes potenciais, digamos, acima de 30 ou 50, geralmente se diz que a população é infinita. Outra regra prática: o pressuposto de uma população infinita geralmente será válido quando a população potencial for bastante grande para significar que a chegada de um cliente não afetará significativamente a probabilidade de outra chegada.

- Taxas de distribuição de chegada (de atendimento): o pressuposto mais comum é a distribuição de Poisson. Isto implica que os eventos "atendimento" e "chegada" são completamente independentes. Esta é uma das suposições mais restritivas. Em todos os casos, deve-se ter em mente que a análise fornece resultados em termos de valores esperados ou médios. Além disso, normalmente supõe-se que tanto a taxa de atendimento como as taxas de chegada são constantes no tempo. $\mathrm{Na}$ 
prática, isto pode não ser verdade, uma vez que é comum o uso de tempo ou esforço extra quando surgem filas muito longas.

- Número esperado na fila: número esperado de clientes que aguarda atendimento.

- Número esperado no sistema: número esperado de clientes na fila e/ou sendo atendidos.

- Tempo esperado na fila: tempo que se espera que um cliente gaste aguardando em fila.

- Tempo de sistema esperado: tempo que se espera que um cliente gaste aguardando e sendo atendido.

Alguns desses conceitos são considerados medidas de desempenho do sistema de filas, como número de clientes na fila, tempo esperado no sistema etc. Essas medidas são importantes para se conhecer as características e o comportamento do sistema. As medidas de desempenho das filas a serem utilizadas neste trabalho estão relacionadas na metodologia (capítulo sete).

\subsubsection{Características}

O processo de fila é caracterizado pelos seguintes elementos:

a) Especificação da população de clientes: finita ou infinita;

b) Distribuição da probabilidade do intervalo de tempo entre chegadas: a distribuição de chegada descreve o padrão pelo qual os elementos chegam para serem servidos. Por exemplo, taxas de chegada com distribuição de Poisson são muito comuns em sistemas de fila, mas outras distribuições, como a uniforme e a normal, são às vezes mais apropriadas;

c) A disponibilidade do serviço: alguns sistemas só atendem durante um certo intervalo de tempo, outros estão sempre disponíveis;

d) A capacidade do sistema, isto é, o número de clientes atendidos simultaneamente; as unidades podem ser atendidas individualmente (bilheteria do cinema etc.) ou em grupos (pessoas num elevador, veículos num semáforo etc.);

e) A duração do tempo de serviço de cada cliente: a distribuição de serviço descreve o padrão pelo qual o servidor provê o serviço. Pode ser constante ou aleatória; 
f) Número de canais e fases: o número de canais descreve o número de linhas que existem em um sistema; o número de fases se refere ao número de instalações de serviço através das quais um elemento pode passar antes de se completar o serviço;

g) Disciplina da fila: é o conjunto de regras que determinam a ordem em que os elementos da fila são atendidos. Há várias possibilidades, como atendimento pela ordem de chegada, atendimento aleatório, datas de entregas prometidas etc.

As características das filas de espera formam a base para sua classificação. A divisão dos modelos de filas pode se basear no número de canais e fases. O número de canais descreve o número de linhas que existem em um sistema; segundo este critério, os sistemas de fila podem ser classificados em simples ou multicanais. $\mathrm{O}$ número de fases se refere ao número de instalações de serviço através das quais um elemento pode passar antes de se completar o serviço; segundo este critério, os sistemas de fila podem ser classificados em simples ou multifásicos (WATSON, 1981). A classificação baseada em canais e fases é ilustrada na FIGURA 08.

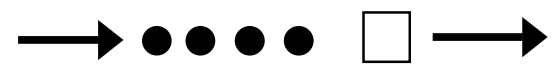

(a) Caso do canal simples, monofásico

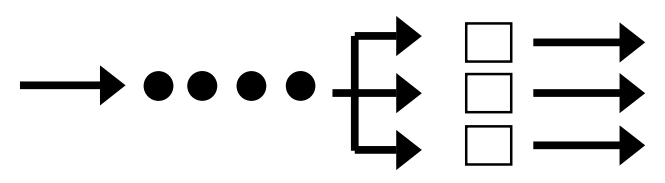

(b) Caso do canal múltiplo, monofásico

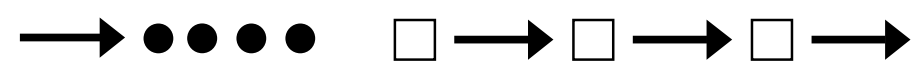

(c) Caso do canal simples, multifásico

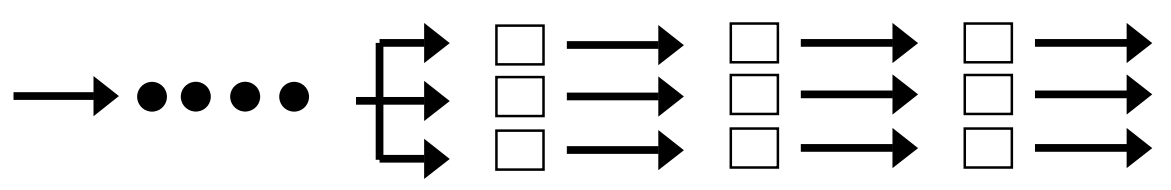

(d) Caso do canal múltiplo, multifásico

\section{Legenda:}

= Cliente

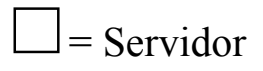

$\rightarrow=$ Fluxo de Clientes

FIGURA 08 - Estruturas básicas de modelos de fila de espera

Fonte: BUFFA (1972) 
As figuras acima representam as quatro estruturas básicas de situações de fila

de espera. A situação mais simples ocorre quando as unidades que chegam formam uma fila única para ser atendida por um único equipamento de serviço. Caso se aumente o número de estações de processamento, mas haja uma só fila de espera, temos o caso de canais múltiplos monofásicos. Uma linha de montagem simples tem um número de equipamentos de serviço em série; este é o caso do canal simples, multifásico. Finalmente, tem-se o caso dos canais múltiplos multifásicos, que pode ser ilustrado por duas ou mais linhas de produção paralelas. Neste trabalho, será abordado o sistema de fila de canal simples e multifásico.

\subsubsection{Simulação de filas}

De todos os conceitos tratados pelas técnicas de pesquisa operacional básica, a teoria das filas parece ter a mais ampla aplicação. Empresas, escolas, hospitais, governo etc. têm se utilizado dessa técnica para resolver seus problemas de congestionamento e dimensionamento de instalações.

Segundo WATSON (1981), existem três tipos de análise de sistemas de fila: tentativa e erro, analítico e métodos de simulação. O principal objetivo deste trabalho é ilustrar como se pode adquirir conhecimento sobre um sistema de fila através da simulação de seu comportamento.

Um projeto de um sistema pode evoluir em uma base de tentativa e erro. Para sistemas simples, essa abordagem é usualmente efetiva em termos de custo, pois um projeto ótimo é com freqüência identificado após a exploração de algumas poucas alternativas. Porém, conforme sistemas mais complexos são analisados, torna-se menos provável que um projeto ótimo seja descoberto por procedimentos de tentativa e erro. Eles são também inapropriados no desenvolvimento de novos sistemas, para os quais modificações do projeto inicial serão difíceis ou impossíveis.

Uma segunda abordagem envolve o uso do modo analítico. Por meio de métodos matemáticos e estatísticos, expressões que descrevem o comportamento do sistema são desenvolvidas. Essa abordagem deve ser usada sempre que possível; entretanto, muitos sistemas de filas são complexos demais para serem estudados através de métodos analíticos. Nesses casos, o analista deve voltar-se à abordagem de simulação. 
Segundo MIRSHAWKA (1977), pode-se simular qualquer sistema de fila que possa ser descrito e para o qual se possam obter dados de chegada e de tempo de serviço. A disponibilidade de computadores reduziu consideravelmente o tempo requerido para a simulação de problemas de fila complexos. Com o auxílio dos computadores, o tempo de operação ficou mais curto, e o gasto de tempo com a programação pôde ser reduzido pelo uso de linguagens e pacotes de simulação (ver seção 5.7).

\section{4 O Método de Monte Carlo}

A maior dificuldade encontrada na PO é lidar com situações tão complexas que tornam impossível o estabelecimento de uma expressão analítica, seja ela determinística ou probabilística, que possa ser manipulada para produzir respostas imediatas e analíticas. Em muitos casos, a simulação é o único método útil para a solução de problemas de decisão.

Como relatado no capítulo anterior, o Método de Monte Carlo (MMC) originou o que hoje se denomina simulação probabilística. Mas, a que se refere este método?

Segundo NAYLOR (1971), a análise de Monte Carlo é uma técnica de simulação para problemas que têm base probabilística ou estocástica, e é aplicada a dois tipos gerais de problemas:

$1^{\circ}$ ) Problemas que envolvem alguma forma de processo estocástico. $\mathrm{O}$ método foi desenvolvido para simular distribuições de probabilidade conhecidas ou empíricas;

$2^{\circ}$ ) Certos problemas matemáticos determinísticos que não podem ser facilmente resolvidos por métodos determinísticos. Nesses casos, obtém-se soluções aproximadas simulando um processo estocástico cujos momentos, funções de densidade ou funções de distribuição cumulativas satisfaçam as relações funcionais ou requisitos de solução de problemas determinísticos.

Ainda segundo esse autor, a origem do Método de Monte Carlo remonta ao trabalho de Von Neumann e Ulam, em 1940, no Laboratório de Los Alamos (Estados 
Unidos). Nesse trabalho, os pesquisadores associaram a expressão "Análise de Monte Carlo" a uma técnica matemática que utilizaram para solucionar certos problemas de blindagem em reatores nucleares, os quais seriam muito caros em uma solução experimental ou muito complicados para tratamento analítico.

SALIBY (1989) trata da evolução do MMC. De acordo com ele, a aplicação original desse método voltava-se à avaliação de integrais múltiplas, mas logo se verificou sua aplicabilidade na solução de diversos outros problemas matemáticos complexos.

Após o momento inicial, as deficiências do método foram mais bem reconhecidas, entre elas o grande esforço computacional envolvido e a baixa precisão dos resultados. Como no final da década de 40 os computadores apenas começavam a se tornar realidade, as melhorias no método direcionaram-se para a obtenção de resultados mais precisos, sem o aumento proporcional dos tempos de processamento. Esse esforço resultou no desenvolvimento de técnicas de redução da variância.

$\mathrm{O}$ advento dos primeiros computadores, no início da década de 50, permitiu a extensão do Método de Monte Carlo à solução de problemas probabilísticos de caráter mais geral, como é o caso das filas de espera. Com isso, observou-se que se poderia simular um processo e estimar seus principais parâmetros de operação; nascia assim a simulação de Monte Carlo.

O barateamento dos recursos computacionais e o desenvolvimento de programas e linguagens de simulação contribuíram para uma maior utilização da simulação de Monte Carlo. Ainda assim, o problema da precisão dos resultados sempre foi um obstáculo, pois as técnicas de redução de variância desenvolvidas até então se revelaram pouco eficientes na simulação de sistemas. Esse fenômeno se deveu a uma maior restrição imposta ao processo de amostragem, restrição essa derivada da idéia de que uma simulação deveria ser uma simples cópia da realidade e não uma ferramenta com grande capacidade de avaliação de cursos de ações e treinamento.

O capítulo seguinte trata da simulação de sistemas e suas principais características e particularidades. 


\section{CAPÍTULO 5 A SIMULAÇÃO DE SISTEMAS}

Cada vez mais, as grandes entidades e empresas têm se reorganizado para que as decisões, cada vez mais complexas, possam ser tomadas mais cientificamente. Tal procedimento permite que a transmissão de informação acompanhe as mudanças rápidas de circunstâncias, de forma que as necessidades no mercado consumidor possam ser satisfeitas.

Hoje, possuímos certas formas de conhecimento, mais particularmente de métodos, que nos possibilitam trazer para a intuição uma quota da lógica matemática, além do empirismo e da experiência dos profissionais e especialistas. Um desses métodos é a simulação.

Graças ao surgimento de ferramentas cada vez mais acessíveis, tanto em termos de custo quanto em facilidade de uso, a simulação tem se popularizado e fornecido importantes resultados.

Mas, antes de se proceder à utilização de simulação para resolver um problema particular, deve-se responder a três perguntas, sugeridas em NAYLOR et al. (1971, p.35):

“ É o processo de mais baixo custo para a solução do problema?

- Há segurança de se obter uma solução satisfatória?

- A técnica a ser usada permitirá uma interpretação relativamente fácil por parte do usuário?"

A escolha da simulação como abordagem de resolução de problemas complexos foi discutida no item 4.1.2 do capítulo anterior. Assim sendo, supõe-se que as respostas às perguntas acima sejam positivas.

SHIMIZU (1975) menciona alguns exemplos em que o emprego de técnicas de simulação é aconselhável: 
- Resolução de certos tipos de equações diferenciais, quando as condições de contorno levam a soluções analíticas complicadas ou impossíveis;

- Testes de novas políticas administrativas em uma empresa, quando um engano pode ter conseqüências desastrosas;

- Descoberta de novas técnicas de estratégia em guerra moderna;

- Quando uma formulação matemática completa do problema não existe ou os métodos analíticos para solução do modelo matemático ainda não foram desenvolvidos;

- Quando métodos analíticos são possíveis, mas muito complexos; nesse caso a simulação pode prover um método mais simples de solução do problema.

Diversos autores, entre eles LAW \& KELTON (2000), NAYLOR (1971) e SHIMIZU (1975), citam algumas atividades onde a simulação em computador digital pode ser empregada:

- Experimentação e avaliação, isto é, na tentativa de prever as conseqüências de mudanças sem a necessidade de implementá-las no sistema real, o que poderia acarretar gastos excessivos sem a garantia de se obter os resultados esperados;

- Como maneira de estudar novos sistemas, a fim de projetá-los ou refinálos;

- Projeto e análise de sistemas de manufatura/

- Compreensão de um sistema real (componentes, interações, processos);

- Como ferramenta para familiarizar equipes com equipamentos ou sistemas;

- Exame de processos transitórios ou intermediários;

- Análise dos efeitos de variações do meio-ambiente na operação de um sistema;

- Verificação ou demonstração de uma nova idéia, sistema ou maneira de resolução de um problema;

- Determina;ao de pol[iticas de gerenciamento de estoques

- Ensino, como material pedagógico para estudantes e profissionais;

- Aquisição de conhecimento através das etapas de uma simulação, principalmente na formulação do problema, na construção do modelo e na análise dos resultados; 
- Verificação e comparação de soluções dos métodos analíticos ou intuitivos com aquelas obtidas em outras simulações. Essa atividade visa comparar as abordagens de resolução de problemas, bem como avaliar a capacidade dos pesquisadores e tomadores de decisão;

- Estudo de sistemas dinâmicos em tempo real, reduzido ou dilatado;

- Projeção do futuro, isto é, previsão e planejamento quantitativo.

Dessa forma, a simulação é uma ferramenta muito útil, na medida em que possibilita uma análise de várias situações que a empresa pode enfrentar, antes que ela as enfrente; além disso, ela possibilita às pessoas uma compreensão mais ampla do problema ou sistema sob estudo. A simulação utiliza-se de um modelo para estudar o sistema real sem a necessidade de gastos com pessoal e equipamentos e com riscos de falha reduzidos.

As seções seguintes compreendem diversos aspectos da técnica de simulação, entre eles sua definição, evolução, metodologia etc.

\section{1 Definição}

Em essência, a simulação é uma técnica que consiste em realizar um modelo da situação real, e nele levar a cabo experiências. Essa definição, dada por (NAYLOR et al., 1971), é muito ampla, e pode incluir coisas aparentemente não relacionadas, como jogos militares, jogos de negócios, modelos reduzidos e econométricos etc. Entretanto, faz-se necessária uma definição mais restrita, como a dada por EHRLICH (1985).

Segundo esse autor, a simulação é um método empregado para estudar o desempenho de um sistema por meio da formulação de um modelo matemático, o qual deve reproduzir, da maneira mais fiel possível, as características do sistema original. Manipulando o modelo e analisando os resultados, pode-se concluir como diversos fatores afetarão o desempenho do sistema.

Através da simulação não é possível obter, de imediato, resultados que levem à otimização de um objetivo desejado. Entretanto, é possível simular, por meio do modelo, uma série de experimentos em diferentes condições e, posteriormente, escolher a condição cujos resultados sejam mais aceitáveis (EHRLICH, 1985). 
Dessa definição podemos concluir que o principal objetivo de um estudo de simulação é conhecer o comportamento de um sistema e avaliar várias estratégias para a sua operação.

Segundo SHIMIZU (1975), o grande volume e complexidade de cálculos repetitivos em uma simulação demanda o uso intensivo do computador. A utilização desse recurso reduziu significativamente o tempo de construção e solução dos modelos. Graças ao aperfeiçoamento do computador eletrônico, com sua grande velocidade de cálculo, poder de armazenamento de dados e capacidade de decisões lógicas, o ramo experimental da simulação tem se tornado um instrumento de pesquisa e planejamento cada vez mais importante.

\section{2 Evolução da simulação}

O desejo de conhecer o futuro, a eterna questão "e se", motiva o ser humano a utilizar técnicas como a simulação para tentar prever e entender o mundo à sua volta. Esta busca de conhecimento é tão antiga quanto a própria história da raça humana.

A partir da definição de que simular é construir modelos de sistemas reais, experimentá-los e aprender com eles, pode-se inferir que a simulação é uma técnica muito antiga. Comprova-se isso nas pinturas rupestres dos primeiros seres humanos, que utilizavam desenhos para simular as caçadas e rituais.

Segundo NAYLOR et al. (1971), antes do século XVII a busca do poder de predição estava limitada aos métodos dedutivos de filósofos como Platão e Aristóteles. Esses métodos formavam a chamada filosofia especulativa; nela, as questões eram respondidas pela lógica dedutiva.

Mas, em 1620, Francis Bacon reconheceu as limitações da filosofia especulativa como metodologia para predição do futuro. Segundo ele, a razão por si só não tem nenhuma capacidade de previsão, ela o consegue somente com a ajuda da observação; lógicas dedutiva e indutiva devem caminhar juntas na busca do conhecimento. Bacon é considerado o criador da filosofia ou método científico, base para os estudos de pesquisa operacional e, por conseguinte, de simulação.

Com o passar do tempo, a busca pela resolução de problemas através de uma analogia com a realidade experimentou um grande crescimento, a ponto de se 
integrar ao cotidiano. A impossibilidade de testar técnicas e hipóteses de resolução diretamente no sistema real levou o ser humano a métodos como o de simulação.

Segundo NAYLOR et al. (1971), a simulação é uma palavra que apareceu recentemente na documentação científica para descrever a antiga arte da construção de modelos. Dessa forma, a simulação geral, que foi aplicada na construção de modelos de formas extremamente diversas, desde as esculturas e pinturas da Renascença até os modelos analíticos de processos mentais, tornou-se algo quase que específico para cientistas teóricos e práticos.

O uso moderno do vocábulo remonta sua origem ao Método de Monte Carlo (por volta de 1940). Esse método, como referenciado no capítulo 4, proporcionou a solução de problemas matemáticos não probabilísticos através da simulação de um processo estocástico.

Apesar da aplicação original do Método de Monte Carlo voltar-se à avaliação de integrais múltiplas, logo se verificou sua aplicabilidade na solução de diversos outros problemas matemáticos complexos.

Com o advento dos primeiros computadores, no início da década de 50, a idéia do Método de Monte Carlo foi estendida para solução de problemas probabilísticos de caráter mais geral, como é o caso das filas de espera; nascia assim a simulação de Monte Carlo (SALIBY, 1989).

A partir de então, a simulação tornou-se uma abordagem de estudo cada vez mais utilizada nas mais variadas áreas de conhecimento. Dois fatores contribuem para isso: a crescente complexidade dos problemas enfrentados e a maior disponibilidade de recursos computacionais.

A crescente competição entre empresas que desenvolvem equipamentos de informática tem levado à criação de produtos cada vez melhores. A indústria dos programas de simulação vem acompanhando essa evolução.

Assim, o barateamento e desenvolvimento dos recursos computacionais, programas e linguagens contribuem de maneira decisiva para a disseminação da simulação.

As linguagens de propósito geral foram as primeiras a serem utilizadas para a simulação (ver TABELA 03). Essas linguagens, como o FORTRAN e o PASCAL, podem ser usadas para implementar praticamente qualquer problema computacional, 
e muitos programas de simulação foram escritos nessas linguagens. No início, a simulação se restringia a um seleto grupo de pessoas trabalhando em Universidades, centros de pesquisa e no meio militar. Cada programa tinha uma aplicação específica e suas execuções eram problemáticas, pois, naquela época, os computadores eram bem menos poderosos que os atuais.

TABELA 03 - História do uso da simulação computacional

\begin{tabular}{|c|c|c|c|}
\hline Anos & Ferramenta & Características do estudo de simulação & Exemplos \\
\hline 50 e 60 & $\begin{array}{l}\text { Linguagens } \\
\text { de propósito } \\
\text { geral }\end{array}$ & $\begin{array}{l}\text { Aplicação em Grandes corporações; } \\
\text { Grupos de desenvolvimento de modelos com } 6 \text { a } 12 \text { pessoas; } \\
\text { Geram programas a serem executados em grandes } \\
\text { computadores; } \\
\text { Grandes investimentos em capital; } \\
\text { Aplicáveis a qualquer contexto; } \\
\text { Exigem conhecimento profundo da linguagem; } \\
\text { Exigem muito tempo de desenvolvimento; } \\
\text { Não são totalmente reutilizáveis. }\end{array}$ & $\begin{array}{l}\text { FORTRAN, } \\
\text { PASCAL e } \\
\text { C. }\end{array}$ \\
\hline $\begin{array}{l}70 \text { e } \\
\text { início } \\
\text { dos } 80\end{array}$ & $\begin{array}{l}\text { Linguagens } \\
\text { de simulação }\end{array}$ & $\begin{array}{l}\text { Utilização em um maior número de corporações; } \\
\text { Desenvolvimento e uso dos pacotes de linguagens; } \\
\text { Surgem linguagens de simulação baseadas em System } \\
\text { Dynamics; } \\
\text { Comandos projetados para tratar lógica de filas e demais } \\
\text { fenômenos comuns; } \\
\text { Mais amigáveis, mas ainda requerem programador } \\
\text { especializado. }\end{array}$ & $\begin{array}{l}\text { SIMSCRIPT, } \\
\text { GPSS, GASP } \\
\text { IV, } \\
\text { DYNAMO, } \\
\text { SIMAN e } \\
\text { SLAM }\end{array}$ \\
\hline $\begin{array}{l}80 \text { e } \\
\text { início } \\
\text { dos } 90\end{array}$ & $\begin{array}{l}\text { Simuladores } \\
\text { de alto nível }\end{array}$ & $\begin{array}{l}\text { Introdução do PC e da animação; } \\
\text { Presença de guias, menus e caixas de diálogos; } \\
\text { Simulação realizada antes do início da produção; } \\
\text { Facilidade de uso; } \\
\text { Menos flexível que as linguagens de propósito geral e de } \\
\text { simulação; } \\
\text { Projetados para permitir modelagem rápida; } \\
\text { Dispõem de elementos específicos para representar filas, } \\
\text { transportadores etc.; } \\
\text { Restringem-se a sistemas de certos tipos. }\end{array}$ & $\begin{array}{l}\text { Simfactory e } \\
\text { Xcell }\end{array}$ \\
\hline $\begin{array}{l}\text { Após } \\
90\end{array}$ & $\begin{array}{l}\text { Pacotes } \\
\text { flexíveis de } \\
\text { programas de } \\
\text { simulação }\end{array}$ & $\begin{array}{l}\text { Melhor animação e facilidade de uso; } \\
\text { Fácil integração com outras linguagens de programação; } \\
\text { Usada na fase de projeto; } \\
\text { Grande uso em serviços; } \\
\text { Uso para controle de sistemas reais; } \\
\text { Grande integração com outros pacotes (base de dados e } \\
\text { processadores de texto); } \\
\text { Aprimoramento dos simuladores, o que permite modelagem } \\
\text { rápida; } \\
\text { Integram a flexibilidade das linguagens de simulação, com a } \\
\text { facilidade de uso dos pacotes de simulação. }\end{array}$ & $\begin{array}{l}\text { Witness, } \\
\text { Extend, } \\
\text { Stella, } \\
\text { ProModel for } \\
\text { Windows }\end{array}$ \\
\hline
\end{tabular}

Fonte: KELTON et al. (1998) 
A partir da utilização das linguagens de propósito geral, observou-se que os programas resultantes possuíam muitas características comuns, as quais foram usadas no desenvolvimento de linguagens de simulação, mais poderosas e eficientes.

Uma linguagem de simulação é um simulador que é designado para representar qualquer caso específico de uma classe de situações, através de inserções de valores próprios para os parâmetros. Essas linguagens de simulação têm o benefício de reduzir o tempo necessário para a implementação de um modelo. Elas são mais rápidas que uma linguagem de propósito geral, desde que nenhum projeto ou programa do modelo seja requerido.

Dentre as linguagens de simulação, estão o GPSS, SIMAN, SLAM e o SIMSCRIPT. Graças ao surgimento de linguagens próprias, a simulação foi difundida nos setores de engenharia e negócios. Mas, apesar do avanço propiciado pelas linguagens de simulação, o tempo gasto com aprendizado e a eliminação de erros eram ainda muito longos.

Uma das linguagens de simulação mais utilizadas é o GPSS (General Purpose Simulation System). Sua estrutura fundamental é conceitualmente diferente das linguagens de propósito geral, como o FORTRAN. O uso do GPSS facilita a tarefa de construir modelos computacionais para certos tipos de simulações de eventos discretos.

Após as linguagens de propósito geral, surgiram os programas baseados em System Dynamics (SD), entre eles DYNAMO e, mais tarde, o STELLA. Esses programas trouxeram uma nova visão das interações e relações entre os componentes dos sistemas e dos sistemas com o ambiente.

Jay Forrester $^{8}$ foi o criador da metodologia System Dynamics (Dinâmica de Sistemas), que se baseia nos conceitos de pensamento sistêmico e possui um conjunto específico de ferramentas e formas de abordagem para estudo de sistemas. Os trabalhos de Forrester forneceram uma visão mais dinâmica e sistêmica para a simulação.

Durante os anos 80 , graças aos avanços dos computadores e ao aumento da competitividade, a simulação estendeu-se a muitas indústrias, e programas direcionados a elas foram criados (ProModel, AutoMod etc.). Essas ferramentas de

\footnotetext{
${ }^{8}$ Suas principais publicações foram "Industrial Dynamics" (1961), "Human Dynamics" (1969) e "World Dynamics" (1972).
} 
simulação eram passíveis de serem usadas por profissionais de diversas áreas e com diferentes níveis de conhecimento em simulação.

Os anos 90 viram o surgimento de programas de simulação mais flexíveis, com melhor animação e integração com outras linguagens de programação. Nesses programas, o tempo e esforço despendidos se concentram mais na atividade de análise dos resultados e menos na programação e eliminação de erros. A evolução das ferramentas de simulação nas últimas décadas é resumida na TABELA 03 e na FIGURA 09.

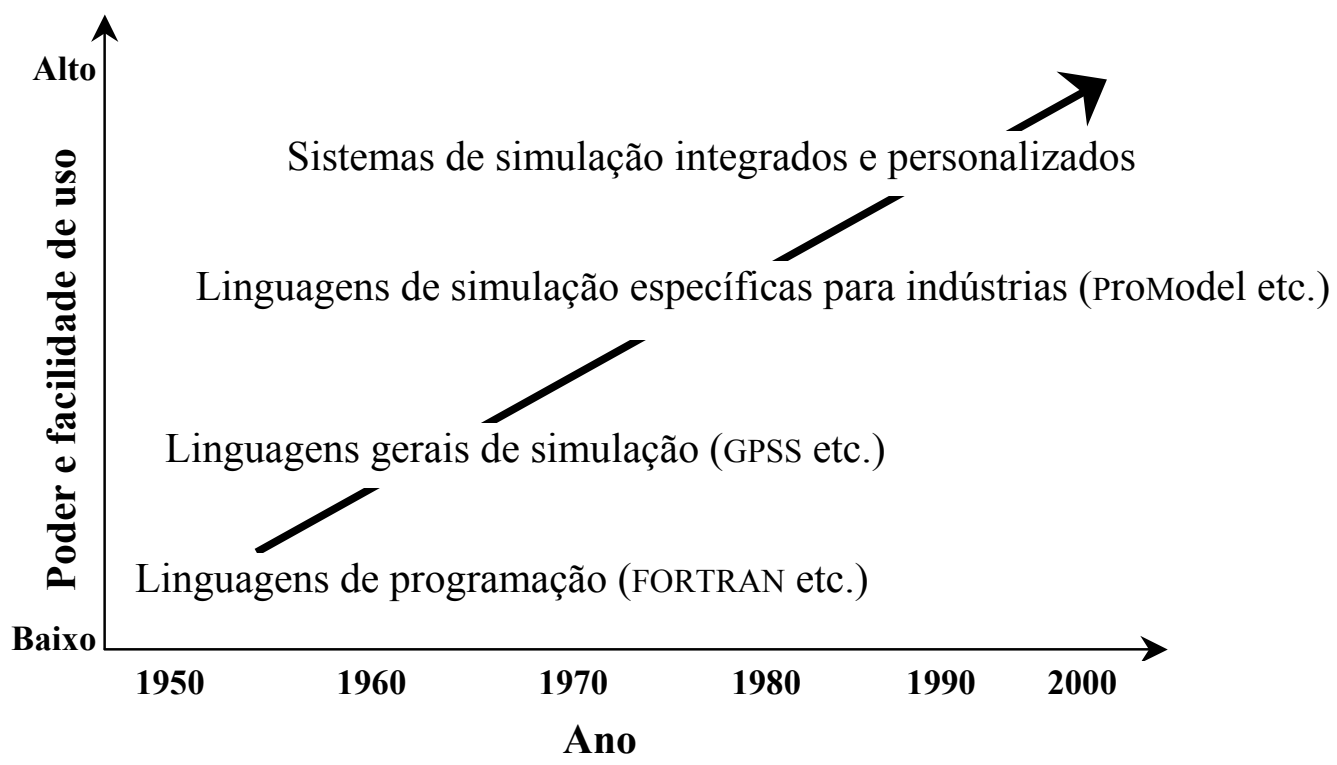

FIGURA 09 - A evolução das ferramentas de simulação computacional Fonte: HARRELL \& TUMAY (1995)

A TABELA 03 e a FIGURA 09 mostram a significativa diminuição do tempo de programação e execução requeridos à medida que as técnicas de simulação evoluíam.

As ferramentas de simulação continuam a evoluir, tornando-se mais adaptáveis, flexíveis e fáceis de usar, além de apresentarem melhores recursos gráficos, de comunicação e interação com o usuário, estatísticos, de animação etc.

O foco deste estudo está na simulação computacional de sistemas (a partir daqui, chamada apenas de simulação), a qual teve sua origem na Pesquisa Operacional (PO). Neste trabalho, utilizar-se-á um pacote de simulação (STELLA ${ }^{\complement}$ ) para análise da aquisição de conhecimentos sobre um sistema de fila. 


\section{3 Tipos de simulação}

Toda simulação requer a construção de um modelo com o qual serão feitos os experimentos. Um modelo matemático estudado através da simulação é chamado de modelo de simulação (SALIBY, 1989). O termo modelo foi definido no capítulo quarto.

Segundo BARTON (1970), um modelo de simulação tem as seguintes propriedades:

1. Intenção de representar a totalidade ou parte de um sistema;

2. Possibilidade de ser executado ou manipulado;

3. O tempo ou um contador de repetições é uma de suas variáveis;

4. Proposta de auxiliar no entendimento do sistema, o que significa um ou mais dos seguintes itens:

a. É uma descrição (parcial) do sistema objeto.

b. Seu uso tenta explicar o comportamento passado do sistema objeto.

c. Seu uso tenta predizer o comportamento futuro do sistema objeto

d. Seu uso tenta ensinar a teoria existente pela qual o sistema objeto pode ser entendido.

Pode-se dividir os modelos de simulação de maneira semelhante aos modelos em geral. Um tipo de classificação é resumido na FIGURA 10. As classificações mais relevantes para este trabalho são descritas a seguir, e outras podem ser encontradas no capítulo anterior.

\section{Estáticos ou dinâmicos}

Um modelo de simulação estático representa um sistema em um ponto particular no tempo ou um sistema no qual o tempo não desempenha papel importante. Modelos dinâmicos representam sistemas à medida que eles mudam ao longo do tempo.

\section{Determinísticos ou estocásticos}

Um sistema pode ser determinístico ou estocástico, dependendo da natureza da entrada, do processo e da saída em vários estágios do sistema. Modelos de simulação que não contêm variáveis aleatórias são classificados como 
determinísticos; esses modelos têm um conjunto conhecido de entradas que resultarão em um único conjunto de saídas. Um modelo de simulação estocástico tem uma ou mais variáveis aleatórias como entrada. As entradas aleatórias levam a saídas aleatórias (uma gama de possíveis saídas, segundo alguma distribuição de valores).

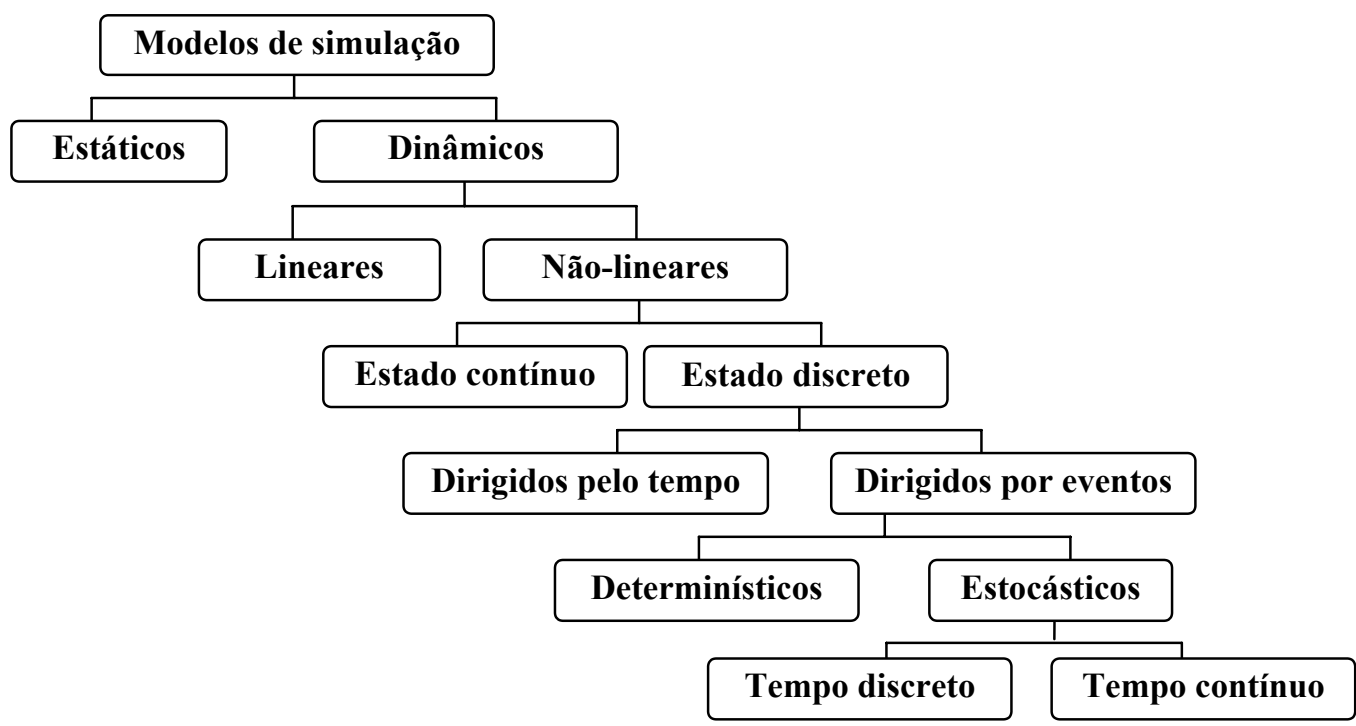

FIGURA 10 - Classificação dos modelos de simulação

Fonte: Elaborada pelo autor

Muitos processos somente são descritos adequadamente por distribuições de probabilidade, como aquelas refletindo a demanda variável por produtos e serviços e os modelos de fila e linha de espera (BUFFA \& DYER, 1977).

\section{Discretos ou contínuos}

Modelos de simulação discretos e contínuos são definidos de uma maneira análoga aos modelos discretos e contínuos. Porém, um modelo de simulação discreto nem sempre é usado para modelar um sistema discreto; de maneira análoga, a modelagem de um sistema contínuo não implica na utilização de um modelo contínuo. A escolha entre os modelos (ou o uso de ambos) é uma função das características do sistema e do objetivo do estudo (BANKS et al., 1996).

Conforme BUFFA \& DYER (1977), modelos de simulação em sistemas gerenciais são usualmente do tipo discreto e são, freqüentemente, uma combinação de processos determinísticos e estocásticos, especialmente em modelos representando um sistema complexo. 
Este estudo restringe-se aos modelos de simulação construídos para uso em computadores digitais. Estes experimentos (simulações) vão permitir inferências sobre o sistema sem a necessidade de construí-lo.

\subsubsection{Simulação de sistemas dinâmicos de eventos discretos}

O enfoque desse trabalho restringe-se à simulação computacional de sistemas dinâmicos de eventos discretos. Para isso, um exemplo de sistema de fila será analisado.

Muitas das aplicações da simulação referem-se ao estudo de um sistema ao longo do tempo, caracterizando assim uma simulação dinâmica. De fato, um importante aspecto numa simulação refere-se à observação, ao longo do tempo, das várias atividades que compõem o modelo.

Numa simulação discreta, a passagem do tempo é feita aos saltos, entre um evento e outro, por isso é também chamada de simulação de eventos discretos (LAW \& KELTON, 2000). Neste caso, supõe-se que o estado do sistema não se altera ao longo do intervalo compreendido entre dois eventos consecutivos.

\section{4 Vantagens e desvantagens}

Os benefícios da simulação são citados por SALIBY (1989), BANKS et al. (1996), BANKS (2000), PEGDEN et al. (1995) LAW \& KELTON (2000) entre outros, e são relacionados abaixo:

- Modelos mais realistas: maior liberdade na construção do modelo de simulação. A simulação não obriga a enquadrar um problema em determinado modelo padrão para que se possa obter uma solução, como ocorre, por exemplo, no caso da programação linear;

- Processo de modelagem evolutivo: começa-se com um modelo relativamente simples e aumenta-se sua complexidade aos poucos, identificando de maneira mais clara as peculiaridades do problema;

- Perguntas do tipo "e se?" ("what if?"): muitas vezes, em lugar da busca de uma solução, o objetivo resume-se em tornar mais claras as possíveis conseqüências de um conjunto de decisões; 
- Aplicação a problemas "mal-estruturados": muitos problemas da vida real referem-se a situações em que dispomos apenas de um conhecimento parcial sobre suas variáveis ou relações. A simulação é uma das poucas ferramentas para o estudo deste tipo de problema;

- Facilidade de comunicação: um modelo de simulação é, em geral, mais fácil de se compreender do que um conjunto de complicadas equações matemáticas;

- Soluções rápidas: no conturbado ambiente empresarial dos dias de hoje, onde as "regras" mudam da noite para o dia, esta vantagem é muito importante;

- Grande flexibilidade: aplica-se aos mais variados problemas;

- Aquisição de visão sistêmica: visão do efeito que alterações locais terão sobre o desempenho global de todo o sistema;

- Escolha correta: a simulação permite o teste de muitos aspectos de uma mudança, sem comprometer recursos;

- Compressão e expansão do tempo: para examinar o comportamento do sistema;

- Exploração de possibilidades: uma vez desenvolvido um modelo de simulação válido, pode-se explorar novas políticas, procedimentos operacionais, arranjos físicos ou métodos sem perturbar o sistema real;

- Diagnóstico de problemas: a simulação leva a um melhor entendimento das interações entre as variáveis de sistemas complexos. O diagnóstico de problemas é dessa forma mais eficiente;

- Desenvolvimento de entendimento: estudos de simulação ajudam no entendimento dos componentes do sistema e de como ele realmente opera;

- Visualização de planos: a animação em uma simulação oferece a possibilidade de visualizar a operação de uma organização enquanto a simulação ocorre;

- Construção de consenso: o resultado de uma simulação, submetido a uma série de etapas de modelagem, teste, validação e representação visual, tem melhor aceitação que a opinião de uma única pessoa; 


\section{- Preparação para mudanças e análise de investimentos prudentes:} como o custo das mudanças em um sistema é muito grande, a simulação é um investimento válido para analisar suas conseqüências;

- Treinamento de equipes: a equipe e seus membros podem aprender como trabalhar melhor através de erros e acertos realizados na simulação.

Os mesmos autores citam também algumas desvantagens da simulação:

- A construção de modelos requer treinamento especial; a técnica é aprendida e aperfeiçoada com o tempo e através da experiência;

- Os resultados da simulação podem ser difíceis de interpretar, pois geralmente as saídas da simulação são variáveis aleatórias;

- A modelagem e a análise da simulação podem ser dispendiosas em termos de recursos financeiros e de tempo;

- Pode ser usada inapropriadamente, por exemplo, quando uma solução analítica é factível;

- Os resultados da simulação podem ser de difícil implementação;

- Dificuldade de modelagem;

- A programação de um modelo de simulação pode tornar-se uma tarefa altamente dispendiosa e desgastante se os recursos computacionais não forem apropriados;

- Tempo de processamento e baixa precisão dos resultados: a baixa precisão dos seus resultados é o que faz da simulação um "último recurso". Esta imprecisão é geralmente conseqüência do uso da amostragem.

Atualmente, muitas pessoas vêm trabalhando na resolução de alguns dos problemas acima citados. As deficiências da simulação têm sido resolvidas através de simuladores mais rápidos, simples, amigáveis e flexíveis; de novos métodos de análises de saídas; de equipamentos de informática mais eficientes etc.

Empresas de programas de simulação têm desenvolvido produtos que facilitam a modelagem: pacotes com modelos que precisam apenas dos dados de entrada e pacotes que possuem capacidade de análise de saídas. Esses produtos 
permitem a redução das necessidades de conhecimentos computacionais dos usuários, além de reduzirem o tempo de projeto.

Um erro cometido por alguns analistas e usuários de simulação consiste em considerar a simulação apenas como uma simples cópia da realidade ou como um exercício de programação em computador. Por causa desse tipo de pensamento, muitos estudos de simulação têm sido compostos de verificações e validações insuficientes. A simulação é uma poderosa ferramenta de avaliação de cursos de ações, mas que requer um grande esforço metodológico e um rigoroso estudo estatístico para levar a conclusões satisfatórias.

\section{5 Metodologia da simulação}

A simulação, por ser uma técnica de Pesquisa Operacional, utiliza-se do método científico para desempenhar seu papel. Um processo de simulação baseia-se numa série de etapas que pode ser chamada de metodologia de simulação. Diferentes metodologias têm sido apresentadas por vários autores, entre eles SHANNON (1975), EMSHOFF \& SISSON (1970), BANKS et al.(1996), LAW \& KELTON (2000). Essas metodologias são muito semelhantes entre si, já que se baseiam no mesmo método (o científico). Neste trabalho, serão utilizados os passos de um estudo de simulação sugeridos por LAW \& KELTON (2000), como mostrado na FIGURA 11. Esse método foi escolhido porque seus passos foram avaliados, pelo autor, como mais eficientes. Apesar disso, outros autores foram consultados para um maior esclarecimento de cada passo.

Esses passos (enumerados abaixo) serão utilizados em todas as simulações contidas nesse trabalho.

1. Formulação do problema e planejamento do estudo

2. Coleta de dados e definição do modelo

3. Validação do modelo conceitual

4. Construção do programa computacional e verificação

5. Realização de execuções piloto

6. Validação do modelo programado

7. Projeto dos experimentos

8. Realização das execuções de simulação 
9. Análise de resultados

10. Documentação e implementação

As fases compostas de duas atividades estão assim dispostas para representar tarefas que podem ser realizadas ao mesmo tempo.

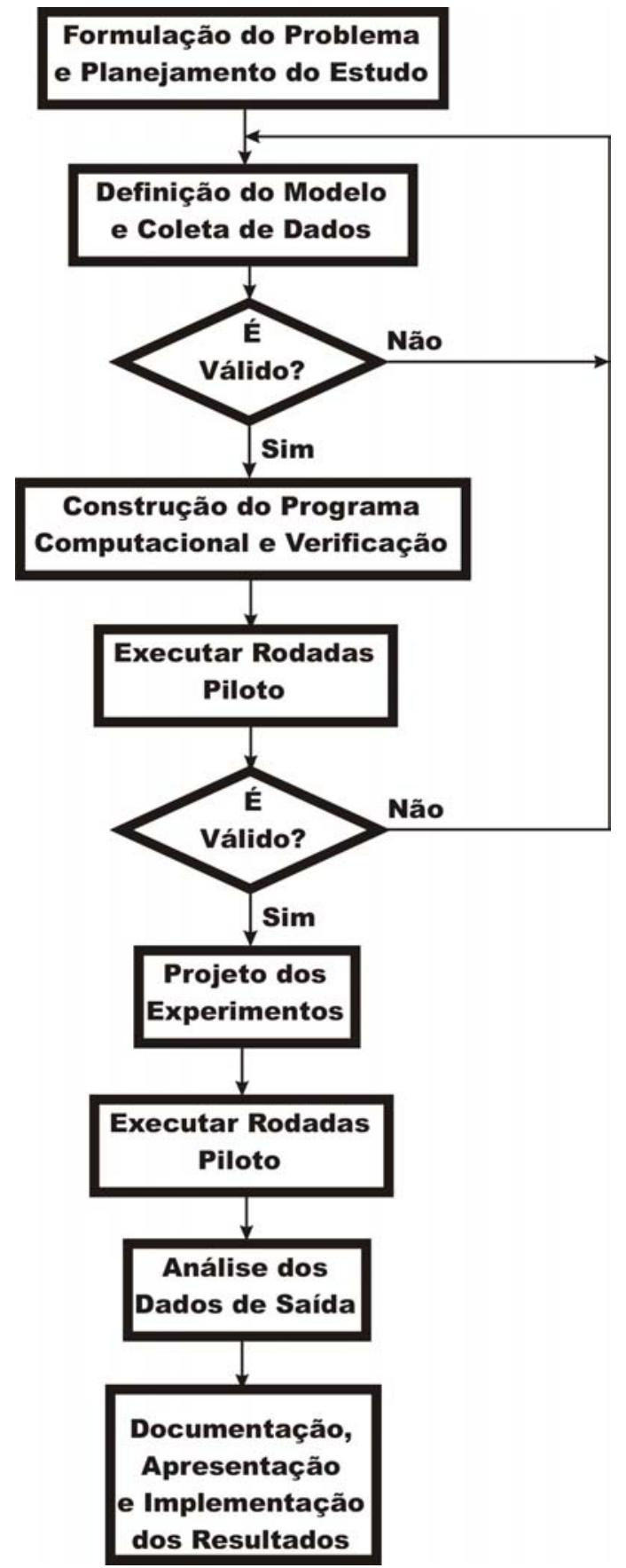

FIGURA 11 - Passos de um estudo de simulação

Fonte: LAW \& KELTON (2000) 
Assume-se aqui que a abordagem de resolução de problemas escolhida foi a simulação e que as outras abordagens (intuitiva e analítica) foram desconsideradas por não se aplicarem ao sistema estudado (ver discussão sobre o estudo de sistemas no capítulo 4).

\subsubsection{Formulação do problema e Planejamento do estudo}

Um experimento de simulação computacional deve iniciar-se com a formulação do problema e com o planejamento do estudo. Isto porque a obtenção de uma solução aceitável depende de um bom conhecimento do problema e da criação de um plano para sua avaliação.

Nessa etapa, decide-se se o estudo será feito pelos tomadores de decisão (ou aqueles que estão ligados diretamente ao sistema ou problema a ser simulado) ou por analistas de simulação. Caso se decida por um analista, este deve se assegurar de que o problema descrito esteja claramente entendido. Também nesse caso é importante que os tomadores de decisão entendam e concordem com a formulação do problema feita pelo especialista. O ideal é que em todos os passos, principalmente nesse primeiro, analista e tomador de decisão trabalhem juntos para uma maior eficiência e eficácia da simulação.

A interação entre aquelas pessoas que lidam com o sistema a ser simulado, sejam elas administradores, trabalhadores, etc. (a partir daqui chamados apenas de gerentes ou tomadores de decisão) e os analistas de simulação (ou apenas analistas) é fundamental para o sucesso do processo de simulação.

Esse primeiro passo é composto também das seguintes etapas:

a. O problema de interesse é detectado pelo tomador de decisão do sistema (ou por aquele ligado diretamente ao problema ou projeto);

b. Reuniões, entre tomadores de decisão, analistas de simulação e especialistas nos problemas, são realizadas para a determinação dos seguintes itens:

- Objetivos do estudo;

- Questões a serem respondidas; 
- Estágios da investigação;

- Avaliadores de desempenho que serão utilizados para medir a eficácia de diferentes configurações do sistema;

- Escopo do modelo;

- Configurações do sistema a ser modelado (limites, restrições, entidades, processos etc.);

- Equipamento e programa de simulação a serem utilizados;

- Estrutura de tempo para o estudo e recursos requeridos.

Muitas vezes, o problema é reformulado à medida que se realiza o estudo, isto ocorre devido a um maior entendimento do sistema.

NAYLOR (1971) ressalta a importância do estabelecimento explícito dos objetivos da simulação e declara que objetivos têm habitualmente a forma de: (a) questões a serem respondidas, (b) hipóteses a serem testadas ou (c) efeitos a serem estimados.

O planejamento do estudo deve conter uma declaração de sistemas alternativos (ou partes deles) a serem considerados e o método de avaliação da eficiência desses sistemas. Além disso, deve conter informações como número de pessoas envolvidas, custo do estudo e tempo requerido para completar cada fase do trabalho, assim como os resultados esperados de cada fase.

\subsubsection{Coleta de dados e Definição do Modelo}

Nesta fase, o sistema real sob investigação é abstraído através de um modelo conceitual e, ao mesmo tempo, dados do sistema são coletados.

Segundo SHANNON (1975), a coleta refere-se a dados quantitativos e qualitativos sobre as entradas e saídas do sistema, bem como informações sobre os componentes do sistema e suas interconexões ou relações. O modelador deve decidir que dados são necessários, se eles são pertinentes, se os dados existentes são válidos a este propósito e como eles foram obtidos e validados.

Esta etapa também envolve a escolha entre a utilização de dados empíricos diretamente no modelo ou o uso de distribuições de probabilidade teóricas. 
A fase de definição do modelo é uma das mais cruciais para a simulação. Alguns autores, como BANKS et al. (1996), dizem que a construção do modelo é mais uma arte do que ciência. Esse autor declara que a arte da modelagem consiste de uma habilidade para abstrair as características essenciais do modelo, da seleção e modificação de suposições básicas que caracterizam o sistema, e então do enriquecimento e elaboração do modelo até uma aproximação útil dos resultados.

Segundo BARTON (1970), o conhecimento é a base para a construção de modelos. É obrigatório conhecer algo sobre o sistema que se quer estudar e sobre o método a ser utilizado. O conhecimento que se usa para construir um modelo é obtido pelo modelador através de diversas fontes (referências bibliográficas, experiência etc.).

O ser humano acumula conhecimento ao longo do tempo. Isto é feito passando-se princípios de geração em geração, através das várias formas de comunicação e de reprodução do conhecimento. Mas, raramente os princípios gerais permanecem os mesmos; as pessoas mudam os princípios sempre que obtêm um melhor entendimento sobre si mesmas, o mundo e como viver em seu ambiente. Assim, o modelo é ao mesmo tempo um solicitador e difusor de conhecimento, pois proporciona ao modelador aquisição de mais experiência sobre o sistema e a modelagem.

Portanto, de início, o conhecimento permite um verdadeiro começo do estudo; ao final, ele é alterado através de novos dados e observações, ou é simplesmente confirmado.

Pode-se usar qualquer dispositivo conveniente e útil para construir um modelo, mas como o objetivo desse estudo é a utilização dos modelos de simulação, as ferramentas ficam circunscritas à utilização de equações matemáticas em programas de computador que simulam o comportamento do sistema.

De acordo com NAYLOR (1971), a formulação do modelo consiste na especificação de seus componentes, variáveis, parâmetros e relações funcionais.

Desse modo, é melhor utilizar-se, inicialmente, de um modelo simples, para depois aumentar sua complexidade progressivamente. A complexidade do modelo não deve exceder a necessidade de abstração demandada pelos objetivos do estudo. A violação desse princípio apenas acrescentará esforço computacional e de 
construção do modelo. Não há necessidade de um completo mapeamento entre modelo e sistema real; apenas a modelagem da essência do sistema real é necessária.

SHANNON (1975) sugere algumas qualidades para se saber se um modelo de simulação é realmente válido. Segundo ele, um modelo deve:

- $\quad$ ser simples de entender pelo usuário;

- ter objetivos e propósitos direcionados;

- $\quad$ ser robusto, isto é, não deve dar respostas incoerentes;

- ser simples de ser controlado e manipulado pelo usuário;

- $\quad$ ser completo em questões importantes;

- ser adaptativo, com um procedimento simples para modificação e atualização do modelo;

- ser evolucionário, isto é, ele deve iniciar-se simples e tornar-se gradativamente mais complexo, com a ajuda do usuário.

Assim, esta fase consiste dos seguintes pontos:

a. Coleta de informações no arranjo físico do sistema e nos procedimentos de operação (as informações também serão utilizadas na validação do modelo no passo 6);

b. Coleta de dados (se possível) para especificar os parâmetros do modelo e as distribuições de probabilidade das entradas;

c. Delineamento das informações e dados do item anterior em um “documento de suposições", que é o modelo conceitual;

d. Determinação do nível de detalhe do modelo. Esse nível pode estar sujeito aos seguintes itens:

- Objetivos do projeto de simulação;

- Medidas de desempenho;

- Disponibilidade de dados;

- Credibilidade;

- Restrições computacionais;

- Opiniões das pessoas ligadas ao sistema;

- Restrições de tempo e capital. 
e. Não é necessário que haja uma correspondência um-para-um entre cada elemento do modelo e o elemento correspondente do sistema;

f. Interação regular com o tomador de decisão.

\subsubsection{Validação do modelo conceitual}

a. Percorrer de maneira estruturada o modelo conceitual usando o documento de suposições, antes de se agendar uma reunião com os responsáveis pelo sistema (problema);

- Ajudar a garantir que as suposições do modelo estão corretas e completas;

- Promover o domínio do modelo;

- É alocado antes da programação começar para evitar reprogramações significativas mais adiante.

\subsubsection{Construção do programa computacional e verificação}

Este passo é dividido em duas atividades:

a. Programação do modelo em uma ferramenta de simulação;

b. Verificação (eliminação de erros) do programa de simulação computacional.

Sistemas reais resultam em modelos que requerem um grande esforço de manipulação de informações, por isso o modelo deve ser concretizado em um formato computacional reconhecível.

Nessa etapa, o modelador deve decidir se programa o modelo numa linguagem de propósito geral (como FORTRAN ou C), numa linguagem de simulação (como GPSS/H, SIMAN V, SIMSCRIPT II.5) ou usa um pacote de simulação (como EXTEND, STELla, AutoMod, ProModel for Windows, ARENA etc). 
Cada tipo de ferramenta possui determinadas vantagens e desvantagens. Algumas das linguagens e pacotes de simulação mais populares serão discutidos na seção 5.6 deste capítulo.

O segundo passo desta etapa consiste na verificação do programa computacional. Aqui, verifica-se se o programa é adequado para o modelo e se ele funciona adequadamente. Em se tratando de sistemas complexos, é muito difícil traduzir o modelo em um programa sem um grande dispêndio de tempo, principalmente para a correção dos erros de execução do programa.

\subsubsection{Realização de execuções piloto}

Esta etapa consiste na realização de execuções piloto para a validação proposta no item 5.5.6. Neste momento, cabe o esclarecimento de alguns termos aqui utilizados e que serão empregados principalmente na fase metodológica do trabalho.

O termo "execuções" (ou replicações) refere-se à realização de uma simulação (execução do programa) com os mesmos parâmetros (distribuição de probabilidade de entrada, número de servidores, tamanho máximo da fila etc.). Já a palavra "simulação" será utilizada para designar as execuções do programa usando diferentes parâmetros; uma simulação é composta de diversas execuções.

As expressões "estudo de simulação" ou "projeto de simulação" referem-se a todos os passos referentes a um processo de simulação (ver FIGURA 11).

As execuções são necessárias para que se tenha resultados mais confiáveis para o modelo, pois, em se tratando de variáveis aleatórias, cada execução produzirá respostas diferentes, o que significará maior proximidade de uma situação real.

\subsubsection{Validação do modelo programado}

Validação é a determinação de que o modelo é uma representação confiável do sistema real. A validação é geralmente conseguida através da calibração do modelo, consistindo de um processo interativo de comparação entre o modelo e o comportamento real do sistema, bem como do uso de discrepâncias entre os dois e 
das idéias obtidas para melhorar o modelo. Esse processo é repetido até que a confiabilidade do modelo seja julgada aceitável (BANKS et al.,1996).

Dentre as técnicas de ponderação da validade e credibilidade do modelo, pode-se citar:

- Coleta de informações e dados de alta qualidade no sistema:

- Comunicação com especialistas no sistema;

- Observações do sistema;

- Teoria existente;

○ Resultados relevantes de estudos de simulação similares;

○ Experiência e intuição dos modeladores;

- Interação constante entre gerente e analista;

- Manutenção de documentação sobre suposições e desempenho;

- Técnicas quantitativas para validação de componentes do modelo;

- Validação da saída do modelo de simulação;

- Comparação das saídas do modelo e do sistema.

- Análise de especialistas.

- Animação.

Os métodos de validação podem seguir os preceitos abaixo:

a. Se há um sistema real, comparam-se as medidas de desempenho e os resultados do modelo e do sistema real;

b. Independente de haver ou não um sistema real, os analistas de simulação ou as pessoas ligadas ao sistema devem revisar os resultados do modelo para correções;

c. Utilização de análise de sensibilidade para determinar quais fatores do modelo têm um impacto significativo nas medidas de desempenho e, então, modelá-los com cuidado.

\subsubsection{Projeto dos experimentos}

Nesta etapa, são determinados os seguintes itens:

- Comprimento das simulações; 
- Número de simulações e suas configurações;

- Condições iniciais da simulação;

\subsubsection{Realização das execuções de simulação}

Várias simulações e execuções são realizadas para que os resultados e medidas de desempenho sejam empregados na seção 5.5.9.

\subsubsection{Análise de Resultados}

Os dois maiores objetivos na análise dos dados de saída são:

a. Determinação do desempenho absoluto de certas configurações do sistema;

b. Comparação de configurações alternativas do sistema em termos relativos.

Procedimentos estatísticos são empregados para se comparar os dados de saída do modelo e do sistema. Entre as abordagens para análise de resultado, tem-se:

- Testes estatísticos clássicos (como t, qui-quadrado, Kolmogorov-Smirnov etc.) para determinar se dois conjuntos de dados podem ser considerados semelhantes;

- Abordagem por inspeção: aqui podem ser utilizadas estatísticas como média, variância simples, função de correlação e histogramas.

- Abordagem de intervalo de confiança baseado em dados independentes.

- Abordagem de séries temporais.

\subsubsection{Documentação e implementação}

Nenhum projeto de simulação pode ser considerado completo se não foi aceito, compreendido e usado.

Uma documentação adequada serve para auxiliar o entendimento do estudo realizado e para dar credibilidade aos resultados do processo. Além disso, ela facilita 
as modificações e proporciona ao analista o conhecimento de seus erros e um conjunto de subprogramas que pode ser reutilizado em projetos futuros. Uma cuidadosa e completa documentação de todas as fases do projeto também auxilia muito o estágio de implementação.

Do mesmo modo, essa atividade possibilita:

- a utilização do mesmo programa, ou de parte dele, pelo mesmo analista ou por outros;

- a mudança de parâmetros do modelo pelos usuários;

- a diminuição dos esforços para determinação de relacionamentos, parâmetros de entrada e medidas de desempenho;

- a cronologia do trabalho realizado e das decisões tomadas.

Há dois tipos de documentação em um estudo de simulação: do programa e do desenvolvimento da simulação (relatórios parciais e final).

MUSSELMAN (1993) sugere que sejam realizados relatórios freqüentes (pelo menos mensais) durante o desenvolvimento do estudo de simulação. Ele também reforça que esses relatórios devem prover um registro compreensivo das realizações, mudanças e decisões chave do processo.

Outra forma de documentação é o relatório final. Esse deve ser composto de especificações do modelo, demonstrações da evolução da construção do modelo, análises intermediárias, configurações alternativas do sistema, critérios de comparação de alternativas, resultados de treinamentos, animações, documentação do programa, resumo dos relatórios parciais de progresso e a(s) solução(ões) final(is) do problema.

Os relatórios citados acima ajudam a dar confiabilidade ao estudo e ao modelo frente aos gerentes, assim como permitem aos envolvidos uma maior compreensão do sistema estudado.

O sucesso da fase de implementação depende do bom desenvolvimento de todas as fases anteriores. Esta etapa é favorecida no caso de analistas e gerentes trabalharem juntos, durante todo o estudo, já que o tempo necessário para persuadir o gerente dos benefícios do projeto é menor e sua motivação e comprometimento com o estudo são estimulados. 
Pode-se resumir essa fase nos seguintes itens:

a. Documentação das suposições, do programa de simulação e dos resultados do estudo para uso em projetos atuais e futuros;

b. Resultados do estudo atual.

- Uso de animação para difundir o modelo entre os tomadores de decisão e outras pessoas que não estão familiarizadas com todos os detalhes do modelo.

- Discussão da construção do modelo e do processo de validação para promover sua credibilidade.

c. Os resultados são usados no processo de tomada de decisão caso eles sejam válidos e tenham credibilidade.

Apesar dos passos de simulação serem seqüenciais, a simulação não é um simples processo seqüencial. Há, muitas vezes, a necessidade de se refazer passos anteriores (esse fato é indicado na FIGURA 11 através das setas retroativas).

Os passos abordados nesse item são explicados concisamente, já que seu estudo é muito amplo. As investigações sobre a metodologia de simulação são tão extensas que alguns de seus passos (análise de dados estatísticos, construção de modelos) tornaram-se temas principais de diversos livros e teses.

\section{6 Ferramentas de simulação}

O quarto passo da metodologia de simulação consiste na construção e verificação do programa computacional. Um programa de computador digital é uma seqüência definida de operações necessárias para que o programador possa resolver as equações que descrevem um modelo do sistema (KHEIR, 1996). Esse programa utilizar-se-á de um computador para exercitar o modelo, de forma a gerar saídas que possam ser analisadas, a fim de que decisões possam ser tomadas.

Os programas computacionais para simulação podem ser implementados nas aqui chamadas ferramentas de simulação e classificados em três grandes abordagens: programas codificados em uma linguagem de propósito geral, em uma linguagem de simulação e em um pacote de simulação. O modelo conceitual (modelo inicial 
desenvolvido fora do programa) será aqui traduzido para um programa de computador feito em um pacote de simulação.

Também existem linguagens e pacotes de simulação específicos para determinadas aplicações. As linguagens ou pacotes específicos são aqueles que se limitam a uma determinada área do conhecimento; por exemplo, existem pacotes específicos para simulações de manufatura, financeiras, econômicas, de sistemas de transportes, de produtos etc. Segundo BANKS et al. (1996), dentre os pacotes de simulação destinados a sistemas de manufatura e de manipulação de materiais, podese citar: SIMFACTORY II.5, ProModel, AutoMod, Taylor II, WITNESS e ARENA. Este trabalho não analisou ou utilizou linguagens de simulação específicas, limita-se apenas aos programas de simulação implementados em ferramentas mais gerais.

A determinação da ferramenta adequada a um estudo específico é uma tarefa árdua e complexa. A caracterização completa das várias ferramentas disponíveis e seus aspectos educacionais foge ao escopo deste trabalho. Aqui, busca-se apreender como a simulação de um sistema colabora para a aquisição de conhecimento sobre o sistema modelado. Apesar disso, as características e a metodologia de modelagem das linguagens de simulação também acabam (mesmo que parcialmente) sendo compreendidas por quem simula. Para o alcance dos objetivos relacionados, o exemplo de fila escolhido será modelado em um pacote de simulação (STELLA ${ }^{\circledR}$ ).

Esta seção faz uma breve descrição dos tipos de ferramentas de simulação, inclusive daquela que será utilizada no trabalho.

Uma descrição mais ampla da ferramenta utilizada (STELLA) será apresentada no final desse capítulo. O desenvolvimento das simulações será explorado no capítulo 7.

Cumpre observar ainda que, nesta seção, serão enfocados apenas os aspectos dos programas computacionais ligados à simulação digital de sistemas dinâmicos de eventos discretos.

\subsubsection{Linguagens de propósito geral ou linguagens de programação}

As primeiras simulações em computador digital foram escritas em linguagens de programação de propósito geral (também chamadas de linguagens de alto nível e linguagens de compilador). Dentre elas, destacam-se o FORTRAN, o PASCAL e o C. 
Nessas linguagens, um programa especial é escrito para a simulação de cada sistema a ser estudado. Se escrito de maneira eficiente, seu tempo de execução será menor do que o mesmo problema programado em uma linguagem de simulação. Além disso, segundo NAYLOR et al. (1971), essa alternativa oferece ao programador a máxima flexibilidade em projeto e formulação do modelo matemático do sistema em estudo, tipo e formato dos dados de saída gerados e espécies de experiências de simulação executadas com o modelo.

WATSON (1981) lista algumas razões para o uso das linguagens de programação de propósito geral:

- Flexibilidade oferecida na descrição matemática do sistema modelado; não há estruturas inerentes limitantes;

- O programador pode selecionar um tipo ou formato de relatórios de saída. Somente o tempo e a habilidade de programação limitam os relatórios que podem ser gerados;

- Flexibilidade em termos dos tipos de experimentos que podem ser desempenhados no sistema modelado.

Embora estas linguagens permitam a modelagem em várias e diferentes aplicações, o tempo e as habilidades de programação necessários desencorajavam muitos modeladores em potencial (BATEMAN et al., 1997). O uso dessas linguagens está restrito a profissionais que tenham bons conhecimentos em programação.

Mas, de acordo com NAYLOR et al. (1971), a principal deficiência da modelagem em linguagens de propósito geral é a dificuldade de confecção dos programas. O modelador pode se ver emaranhado nas dificuldades do controle seqüencial, o que dá espaço ao aparecimento de pequenos erros. Além disso, os equívocos nesta fase são responsáveis pelo surgimento de efeitos obscuros e difíceis de eliminar.

\subsubsection{Linguagens de simulação}

Após várias simulações com linguagens de propósito geral, os analistas reconheceram que muitos sistemas ou sub-sistemas modelados eram iguais ou 
semelhantes. E, como muitos dos programas tinham processos similares, a idéia de se desenvolver linguagens de propósito específico, algumas com o objetivo particular de simular, evoluiu entre diversos grupos de pesquisa. Em um esforço para simplificar o processo de construção de modelos, iniciou-se o desenvolvimento das linguagens de simulação.

Introduzidas em 1960, estas linguagens oferecem sentenças de programação especificamente projetadas para gerenciar fenômenos comuns aos sistemas. O SIMSCRIPT e o GPSS são exemplos de linguagens pioneiras desenvolvidas para simulação.

Assim como nas linguagens de programação de alto nível, as linguagens de simulação também fazem uso de compiladores, mas são usadas especificamente para aplicações em simulação. Dentre as primeiras linguagens de simulação, encontram-se o GASP, o DYNAMO, o GPSS, o SIMULA, o SIMSCRIPT II-5, o SLAM, o SIMAN etc.

Essas linguagens mais amigáveis e dedicadas apenas à simulação são, na verdade, bibliotecas compostas por "macros" de linguagens de propósito geral.

EMSHOFF \& SISSON (1970) ilustram as principais semelhanças e diferenças entre as linguagens de propósito geral e as linguagens de simulação através de duas figuras (FIGURAS 12 e 13).

A FIGURA 12 mostra como modelos de simulação computacional são desenvolvidos em uma linguagem de propósito geral. $\mathrm{O}$ analista pensa sobre o problema em sua linguagem nativa. O resultado é uma formulação do problema e uma descrição do modelo. Utilizando uma tecnologia de simulação, o analista desenvolve um modelo matemático apropriado. Com o conhecimento de uma linguagem como FORTRAN, o analista a usa para codificar o modelo em um programa de simulação.

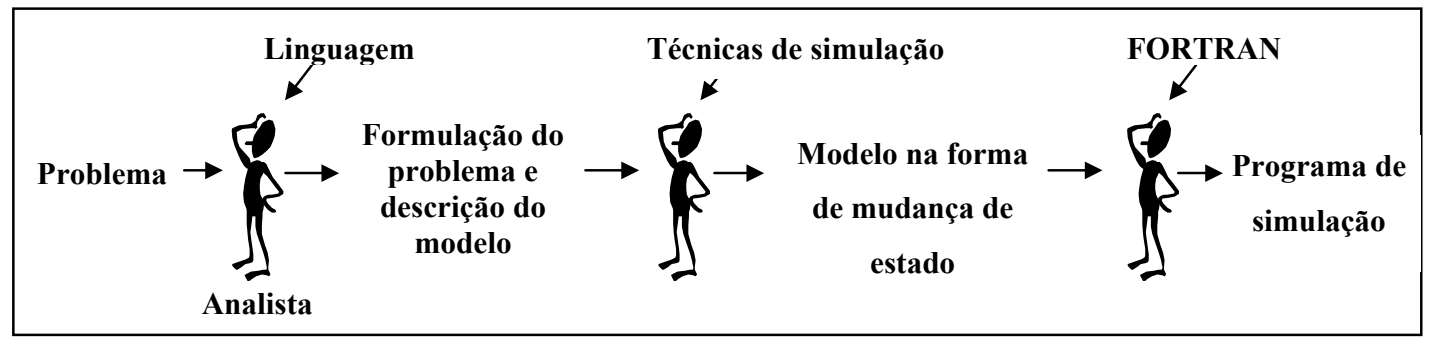

FIGURA 12 - Modelagem com uma linguagem de propósito geral Fonte: EMSHOFF \& SISSON (1970) 
Um analista que usa uma linguagem de simulação segue um processo diferente daquele que utiliza uma linguagem de propósito geral (ver FIGURA 13). A linguagem provê um guia conceitual na definição do problema e na criação do modelo. Pelo fato do modelo ser formulado na mente do analista em termos da linguagem de simulação, isso elimina o passo onde uma descrição na linguagem natural é usada para desenvolver o modelo matemático. Esse modelo, por sua vez, deve ser programado.

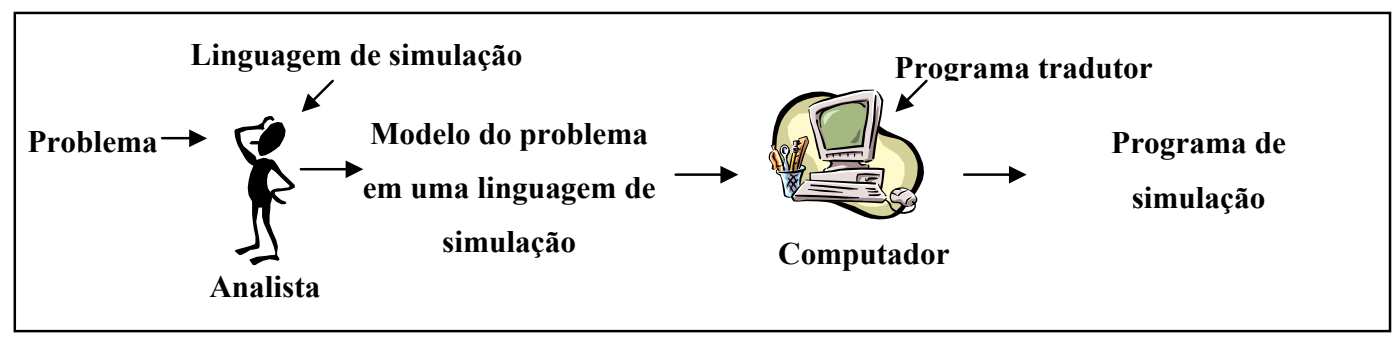

FIGURA 13 - Modelagem com uma linguagem geral de simulação Fonte: EMSHOFF \& SISSON (1970)

A maioria das linguagens de simulação requer um tempo de programação menor que as linguagens de programação; além disso, é mais simples modificar o modelo depois de escrito e mais fácil sanar eventuais problemas. Embora as linguagens de simulação sejam de fácil utilização, elas ainda necessitam de um modelador com experiência em programação e com tempo disponível.

Apesar das vantagens da utilização das linguagens de simulação, segundo NAYLOR et al. (1971), elas padecem de não-generalidade e são menos flexíveis que as linguagens de programação, já que se limitam a certos tipos de problemas.

De uma maneira geral, a vantagem de se usar uma linguagem de simulação está diretamente ligada à desvantagem de usar uma de propósito geral, e vice-versa; as características que são fortes em uma são os pontos mais fracos da outra. Assim, um aumento na flexibilidade de um programa de simulação é obtido às custas de um estudo mais aprofundado dos processos de programação. Da mesma forma, as reduções no tempo de programação obtidas através de uma linguagem de simulação geralmente aumentam os tempos e os custos de processamento.

A TABELA 04, elaborada por SHANNON (1975), compara as vantagens e desvantagens desses dois tipos de linguagem, reunidas a partir de diversas fontes, especialmente NAYLOR (1971) e EVANS et al. (1967). 
TABELA 04 - Comparação das vantagens e desvantagens das linguagens

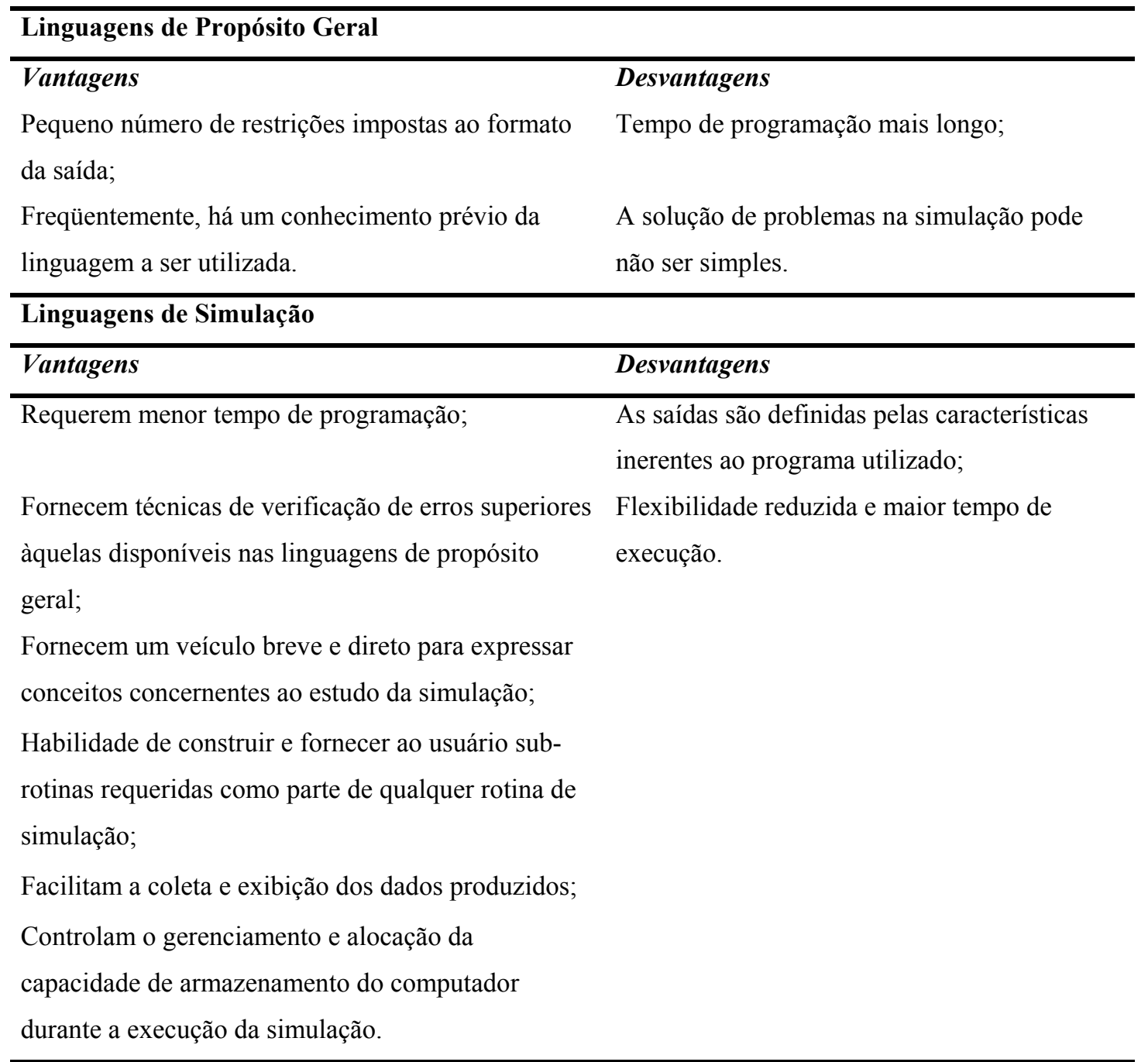

Fonte: Adaptado de SHANNON (1975)

\subsubsection{Pacotes de simulação}

À medida que engenheiros, gerentes e outros tomadores de decisão começavam a perceber o poder da simulação, aumentava o esforço em oferecer ao mercado pacotes de simulação projetados para facilitar a modelagem, proporcionando, principalmente, rapidez.

Segundo KHEIR (1996), na sua forma mais simples, um pacote de simulação digital é uma coleção de rotinas (programas compilados separadamente e então incluídos como parte de um programa principal). Os simuladores atuais, com auxílio 
de equipamentos computacionais mais avançados, fornecem uma das ferramentas mais poderosas para as atividades de modelagem e simulação.

Entre as características comuns a esses pacotes, tem-se:

- Interface gráfica de comunicação com o usuário;

- Animação do modelo;

- Relatórios em tempo real sobre a simulação executada;

- Coleta automática de saídas para medição de desempenho do sistema;

- Desenvolvimento de modelos orientados a objeto;

- Ferramentas estatísticas para tratamento dos dados da simulação.

Acompanhando o desenvolvimento tecnológico, vários esforços têm surgido para melhorar os pacotes de simulação e vários tipos de simuladores têm sido disponibilizados no mercado. Esses esforços aumentaram a gama e a complexidade dos sistemas passíveis de simulação. Dentre essas melhorias, têm-se (BATEMAN et al., 1997):

- Telas de entrada de dados orientadas por menu;

- Construções direcionadas a aplicações específicas que proporcionam rapidez de modelagem;

- O uso de sentenças lógicas similares às da programação;

- Capacidade de atributos especiais;

- Habilidade de importar sub-rotinas externas;

- Simuladores projetados para diversos ambientes operacionais;

- Interfaces gráfica elaboradas;

- Animação gráfica personalizada;

- Produtos projetados para PC;

- Transferências de dados entre aplicações.

As principais vantagens dos simuladores em relação às linguagens de simulação de propósito geral podem ser resumidas como se segue:

- Interação mais amigável entre usuário e simulação;

- Possibilidade de utilização de bibliotecas constituídas de blocos de modelagem anteriormente construídos; 
- Animação e interface gráfica elaboradas;

- Coleta automática de dados de saída;

- Transferências de dados entre aplicações.

Existem muitos pacotes de simulação disponíveis no mercado, entre eles pode-se citar: Arena, extend, stella, AutoMod, ProModel, PowerSim etc.

As ferramentas de simulação, principalmente os pacotes de simulação, requerem recursos consideráveis das empresas, seja em termos financeiros ou de tempo e pessoal. Por isso, a seleção adequada da ferramenta de simulação passa a ser um dos fatores chave no sucesso dos projetos de simulação. Assim sendo, esta seleção deverá ser feita cada vez mais com base em critérios objetivos, levando-se em conta as características dos produtos e as aplicações que se pretende desenvolver.

Uma análise das formas de seleção de ferramentas de simulação fugiria do objetivo deste trabalho. Por isso, ele limita-se a fornecer as informações básicas a respeito do pacote de simulação STELLA e, mais importante, contribuir para um processo de aquisição de conhecimento mais eficiente.

\subsubsection{STELLA}

O pacote de simulação STELLA foi escolhido por duas razões principais: orientação à metodologia de Dinâmica de Sistemas (que é examinada neste trabalho) e extensa utilização em diversos problemas acadêmicos e empresariais. Utilizou-se a versão 5.0 para Windows.

O STELLA é um pacote de simulação baseado na metodologia das Dinâmicas de Sistemas (SD). Ele foi desenvolvido pela empresa High Performance System Incorporation (Estados Unidos), e direciona-se à construção de modelos de sistemas dinâmicos. Para tanto, faz uso de uma hierarquia multinível com três diferentes camadas:

- Camada superior: usada para a construção de um mapa de setores que compõem o modelo; essa camada facilita a navegação pelo modelo (ver FIGURA 14); 
- Camada de construção do modelo: camada na qual são apresentados os diagramas que representam o modelo (ver FIGURA 15);

- Equações: camada que apresenta o código do modelo, construído pelo próprio programa (ver FIGURA 16).

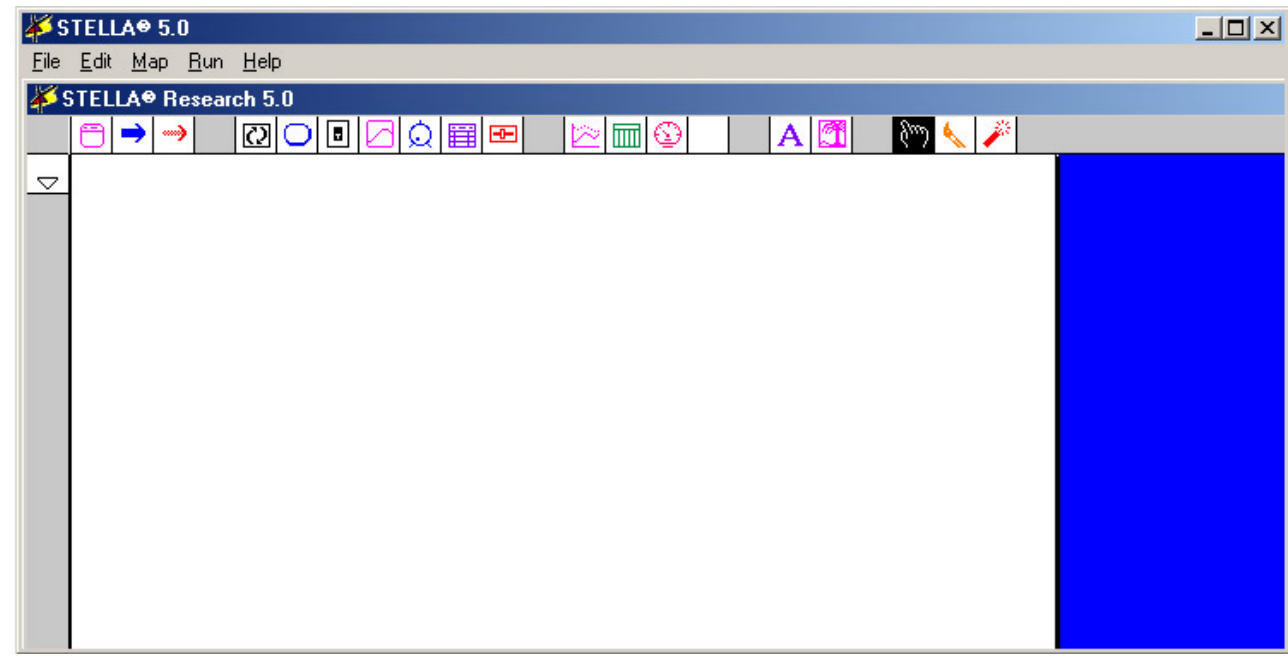

FIGURA 14 - Camada superior do STELLA

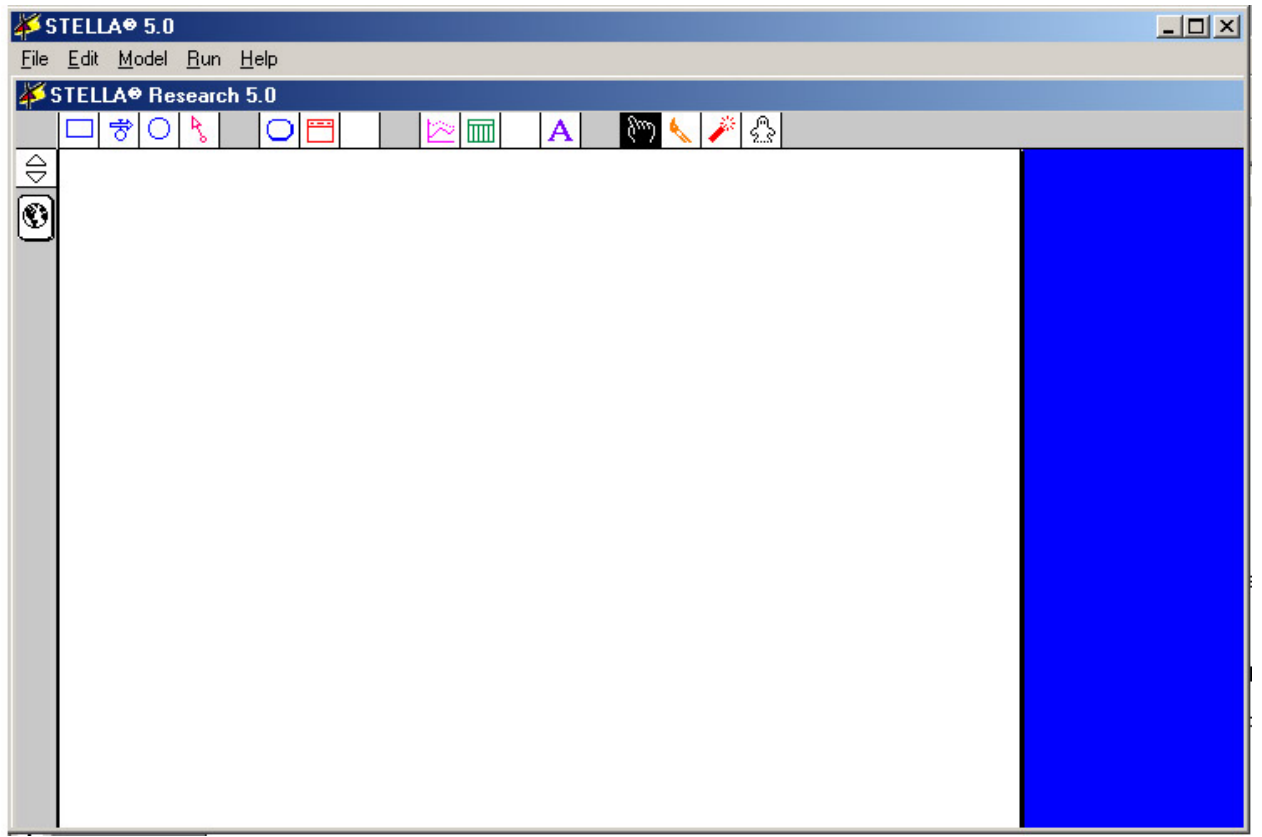

FIGURA 15 - Camada de construção do modelo do STELLA 


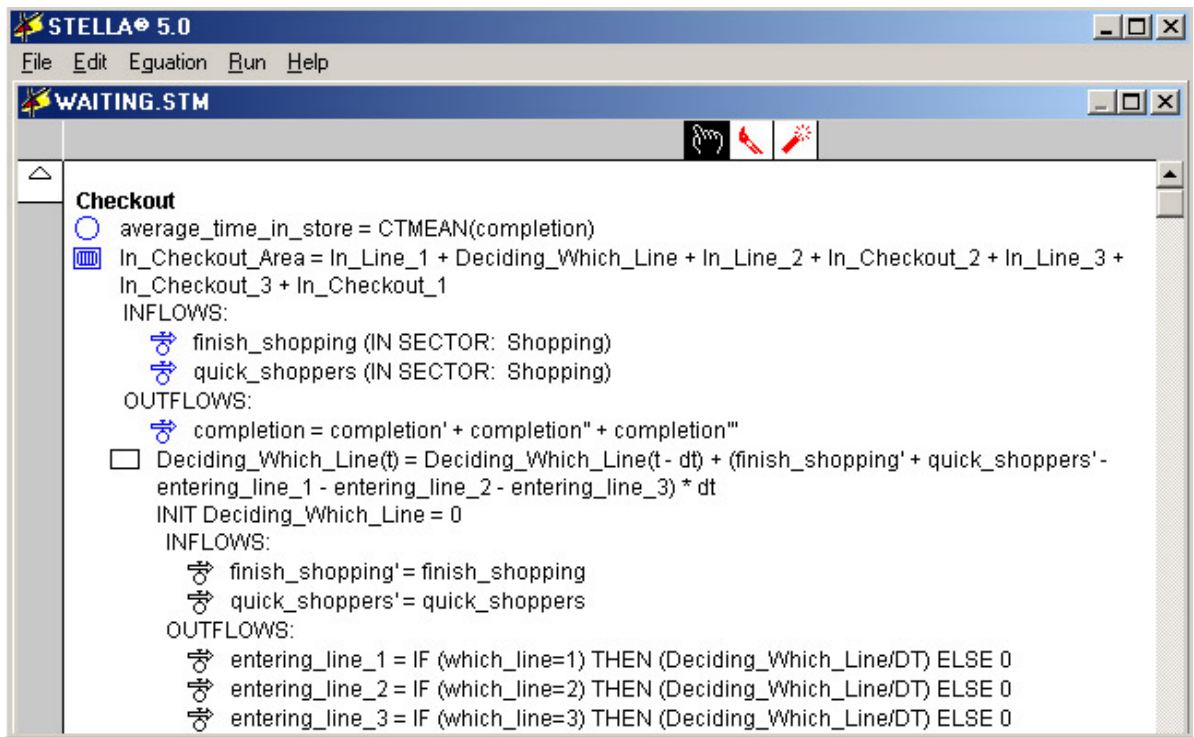

FIGURA 16 - Camada de equações do STELLA

Observa-se nessas figuras a existência de barras de tarefas com diferentes comandos. Essas barras e seus comandos são mostrados nas FIGURAS 17 e 18. Os comandos são explicados a seguir.

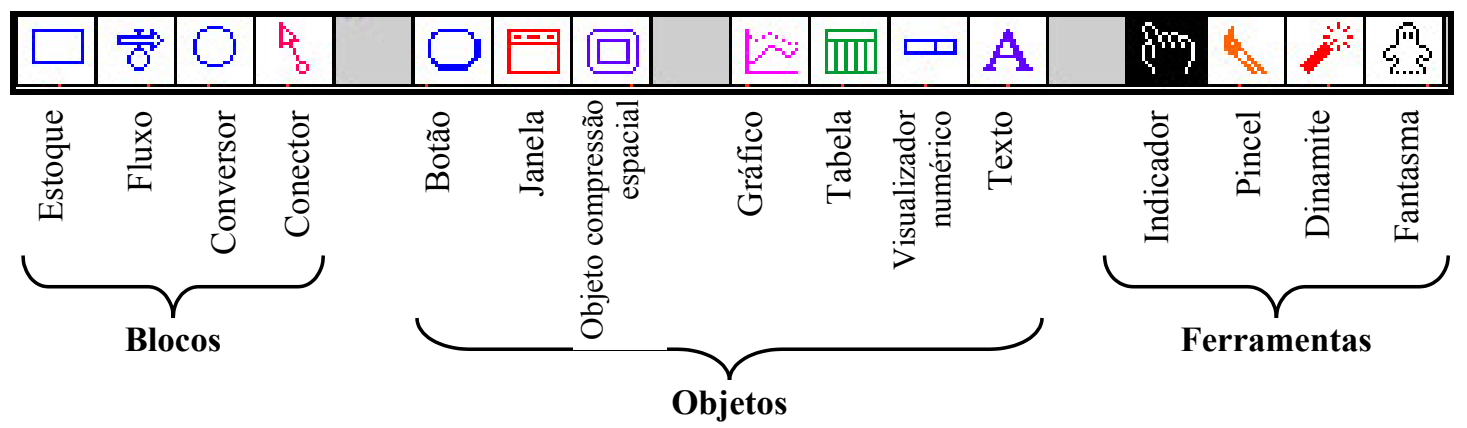

FIGURA 17 - Barra de tarefas da camada de construção do modelo

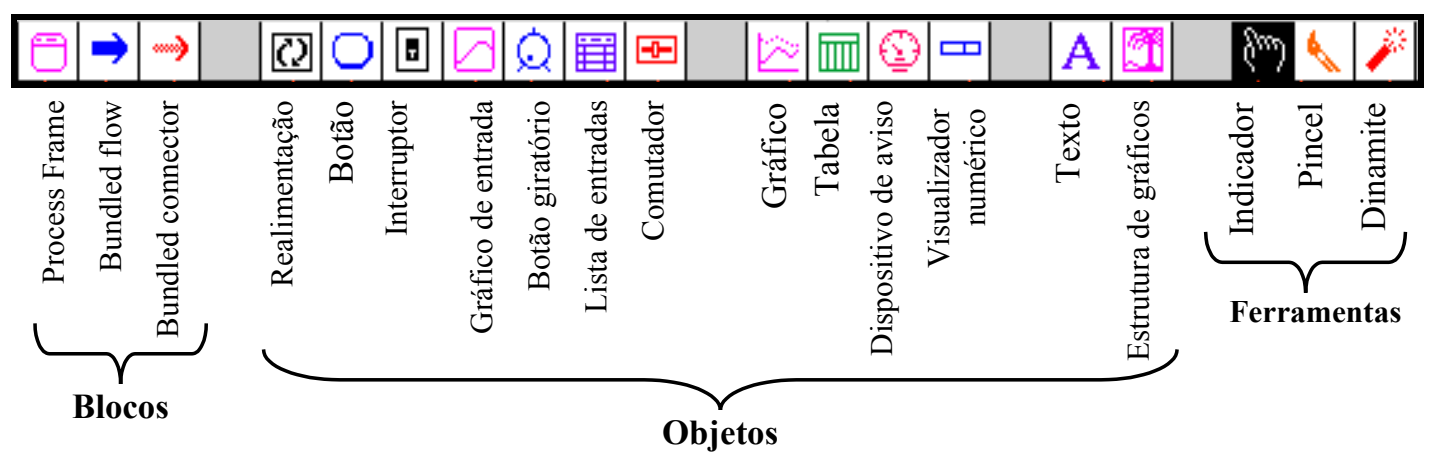

FIGURA 18 - Barra de tarefas da camada superior 
Segundo HIGH PERFORMANCE SYSTEM (1997), os principais elementos utilizados para a construção do modelo em STELLA são: estoques, fluxos, auxiliares e conectores.

O componente estoque, simbolizado por um retângulo, representa variáveis cujos valores deseja-se acumular ao longo do tempo. O estoque pode ser divido em quatro tipos: estoque propriamente dito, esteira, fila e forno.

Já o fluxo, constituído de uma seta portando uma circunferência que representa uma variável, é um componente de ação. A variável conterá uma função ou gráfico que expressa seu valor ao longo do tempo; em uma extremidade haverá a origem do fluxo e na outra haverá o destino deste. Representado em conjunto com o estoque, pode aumentar ou diminuir seu volume.

Os auxiliares, ou conversores, contêm valores numéricos, funções matemáticas, vetores, matrizes ou gráficos que expressem seus valores ao longo do tempo. Servem como auxiliares para o relacionamento entre os outros componentes e/ou outros auxiliares. Um auxiliar é usado para modelar as informações, e não o fluxo físico, sendo capaz de se alterar instantaneamente, sem atrasos (COVER, 1996).

Por fim, os conectores, representados por setas unindo duas variáveis, expressam as inter-relações entre todos os componentes do sistema. Segundo DEATON \& WINEBRAKE (2000), estas inter-relações ligam os componentes que formarão uma expressão matemática.

A seguir (FIGURA 19), são apresentados os símbolos referentes a cada um dos componentes citados acima.

\begin{tabular}{|l|c|c|c|}
\hline Estoque & Fluxo & Conversor & Conector \\
\hline$\square$ & 0 & & \\
\hline
\end{tabular}

FIGURA 19 - Blocos utilizados na simulação em STELLA

Os outros comandos que compõem o STELLA são:

\section{- Blocos}

- Process Frame: espécie de tabela que representa sistemas menores (setores); 
- Bundled flow: forma de ligar sistemas (subsistemas) através de fluxos;

- Bundled connector: maneira de ligar duas tabelas do tipo process frame através de conectores.

\section{- Objetos}

- Botão: facilita a interação entre os usuários finais e seu modelo através da redução do nível de habilidade necessário em programação e fluência de linguagem. Quando selecionados, os botões realizam uma de várias operações: navegar para uma nova localização, executar um comando do menu ou prover eventuais informações;

- Janela: possibilita a criação de diferentes setores. Ela é usada para agrupar funcionalmente partes relacionadas da estrutura do modelo e para exibir imagens gráficas;

- Objeto de compressão espacial: fornece um mecanismo para gerenciar a complexidade do diagrama. Como seu nome sugere, ele habilita o usuário a comprimir o espaço associado à lógica detalhada de um modelo;

- Gráfico: fornece um gráfico para exibir a saída numérica das simulações;

- Tabela: também utilizado para exibir a saída numérica das simulações;

- Visualizador numérico: exibe a saída corrente associada às variáveis do modelo assinaladas;

- Bloco de Texto: exibe textos e observações geradas pelo usuário;

- Realimentação: são visualizações simplificadas do modelo. Os diagramas de realimentação são figuras simples que identificam processos de causa e efeito que trabalham para gerar padrões de comportamento dinâmico;

- Interruptor: tem como função principal ativar ou desativar conversores e janelas;

- Gráfico de entrada: este dispositivo habilita o usuário do modelo a (1) ter uma rápida visualização do formato de uma função gráfica, (2) editar uma função gráfica a partir de uma camada superior, (3) restaurar uma função gráfica para as relações definidas pelo autor do modelo e (4) animar funções gráficas durante uma simulação; 
- Botão giratório: representa uma variável (estoque, fluxo ou conversor). A variável assume o valor referente à marcação do botão;

- Lista de entrada: tabela onde se determinam diferentes valores para diferentes variáveis. As listas de entrada permitem a entrada de muitos valores numéricos exatos, enquanto conserva na tela o estado real da camada superior;

- Comutador: função que atribui um valor inicial às variáveis;

- Dispositivo de aviso: combina um mostrador do tipo velocímetro, números, cores e sons para ilustrar o comportamento de determinada variável durante a execução da simulação;

- Estrutura de gráficos: incrementam a interface com o usuário de diversas maneiras. Eles habilitam a importação de figuras, gráficos e animações.

- Ferramentas

- Indicador: é uma ferramenta de edição de propósito geral. É usado para selecionar, mover, abrir e editar blocos de construção e objetos.

- Pincel: seu propósito é adicionar cor ao modelo.

- Dinamite: usada para eliminar blocos de construção e objetos do espaço de diagrama, e equações (com seus blocos de construção associados) do espaço de equações.

- Fantasma: sua função é fazer réplicas de estoques, fluxos e conversores individuais. Um fantasma de uma entidade não tem identidade independente, é simplesmente uma imagem do bloco de construção a partir do qual foi gerado. A réplica não tem uma equação própria. Quando se seleciona a réplica fantasma, a caixa de diálogo que surge pertence, na verdade, ao bloco original.

Além dos blocos, objetos e ferramentas, o STELLA utiliza-se de uma série de funções para conseguir o modelo adequado. Essas funções são divididas em onze tipos: entradas de teste, funções financeiras, funções matemáticas, funções discretas, funções trigonométricas, funções de tempo cíclico, funções lógicas, funções 
vetoriais, funções estatísticas, funções de propósito específico e amostragem a partir de distribuições não-uniformes.

A estrutura do STELLA fornece ao usuário uma visão geral do sistema, além de facilitar a modelagem e economizar tempo de projeto.

O capítulo 6 tratará com mais minúcia a metodologia da Dinâmica de Sistemas e as simulações serão explicadas no capítulo 7. 


\section{CAPÍTULO 6 DINÂMICA DE SISTEMAS}

O processo de tomada de decisões é muito complexo, especialmente quando estas têm efeitos de realimentação indiretos, atrasados ou múltiplos. Esses efeitos de realimentação, aliados à inabilidade dos administradores em lidarem com eles, acarretam, freqüentemente, um desempenho ruim para as organizações. Segundo muitos teóricos em sistemas, entre eles FORRESTER (1961), um desempenho organizacional ineficiente é normalmente devido às habilidades cognitivas limitadas dos indivíduos frente à complexidade dos sistemas que eles devem enfrentar.

De acordo com SENGE \& STERMAN (1994), os tomadores de decisão experientes comumente têm percepções apuradas da estrutura causal e do processo de tomada de decisão, mas tiram conclusões equivocadas sobre o que acontece quando diferentes partes de um sistema interagem. Esses indivíduos carecem, então, de um mecanismo de inferência para conhecer e deduzir, dentre outras coisas, as conseqüências das interações entre os elementos do sistema do qual fazem parte. A simulação, a visão sistêmica e a metodologia de Dinâmica de Sistemas provêem tal mecanismo.

Por que o construtor do modelo freqüentemente adquire conhecimento e experiência utilizando os conceitos de Dinâmica de Sistemas? Isso ocorre porque o desenvolvimento do modelo (e sua experimentação) cria um micromundo em laboratório, no qual hipóteses são testadas, avaliadas e revisadas, sem a necessidade de se utilizar o sistema real. Os construtores e usuários dos modelos sondam profundamente suas questões relevantes e desenvolvem habilidades no método científico e pensamento crítico (SENGE \& STERMAN, 1994).

Assim, esse capítulo destina-se ao estudo de dois temas importantes na presente pesquisa: a visão sistêmica e a metodologia de Dinâmica de Sistemas. A visão (ou pensamento) sistêmica será abordada com vistas à sua aquisição por meio da simulação e à sua utilização em experimentos baseados na metodologia da 
Dinâmica de Sistemas. A relação entre aquisição do conhecimento, pensamento sistêmico e Dinâmica de Sistemas pode ser visualizada através na FIGURA 20.

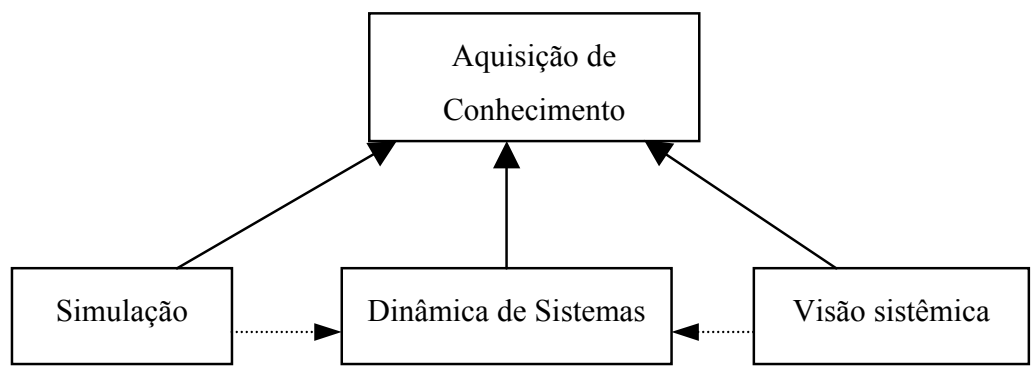

FIGURA 20 - As principais ferramentas de aquisição do conhecimento consideradas no trabalho

Fonte: Elaborada pelo autor

\section{1 Visão sistêmica}

À medida que o mundo se torna mais complexo e interdependente, a capacidade de pensar sistemicamente, de analisar os campos de força e seus efeitos causais, abandonando assim a lógica causal simples, torna-se um fator crítico para a aprendizagem (FLEURY \& FLEURY, 1995).

A visão sistêmica é um instrumento valioso para a apreensão da complexidade do mundo. Sua principal característica é projetar a análise para o sistema mais amplo, levando em conta as propriedades e a influência de cada parte na estrutura do todo.

Em suma, a abordagem sistêmica é uma contínua revisão do mundo, do sistema total e de seus componentes (CHURCHMAN, 1968). Ela encara o mundo como um conjunto de sistemas e subsistemas, sendo que por sistema deve-se entender uma reunião de elementos inter-relacionados que interagem entre si para atingir um determinado objetivo.

\subsubsection{Histórico}

A origem do pensamento sistêmico é considerada anterior à filosofia socrática; o marco moderno da origem do pensamento sistêmico, contudo, é atribuído a Von Bertalanffy. Nas décadas de 1920 e 1930, ele tentou recompor a unidade da ciência através de sua teoria da criação de modelos holísticos, isomórficos, capazes 
de abrigar fenômenos similares das mais distintas áreas. Ele sistematizou as novas idéias científicas que vinham permeando a ciência desde a virada do século $\mathrm{XX}$, as quais postulavam uma abordagem de "todos integrados" (ARAÚJO, 1995).

Antes da Teoria dos Sistemas, a doutrina corrente era a Mecanicista. Sua denominação vem da palavra máquina, e nela a compreensão de algo era feita através da análise de suas partes (ênfase nas partes). Essa característica tem sido chamada de pensamento analítico. De acordo com o pensamento analítico, quando se tem um fenômeno ou problema complexo, deve-se reduzi-lo a um conjunto de partes simples e facilmente compreensíveis, estuda-se os mecanismos através dos quais essas partes interagem e volta-se a juntar as peças. Essa era, segundo seus utilizadores, a forma de se compreender o todo. A TABELA 05 apresenta as principais características do método analítico.

TABELA 05 - Principais características do método analítico

\begin{tabular}{l|l}
\hline \multicolumn{2}{c}{ MÉTODO ANALÍTICO } \\
\hline Reação ao dogmatismo e obscurantismo medieval & Ênfase na parte \\
\hline A serviço da decomposição & Fatos específicos, particulares \\
\hline Tendência reducionista & Via quantitativa \\
\hline Caráter mecanicista & Fundamentos principais: razão e emoção \\
\hline Necessidade e leis & Determinista \\
\hline Exatidão, regularidade & Codificação matemática \\
\hline Reprodutividade & Visa ao controle \\
\hline Previsibilidade & Geral \\
\hline Inclinação indutiva & Progressividade, acumulação \\
\hline Relação causal & Ponto de vista da causalidade \\
\hline Realidade objetiva & Experimental \\
\hline Exclusão do sujeito (dualidade) & Função explicativa \\
\hline Alguns mentores: Galileu, Bacon & Descartes, Newton, Freud \\
\hline
\end{tabular}

Fonte: CREMA (1991)

Para contrapor essa forma de encarar os problemas, surgiu o pensamento sistêmico. Essa nova forma tem como principais características uma abordagem sistêmica de resolução de problemas, a utilização do método sintético, o expansionismo etc. (ver TABELA 06). Ele emergiu durante a primeira metade do século XX, especialmente ao longo dos anos 20, em várias disciplinas. A Biologia foi pioneira, mas foi logo seguida pela psicologia, ecologia, física etc.

Na psicologia, o pensamento sistêmico foi enriquecido pelos estudiosos e pela escola da Gestalt. O que esses psicólogos descobriram é que os organismos vivos não percebem as coisas em termos de elementos isolados, mas em termos de padrões 
perceptivos integrados. A famosa frase "O todo é maior do que a soma das partes" foi autoria dos psicólogos da Gestalt (CAPRA, 2001).

TABELA 06 - Principais características do método sintético

\begin{tabular}{ll}
\hline & MÉTODO SINTÉTICO \\
\hline $\begin{array}{l}\text { Reação ao racionalismo positivista e analismo } \\
\text { moderno }\end{array}$ & Enfase na totalidade \\
A serviço da unificação & Realidade plena, total \\
Tendência ampliativa, globalista & Via qualitativa \\
Caráter organicista & Fundamentos principais: emoção e intuição \\
Liberdade e responsabilidade & Indeterminista \\
Incerteza, flexibilidade & Codificação poético-metafórica \\
Unicidade & Visa a participação \\
Imprevisibilidade & Singular \\
Inclinação dedutiva & Instantaneidade, descontinuidade \\
Relação sem causa, sincronismo & Ponto de vista da finalidade \\
Consciência, valores & Experiencial \\
Inclusão do sujeito (não-dualidade) & Função compreensiva \\
Alguns mentores: Smuts, Jung & Frankl, Soler, Dilthey, Krishnamurti \\
\hline
\end{tabular}

Fonte: CREMA (1991)

$\mathrm{O}$ autor que mais recentemente tratou com minúcia do tema pensamento sistêmico foi Peter Senge (1990). Ele foca inicialmente o indivíduo, seu processo de autoconhecimento; em seguida, o foco desloca-se para o grupo e, finalmente, por meio do raciocínio sistêmico, para a organização. Em seus textos sobre organizações de aprendizagem, ele comenta que o ser humano vem ao mundo motivado a aprender, explorar e experimentar, e que as organizações devem desenvolver cinco "disciplinas" fundamentais para manterem constante o processo de inovação e aprendizagem:

- domínio pessoal: por meio do autoconhecimento, as pessoas aprendem a clarificar e aprofundar seus próprios objetivos, a concentrar esforços e a ver a realidade de forma objetiva;

- modelos mentais: são idéias profundamente enraizadas, generalizações e mesmo imagens que influenciam o modo como as pessoas vêem o mundo e suas atitudes;

- visões partilhadas: quando um objetivo é percebido como concreto e legítimo, as pessoas dedicam-se e aprendem não como uma obrigação, mas por vontade própria, construindo visões partilhadas;

- aprendizagem em grupo: em grupos onde as habilidades coletivas são maiores que as habilidades individuais, desenvolve-se a capacidade para 
ação coordenada. A aprendizagem em grupo começa com a capacidade dos membros do grupo em propor idéias e participar da elaboração de uma lógica comum;

- pensamento sistêmico: constitui um modelo conceitual, composto de conhecimentos e instrumentos, desenvolvidos ao longo dos últimos 50 anos, que visam melhorar o processo de aprendizagem como um todo, e apontar futuras direções para aperfeiçoamento.

O pensamento sistêmico constitui a quinta disciplina, integrando as demais num conjunto coerente de teoria e prática, o que evita que cada uma seja vista de forma isolada. Esta capacidade tem que ser desenvolvida não apenas pelo líder, mas também por todas as pessoas que participam da organização.

O pensamento sistêmico torna-se mais importante à medida que o mundo se torna mais complexo e interdependente, pois a capacidade de analisar os sistemas e seus efeitos causais torna-se um fator crítico para o aprendizado.

Assim, SENGE (1990) afirma que a quinta disciplina é a principal da organização de aprendizagem. Isso decorre da dificuldade das pessoas em abandonar a característica de encarar novas mudanças como um evento isolado, ao invés de reagir a elas como parte de um processo. Como elas falham em notar as interrelações dessas ações, tendem a se enganar.

O sucesso da abordagem sistêmica pode ser atribuído, segundo RAPOPORT (1976), à insatisfação crescente da comunidade científica com a visão mecanicista e à necessidade de se contrabalançar a fragmentação da ciência, cujas especialidades se tornaram quase isoladas umas das outras.

\subsubsection{Características do Pensamento Sistêmico}

Através dos estudos de autores como CAPRA (2001), CHURCHMAN (1968), BERTALANFFY (1977), CHECKLAND (1981), entre outros, pode-se separar as principais características-chave do pensamento sistêmico.

A primeira característica é a mudança das partes para o todo. De acordo com a visão sistêmica, as propriedades essenciais de um sistema são propriedades do 
todo, não encontradas em nenhuma das suas partes. Elas são um resultado das interações e relacionamentos entre essas mesmas partes.

Um segundo aspecto do pensamento sistêmico é pensar em termos de contexto; as propriedades das partes só podem ser compreendidas dentro do contexto mais amplo. Assim, a nova regra é: para compreender algo, não se deve separar, mas sim inserir num contexto mais amplo. Desta forma, o pensamento sistêmico é expansionista, opondo-se ao pensamento analítico reducionista.

$\mathrm{Na}$ visão mecanicista, o mundo é visto como uma coleção de objetos, sendo secundárias as relações entre eles; na visão sistêmica, reconhece-se que os objetos em si são redes de relações inseridas em redes maiores.

Outra característica-chave do pensamento sistêmico é sua capacidade para fazer com que se desloque a atenção através dos diferentes níveis dos sistemas; isto é possível devido ao caráter multinível inerente aos sistemas.

Outro atributo do pensamento sistêmico é fazer com que cada estrutura seja vista como uma manifestação dos processos subjacentes. O pensar sistêmico é sempre pensar em termos de processo.

\section{2 Dinâmica de Sistemas}

Os construtores de modelos podem adotar muitas abordagens diferentes na escolha dos problemas a serem modelados e do conteúdo de seus modelos. Dentre essas abordagens, tem-se a simulação clássica e a simulação baseada em Dinâmica de Sistemas, a última é o principal objeto de discussão deste capítulo.

Dinâmica de Sistemas (SD) é o termo aqui utilizado para denominar a metodologia System Dynamics, cujo conceito foi originalmente desenvolvido, na década de 50, pelo professor Jay W. Forrester, do Massachusetts Institute of Technology (MIT).

O trabalho inicial de Forrester foi o livro Industrial Dynamics (1961), cujas idéias foram posteriormente expandidas a outros sistemas que não os industriais (econômicos, sociais etc.). Todas as suas idéias formaram um novo campo de estudo, conhecido como Dinâmica de Sistemas. Segundo ROBERTS (1983), este novo campo é uma das variantes da abordagem sistêmica, e é fortemente baseado em 
computadores; a SD provê uma estrutura que possibilita a aplicação da idéia da teoria de sistemas a problemas sociais e econômicos.

Desde a publicação da obra Industrial Dynamics, a modelagem e a simulação da Dinâmica de Sistemas têm despertado o interesse de especialistas de diversos campos do conhecimento, desde as engenharias, onde se originou, aos sistemas físicos, biológicos, sociais e econômicos (GALLAHER, 1996). Apesar dessa obra tratar da modelagem do comportamento dinâmico das organizações industriais, suas premissas podem ser estendidas a qualquer outro sistema dinâmico.

Aplicações mais amplas dessa metodologia só foram feitas a partir da década de 90, com o desenvolvimento da tecnologia computacional, com equipamentos mais poderosos e baratos e programas computacionais mais amigáveis e intuitivos.

Segundo FORRESTER (1961), a SD permite a representação, ao longo de grandes períodos de tempo, de sistemas que possuem inter-relacionamentos complexos e processos não-lineares. Essas características são particulares à relação entre as ações humanas e o seu ambiente sócio-econômico, físico e biológico.

A Dinâmica de Sistemas começou com o nome de Dinâmica Industrial, a qual foi definida por FORRESTER (1961, p.13) como:

“... o estudo das características de realimentação de informações de atividades industriais, a fim de mostrar como a estrutura organizacional, a amplificação (em políticas) e os lapsos de tempo (em decisões e ações) interagem para influenciar o sucesso do empreendimento. Ela trata da interação entre os fluxos de informação, dinheiro, pedidos, materiais, pessoal e equipamentos em uma companhia, uma indústria ou uma economia nacional".

Segundo MEIER, NEWELL \& PAZER (1969), a simulação dinâmica é uma técnica para construção e operação de modelos dinâmicos, enquanto a dinâmica industrial é, primariamente, uma filosofia, uma maneira de se olhar para as organizações e sistemas, e uma metodologia para estudo do comportamento de sistemas industriais. Na Dinâmica de Sistemas, a simulação de sistemas dinâmicos é utilizada como uma ferramenta de análise. 
Quatro fundamentos principais melhoraram o entendimento da dinâmica das organizações. Foram eles que tornaram a dinâmica industrial possível: a teoria dos sistemas de realimentação de informação, um conhecimento dos processos de tomada de decisão, a abordagem de modelos experimentais para sistemas complexos e o computador digital como meio para simular modelos matemáticos realísticos (FORRESTER, 1961).

A utilização de modelos dinâmicos tem uma base bastante ampla, podendo fornecer ao tomador de decisão o benefício de um entendimento mais profundo a respeito do sistema com o qual ele lida. BUFFA \& DYER (1977) afirmam que, através da utilização desse tipo de modelo, os indivíduos podem adquirir uma melhor compreensão dos efeitos das variáveis interativas e dos aspectos dinâmicos de como o sistema trabalha; ganham compreensão a respeito de como o sistema funciona como um todo, ao invés de uma maneira mais dissociada.

STARR (1980) afirma que os conceitos envolvidos em SD incluem:

- Um foco no comportamento descritivo através de um tempo contínuo, tais como crescimento, declínio, oscilação etc.

- Identificação de um limite do sistema, tal que o comportamento de interesse será gerado internamente, a partir dos laços de realimentação, contendo os atrasos de tempo e elementos não-lineares.

- Um formato específico para identificação e descrição dos elementos do sistema de realimentação.

- Uma atitude de construção de modelo que tenta incluir e quantificar todos os fatores que se acredita que influenciem o comportamento de interesse.

- Identificação das características de comportamento a partir da inspeção visual dos padrões de resposta gerados pela simulação computacional.

Ainda, segundo o mesmo autor, o último item poderia ser lido como "o uso da simulação computacional para traçar a resposta do sistema", mas o ponto principal não é a obtenção da resposta no tempo, e sim a inspeção das características comportamentais e a sugestão de mudanças nessa base.

Para FORRESTER (1961), a característica-chave do Pensamento Sistêmico está na interdependência, ou seja, na forma como os elementos de um sistema estão 
ligados uns aos outros, o que, para ele, é mais importante do que a análise puntual destes elementos de forma independente.

\subsubsection{Histórico}

Durante a Segunda Guerra Mundial, J. W. Forrester, um engenheiro eletricista, foi contratado para prestar serviço nas forças armadas americanas como técnico no laboratório de servomecanismo do MIT, organizando controles de armas e radares. Mais tarde, ele abandonaria a engenharia e realizaria os primeiros estudos na área da dinâmica de problemas administrativos. Essas experiências resultaram na metodologia SD, amplamente conhecida após a publicação do livro Industrial Dynamics em 1961.

Alguns anos antes da publicação de seu livro, Forrester contatou Richard Bennett, especialista em computação, para auxílio na modelagem computacional. Bennett desenvolveu um compilador que criaria automaticamente o código de uma forma genérica, gerando o embrião de um programa de computador para modelagem de dinâmica de sistemas, posteriormente chamado de DYNAMO.

Às experiências em sistemas industriais, seguiram-se aquelas realizadas em outros tipos de sistemas, resultando em obras como: Urban Dynamics (1969) e World Dynamics (1972). Hoje em dia, a SD é aplicada com sucesso a inúmeros tipos de sistemas e aos mais variados problemas.

$\mathrm{O}$ entendimento dos conceitos de causa e efeito, laços de realimentação e atrasos fornece bons fundamentos para se entender a complexidade da natureza de um sistema. A utilização desses conceitos no estudo de sistemas produtivos provê um acréscimo de experiências, as quais podem ser usadas pelos usuários das ferramentas de simulação como forma de se aperfeiçoar e de entender os sistemas com os quais lida diariamente.

Como toda área do conhecimento, a SD também é discordada por alguns autores. LEGASTO \& MACIARIELLO (1980) fazem uma classificação das principais críticas à Dinâmica dos Sistemas; segundo eles, as mais comuns estão ligadas a fatores como: definição dos limites (escopo do modelo e nível de agregação), seleção 
de um horizonte de tempo apropriado e de uma direção para uma resolução geral das dificuldades e vulnerabilidades na fase de definição do problema.

\subsubsection{Metodologia}

A abordagem de um problema a partir da perspectiva da SD compreende um conjunto de etapas similar ao do método científico (ver FIGURA 21). A pesquisa em SD possui, segundo ANDERSEN \& RICHARDSON (1980), sete etapas: reconhecimento do problema, conceituação do sistema, representação do modelo, comportamento do modelo, avaliação do modelo, análise de política e uso de modelo.

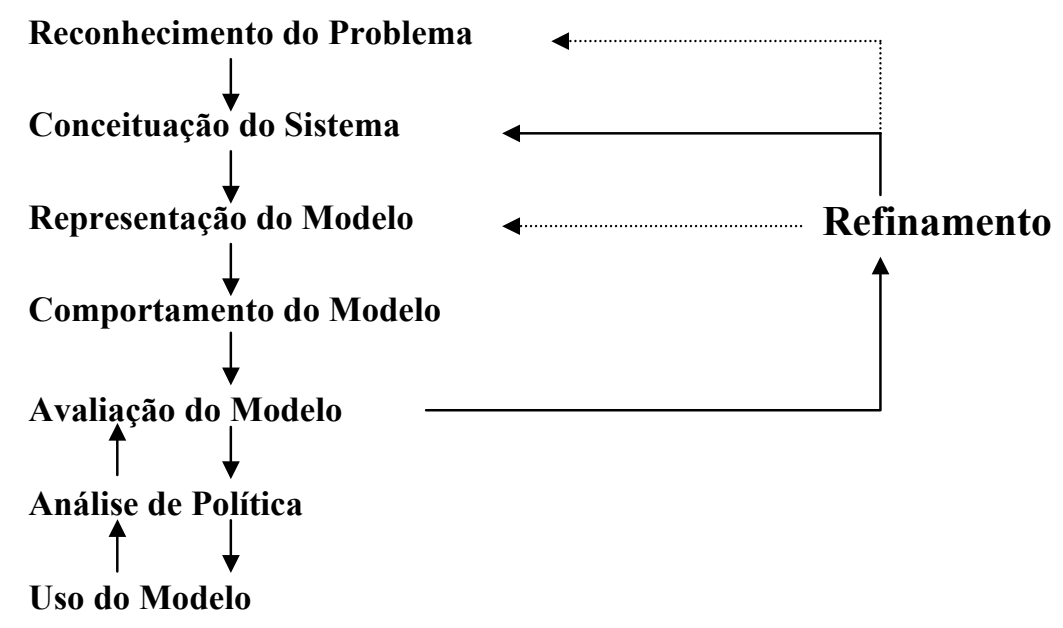

FIGURA 21 - Pesquisa em SD

Fonte: ANDERSEN \& RICHARDSON (1980)

$\mathrm{O}$ uso da metodologia de SD mostra-se interessante devido à sua capacidade de orientar um processo contínuo de aprendizagem sobre o problema estudado, além de permitir incorporar em sua análise diversos fatores, bem como as defasagens de tempo e realimentações a eles subjacentes.

\subsubsection{Características}

Segundo FORRESTER (1961), abordagem SD é baseada em uma série de premissas, entre elas: 
- as decisões em gerenciamento e economia tomam lugar em uma estrutura geral, conhecida como sistemas de realimentação de informação;

- o julgamento intuitivo das pessoas a respeito de como esses sistemas mudarão ao longo do tempo não é confiável, mesmo quando se tem um bom conhecimento das partes individuais do sistema;

- a experimentação do modelo é capaz de preencher a lacuna onde o julgamento e conhecimento das pessoas são fracos, mostrando a maneira pela qual as partes separadas do sistema podem interagir para produzir resultados esperados e problemáticos;

- há informação disponível suficiente para esta abordagem de construção de modelo experimental, sem que haja maiores gastos e atrasos na coleta de informação adicional;

- as mudanças de política e estrutura são passíveis de produzir uma melhora substancial no comportamento industrial e econômico.

São três os aspectos críticos da abordagem de SD no desenvolvimento de modelos de simulação computacional: pensar em termos de relações de causa e efeito, foco nas ligações de realimentação entre componentes do sistema e determinação dos limites apropriados para a definição do que deve ser incluído no sistema (ROBERTS, 1983).

No aspecto dos limites do sistema estudado, deve-se determinar qual o nível de influência dos fatores externos no sistema e quais interações deve-se modelar para compreendê-lo. Já o pensamento causal é a chave para a organização de idéias em um estudo de Dinâmica dos Sistemas.

Com os limites e as relações de causa e efeito do sistema determinados, devese estudar os laços de realimentação. Essas são as estruturas organizadoras ao redor das quais os modelos de SD são construídos, uma vez que esses laços modelam os mecanismos centrais que controlam as mudanças em sistemas reais.

Segundo BUFFA \& DYER (1977), os laços de realimentação são importantes para análises; eles são fechados através de uma seqüência de processos e podem envolver lapsos de tempo bastante longos. Além disso, na SD as relações entre os elementos do sistema podem ser descritas com certeza. Segundo LEGASTO et. al. 
(1980), o laço de realimentação é um caminho que conecta decisão, ação, nível (ou estado) do sistema e informação, com posterior retorno ao ponto de decisão. A FIGURA 22 mostra a estrutura básica dos laços de realimentação e a FIGURA 23 esboça um exemplo desse tipo de estrutura.

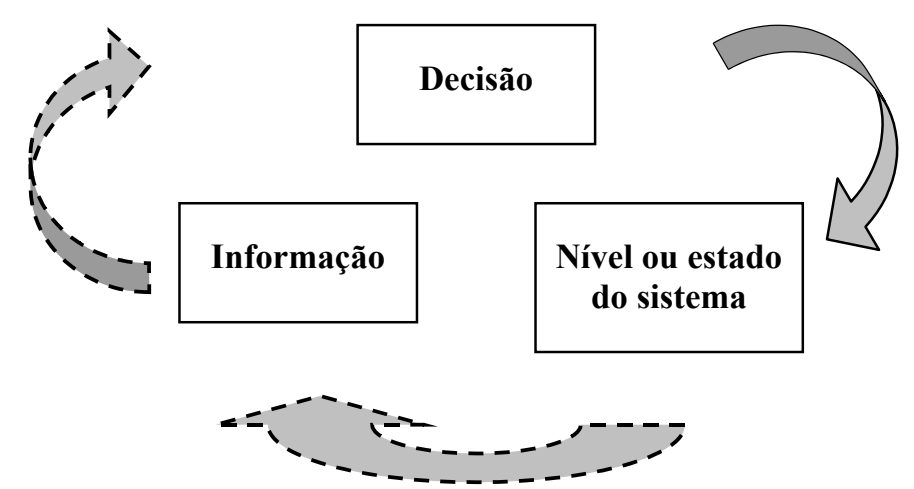

FIGURA 22 - Exemplo de estrutura de realimentação Fonte: LEGASTO et al.(1980)

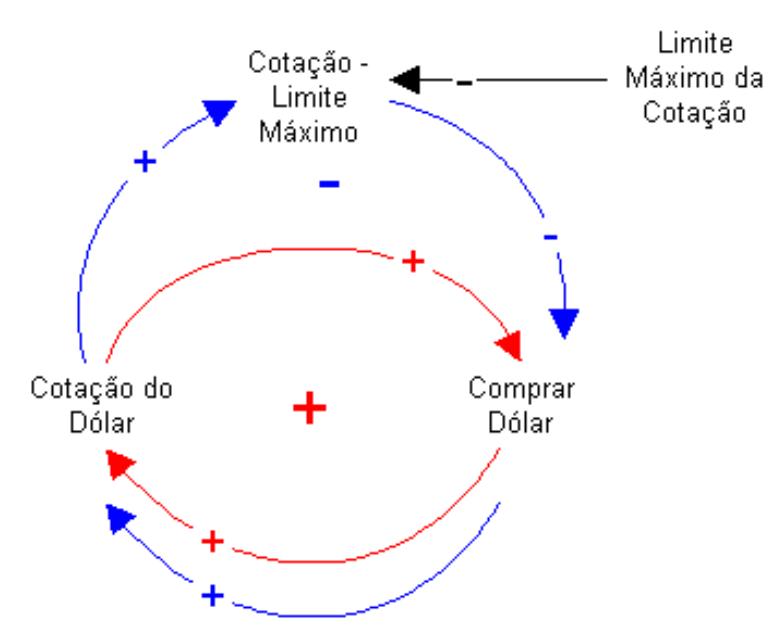

FIGURA 23 - Exemplo de estrutura de realimentação Fonte: VILLELA (2000)

A FIGURA 23 expressa o comportamento das pessoas e do mercado em uma "disparada" da cotação do dólar: as pessoas se sentem tentadas a comprar a moeda, tentando se antecipar a uma alta ainda mais acentuada. Quanto mais pessoas agem desta forma, mais a procura por dólar aumenta e, conseqüentemente, mais sobe a cotação. Neste caso, tem-se um efeito que reforça a decisão inicial de comprar dólar. 
Entretanto, após algum tempo de subida do dólar, as pessoas começam a se dar conta que a cotação cambial passou dos limites do razoável e passam a vender o dólar, aumentando a oferta e baixando a cotação (VILLELA, 2000).

Segundo LEGASTO et al.(1980), qualquer sistema é formado pela interconexão de laços de realimentação. Mas, em uma hierarquia inferior, cada laço contém uma subestrutura. Há dois tipos fundamentais de elementos variáveis com os quais os laços são formados, os níveis e as taxas.

As variáveis de nível (ou estado) representam as condições do sistema em qualquer instante de tempo. As variáveis de nível acumulam os resultados de ações dentro do sistema. No pacote de simulação STELLA, eles são representados pelo bloco Estoque. A computação de um novo valor de uma variável de nível envolve o seu valor anterior, as taxas que causam a mudança no nível e o lapso de tempo desde a última computação do nível. As variáveis de estado acumulam os fluxos descritos pelas variáveis de taxa. As variáveis de nível são as acumulações em um sistema. Os níveis acumulam a diferença entre as taxas de entrada e saída.

Por outro lado, as variáveis de taxa (ação) revelam a que velocidade os níveis estão mudando. Elas não determinam os valores presentes das variáveis de nível, e sim o formato (mudanças por unidade de tempo) destas. A computação do valor de uma variável de taxa é feita usando somente os valores das variáveis de nível e de constantes. As variáveis de ação não dependem de seu valor passado, do intervalo de tempo entre as computações ou de outras variáveis de taxa.

\subsubsection{Ferramentas computacionais}

Segundo ANDERSSON \& KARLSSON (2001), existem vários programas que se baseiam em Dinâmica Industrial, dentre os quais o DYNAMO PLUS e o STELLA/ithink, brevemente descritos a seguir.

\section{DYNAMO PLUS}

O DYNAMO (DYNAmic MOdelling) foi a primeira linguagem de simulação de $\mathrm{SD}$, e por um longo tempo a linguagem e o campo foram considerados sinônimos. Tornou-se disponível comercialmente no começo dos anos 60; inicialmente operando 
em um computador IBM 704, processava em torno de 1.500 variáveis (FORRESTER, 1961). Essa linguagem foi desenvolvida para permitir a implementação dos modelos de dinâmica industrial em computadores digitais.

O desenvolvimento do DYNAMO foi um passo significativo na utilização da $\mathrm{SD}$, devido ao fato da linguagem ter, ela própria, características que auxiliam a conceituação de modelos e simplificam a programação e execução de simulações (ANDERSEN \& RICHARDSON, 1980).

O DYNAMO PLUS permite a construção de modelos extremamente extensos, com uma variedade de características de programação sofisticadas. A programação começa pela digitação de equações, baseadas em diagramas previamente traçados. A ferramenta é complexa, mas tem um grande poder de programação.

O surgimento de outros pacotes de simulação, como o STELLA (High Performance System, 1997), difundiu a SD, pois possibilitou que modelos concebidos a partir dessa metodologia pudessem ser simulados em locais com menor disponibilidade de recursos computacionais. Além disso, esses pacotes proporcionam uma interface mais amigável, economia de tempo de modelagem, facilidade de uso etc.

\section{STELLA/ithink}

Introduzido originalmente para o computador Macintosh, em 1984, o programa Stella forneceu uma ferramenta com orientação gráfica para o desenvolvimento de modelos SD. O STELLA é usado para soluções educacionais, enquanto o ithink é voltado para a área de negócios. Devido às suas características poderosas e sua facilidade de uso, o STELLA/ithink é uma das ferramentas de modelagem de SD mais populares. Ele permite traçar diagramas de estoque e fluxo e mapear a estrutura do sistema, antes de se entrar com as equações. Mais detalhes podem ser adicionados, elementos podem ser agrupados em sub-modelos, e é possível analisar com mais detalhes partes específicas de modelos complexos. 


\section{CAPÍTULO 7 - Desenvolvimento das simulações}

Como mencionado anteriormente, parte deste trabalho consiste de uma pesquisa laboratorial. O objetivo da pesquisa é extrair conhecimentos através da observação da simulação de um sistema produtivo. Este capítulo apresenta uma descrição de todos os aspectos relacionados à pesquisa de simulação desenvolvida.

Os passos adotados foram extraídos de um estudo de simulação sugeridos por LAW \& KELTON (2000). Esses passos (enumerados a seguir e discutidos no capítulo 5) serão utilizados nas simulações contidas nesse trabalho:

1 Formulação do problema e planejamento do estudo

2 Coleta de dados e definição do modelo

3 Validação do modelo conceitual

4 Construção do programa computacional e verificação

5 Realização de execuções piloto

6 Validação do modelo programado

7 Projeto dos experimentos

8 Realização das execuções de simulação

9 Análise de resultados

10 Documentação e implementação

Escolheu-se o dimensionamento de um sistema de produção para análise através da simulação. Esse sistema será descrito com detalhes mais adiante.

No campo da produção, a simulação pode ser aplicada de diversas formas: para projeto e análise de sistemas de movimentação de materiais, de linhas de fabricação e montagem, de sistemas de armazenagem automatizados, etc. Nesses casos, a simulação permite avaliar sistemas de produção complexos pela análise da interação entre seus componentes (PEGDEN et al., 1995). 
Para atingir o objetivo de adquirir conhecimento a respeito do sistema de produção escolhido, este foi modelado no pacote de simulação STELLA. Depois, foram feitas alterações nos recursos, parâmetros, funções e interações do sistema, com o intuito de se testar os efeitos dessas variações no comportamento do modelo, cuja observação deve gerar conhecimento.

A vantagem de se examinar um sistema de produção através da simulação foi discutida na seção "estudo dos sistemas" do capítulo 4. De maneira sucinta, a utilização da simulação para o estudo do sistema justifica-se por benefícios como economia de tempo e de recursos físicos e financeiros.

Além disso, a simulação é bem aceita pelos operadores na área de produção; com as ferramentas atualmente disponíveis, a modelagem é facilmente entendida e os trabalhadores têm uma impressão real de controle e gerenciamento do modelo.

O computador foi usado para modelar o sistema em um pacote de simulação, gerar o comportamento no tempo das variáveis incluídas no modelo e manter o registro das medidas de desempenho.

\section{1 Formulação do problema e Planejamento do estudo}

Em primeiro lugar, deve-se definir o sistema a ser estudado. No caso desta pesquisa, o exemplo para as simulações refere-se a um sistema de fila de uma fábrica de componentes plásticos (EMSHOFF \& SISSON, 1970). Esse exemplo foi escolhido porque problemas de filas em produção são inerentes ao escopo deste trabalho e muito comuns em todas as organizações.

O problema de fila selecionado refere-se a um modelo monocanal multiestação (multifásico) de produto único (ver seção 4.3). São feitas algumas suposições a respeito desse modelo:

- o intervalo de tempo entre as chegadas de pedidos é um valor estocástico com distribuição de probabilidades conhecida. Essa suposição permite ao modelo ser mais fiel à realidade;

- a probabilidade de uma chegada durante um intervalo de tempo específico permanece constante e independente do número de chegadas anteriores e do tempo de espera; 
- cada pedido que a firma recebe deve passar por três processos antes de ser transformado no produto final (componentes plásticos). Esses processos são molde, corte e montagem;

- o tempo gasto por uma ordem em um processo é um valor estocástico com distribuição de probabilidade conhecida.

A oficina simulada tem três estações de processamento (ver FIGURA 24). $\mathrm{Na}$ primeira estação, a matéria-prima plástica é moldada no formato apropriado, usando matrizes especiais na máquina de moldes. Na segunda estação, as partes plásticas são separadas, aparadas e armazenadas. Na última estação, as partes são unidas no produto final. Todos os trabalhos passam através de cada um dos três processos. Como o tempo de processo varia, a fábrica não pode ser programada perfeitamente, e linhas de espera ou filas de trabalhos a serem processados se formam em frente às várias estações de processamento.

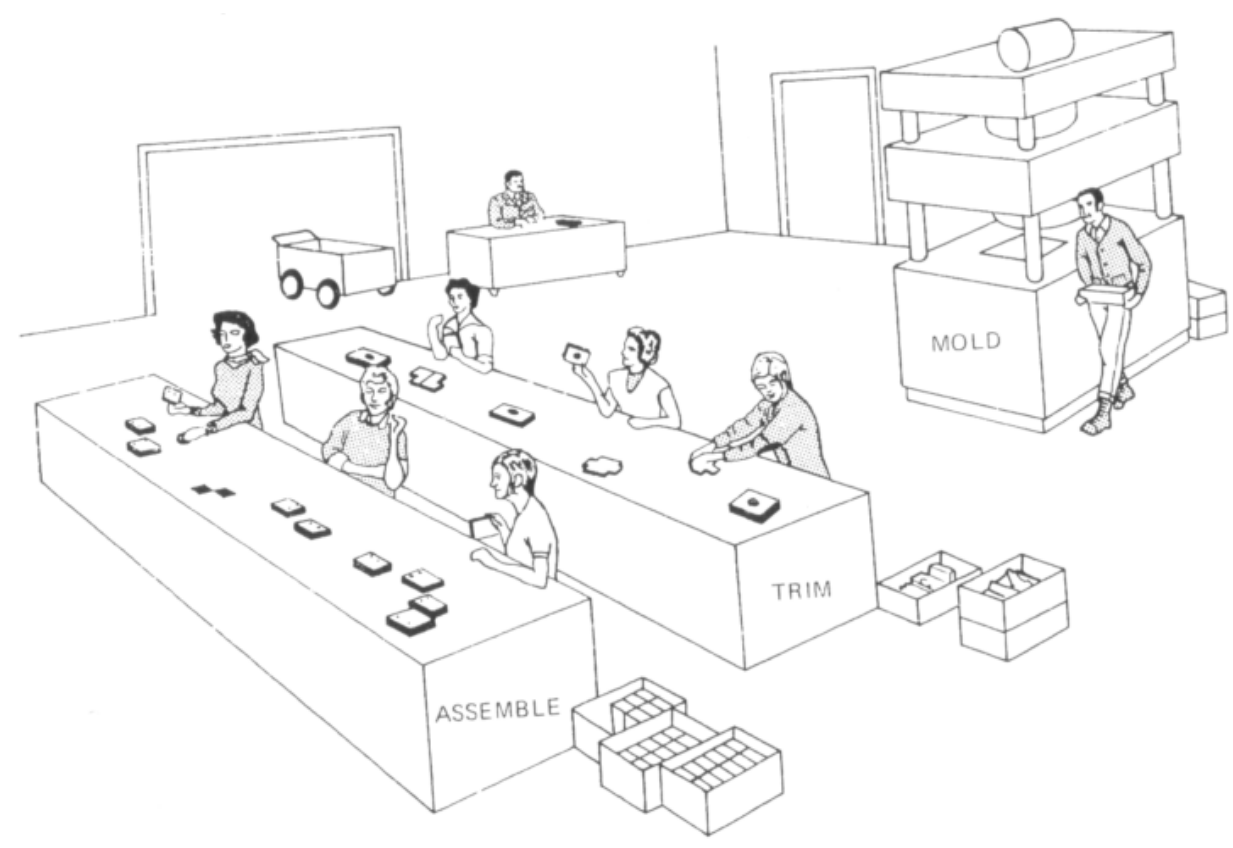

FIGURA 24 - A fábrica de componentes plásticos Fonte: EMSHOFF \& SISSON (1970)

Quando um trabalho chega, os materiais e matrizes necessários para sua confecção estão sempre disponíveis. O tempo médio de atendimento para cada 
estação de processamento é explicitado na TABELA 07; assume-se que esses tempos são exponencialmente distribuídos e dados em horas.

TABELA 07 - Tempo médio de atendimento dos processos

\begin{tabular}{c|c}
\hline Processo & $\begin{array}{c}\text { Tempo médio de processamento } \\
\text { (em horas) }\end{array}$ \\
\hline Molde & 4 \\
Corte & 3 \\
Montagem & 5 \\
\hline
\end{tabular}

Fonte: EMSHOFF \& SISSON (1970)

Segundo EMSHOFF \& SISSON (1970), esse problema é mais bem entendido usando-se uma representação do fluxo de trabalhos através da fábrica, como mostra a FIGURA 25.

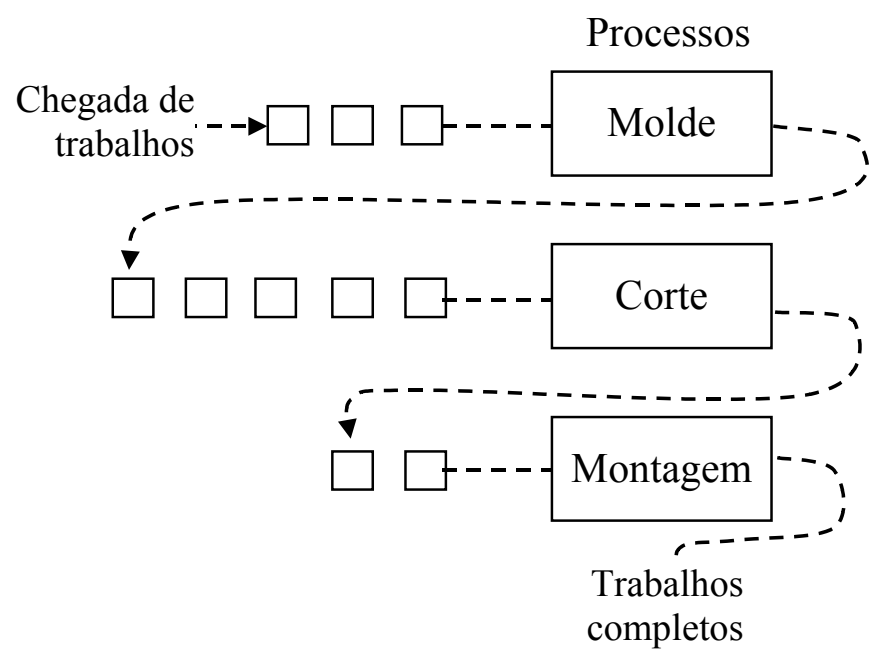

FIGURA 25 - Análise do fluxo da fábrica de plásticos

Fonte: EMSHOFF \& SISSON (1970)

Há muitos aspectos de operação da fábrica que são aqui desconsiderados. Por exemplo, não se distingue o tempo de preparação do tempo de execução na operação de modelagem, nem se considera o tempo de manutenção da máquina. Assume-se que esses e outros detalhes não são necessários para o desenvolvimento de um modelo apropriado para esse estudo.

Embora este modelo possa ser estendido com facilidade para incluir múltiplos produtos, múltiplos servidores, subsistemas etc., por simples questão de 
simplificação restringiu-se sua atuação à simulação de filas monocanal multiestação de um único produto.

O planejamento do estudo consiste na definição de alguns outros itens: objetivos do estudo, questões a serem respondidas, avaliadores de desempenho, configurações do sistema a ser modelado, programa de simulação, entre outros.

\subsubsection{Objetivo do estudo de simulação}

Para atingir seu objetivo, o sistema será estudado a partir da variação dos parâmetros de seu modelo, conforme descrito na TABELA 08.

TABELA 08 - Parâmetros estudados no modelo

\begin{tabular}{l|c|c}
\hline Parâmetros & \multicolumn{2}{|c}{ Variações } \\
\hline Tempo de processamento das estações (horas) & 4 & 2 \\
\hline Molde & 3 & 1,5 \\
\hline Corte & 5 & 2,5 \\
\hline Montagem & 1 & 2 \\
\hline Número de estações
\end{tabular}

O número de estações descreve a quantidade de estações de processamento utilizadas no modelo e o tempo médio de processamento refere-se ao valor da média escolhida para a distribuição de probabilidade adotada para o tempo de serviço (exponencial). Uma diminuição neste último valor simula a utilização de equipamentos mais rápidos e eficientes.

Da combinação desses parâmetros resultaram diferentes modelos da fábrica de plásticos a serem simulados. Apesar de todos eles terem sido realizados, apenas os mais significativos serão aqui mencionados (realização das execuções de simulação).

\subsubsection{Questões a serem respondidas}

As questões específicas a serem respondidas pelo estudo de simulação são:

- Número adequado de estações de processamento;

- Existência de gargalos;

- Tempo médio de processamento. 


\subsubsection{Configurações do sistema a ser modelado}

Neste trabalho, serão utilizados alguns termos relacionados à Teoria de Filas (ver seção 4.3). Seguem abaixo alguns termos básicos relacionados ao sistema simulado:

- Entidades (clientes): trabalhos (serviços); há apenas uma classe de trabalhos;

- Produto final: componentes plásticos;

- Capacidade da fila (linha de espera): refere-se ao número admissível de clientes na fila. Neste caso, a capacidade é infinita;

- Canal de atendimento: monocanal com três estações de processamento (molde, corte e montagem);

- Número de servidores (processos): durante as experimentações, variará entre um e dois para cada estação;

- Capacidade dos servidores: define o número de clientes sendo atendidos ao mesmo tempo. Nas simulações aqui realizadas, utilizou-se uma capacidade de dois clientes por estação;

- Estratégias de admissão: todos os clientes são admitidos no sistema;

- Chegada dos clientes: assume-se que os clientes chegam de acordo com uma distribuição de Poisson. Segundo SHAMBLIn \& STEVENS (1974), essa distribuição corresponde aos sistemas de filas para os quais a chegada de uma entidade independe da chegada de outra entidade.

- Prioridade ou Disciplina da fila: método de decidir qual o próximo cliente a ser atendido. Aqui, adotou-se o esquema para os quais quem chega primeiro é atendido primeiro;

- Tamanho da população: população admitida para o modelo é infinita. Isso porque, de acordo com SHAMBLIN \& STEVENS (1974), diz-se que uma população é infinita se a população potencial for bastante grande para significar que a chegada de um cliente não afetará significativamente a probabilidade de outra chegada; 
- Taxa de chegada: número de entidades atendidas por unidade de tempo. A taxa de chegada aqui adotada está aleatoriamente distribuída conforme a distribuição de Poisson;

- Taxa de atendimento (serviço): a taxa de atendimento segue uma distribuição de Poisson;

- Tempo entre chegadas: caracterizado por uma distribuição exponencial negativa.

- Tempo de atendimento: caracterizado por uma distribuição exponencial negativa.

Pode-se demonstrar que, quando os ritmos de chegada seguem uma distribuição de Poisson, o intervalo de tempo entre as chegadas segue uma distribuição exponencial negativa. Essa relação não é necessariamente satisfeita no caso de outras distribuições.

\subsubsection{Avaliadores de desempenho}

Os avaliadores ou medidas de desempenho serão utilizados para medir a eficácia de diferentes configurações do sistema; elas são estatísticas importantes, úteis na avaliação do sistema. São eles:

- Tempo máximo de processamento de um trabalho: maior número de horas empregadas para se terminar um trabalho;

- Tempo médio de processamento (ou tempo médio de fluxo): tempo médio medido desde a chegada de um cliente no sistema até seu processamento completar-se;

- Tamanho das filas: quantidade de trabalhos em espera dentro da fábrica;

- Número de elementos atendidos: quantidade de trabalhos que saíram do sistema de produção, isto é, componentes que foram processados por todas as estações.

A TABELA 09 mostrada a seguir será utilizada para a coleta das medidas de desempenho. 
TABELA 09 - Medidas de desempenho utilizadas

\begin{tabular}{c|c|c|c|c|c|c}
\hline \multirow{2}{*}{ Modelo } & Tempo médio de & Maior tempo de & \multicolumn{3}{|c|}{ Tamanho máximo das filas } & Elementos \\
\cline { 4 - 7 } & processamento & processamento & Molde & Corte & Montagem & Atendidos \\
\hline 1 & & & & & & \\
\hline 2 & & & & & & \\
\hline 3 & & & & & & \\
\hline 4 & & & & & & \\
\hline$\ldots$ & & & & & & \\
\hline
\end{tabular}

Qualquer que seja o problema atacado, é de grande importância que se determine medidas de desempenho adequadas. A escolha de tais medidas dependerá dos objetivos específicos do estudo.

Os valores das variáveis do modelo podem ser impressos no STELLA, tanto em forma tabular como sob a forma de gráficos, durante e após cada execução.

No item 7.11 serão mostrados os principais resultados conseguidos com a simulação.

\subsubsection{Recursos computacionais utilizados}

Utilizou-se o computador para gerar o comportamento no tempo de todas as variáveis incluídas no modelo de simulação. Ele também foi usado para manter o registro das medidas de desempenho na forma de tabelas e gráficos.

Geralmente, as ferramentas de simulação representam dispêndios consideráveis de recursos para empresas e escolas (recursos físicos, financeiros, de pessoal etc.). Assim, sua seleção adequada passa a ser um dos fatores-chave no sucesso dos projetos de simulação a serem desenvolvidos.

Em princípio, um modelo de simulação pode ser programado em qualquer ferramenta de simulação. Entretanto, devido a suas características técnicas (orientação em Dinâmica de Sistemas) e disponibilidade, foi escolhido o pacote de simulação STELLA (versão 5.0 para Windows).

Segundo HIGH PERFORMANCE SYSTEM (1997), esse pacote tem como requisitos mínimos computacionais: processador 386, 8 Megabytes de memória RAM, disco rígido com capacidade de armazenamento de 16 Megabytes e sistema operacional Microsoft Windows 3.1. 
No caso dessa pesquisa, foram utilizados os seguintes recursos computacionais: processador Pentium III de $650 \mathrm{MHz}, 128$ Megabytes de memória RAM, disco rígido com capacidade de armazenamento de 10 Gigabytes e sistema operacional Microsoft Windows ME.

\subsubsection{Estrutura de tempo para o estudo e recursos requeridos}

O modelo é capaz de simular durante um tempo predeterminado, dividido em intervalos de tempo regulares (dt). A duração escolhida para as execuções foi de 17528 horas (que correspondem a dois anos ininterruptos de trabalho) e o dt escolhido foi de 1 hora.

\section{2 Coleta de dados e Definição do modelo}

O sistema de fila simulado foi extraído do livro de EMSHOFF \& SISSON (1970), sendo, portanto, um exemplo fictício. Assim, não há coleta de dados empíricos diretamente do sistema, e os dados relativos ao sistema estudado referem-se àqueles da bibliografia citada. Valores resultantes das distribuições de probabilidade teóricas serão utilizados como entradas no modelo.

Ao mesmo tempo em que ocorre a coleta de dados, o sistema sob investigação é abstraído através de um modelo conceitual. Nesta etapa, especificaram-se os componentes, variáveis, parâmetros e relações funcionais do modelo. Além disso, examinou-se a realidade para incluir dinâmicas de realimentação importantes, fatores externos são trazidos para o interior dos limites do modelo. Ligações com outras funções na organização não foram consideradas.

Para a construção do modelo conceitual (assim como do modelo de simulação) utilizou-se o método de se iniciar com um modelo simples e depois aumentar sua complexidade progressivamente. Nesse item, houve o cuidado de se garantir um nível apropriado de complexidade do modelo, pois modelos muito complicados apenas acrescentam esforço computacional, enquanto que modelos muito simples não representam adequadamente o sistema. 


\subsection{Validação do modelo conceitual}

A validação do modelo foi realizada através do exame estruturado do modelo conceitual e através de consulta a especialistas. Aqui, objetivou-se garantir a veracidade e abrangência das suposições do modelo, tornando menor a probabilidade de erros.

Os especialistas consultados são pesquisadores do Laboratório de Dinâmica Industrial (LDI) do Departamento de Engenharia de Produção da Universidade Federal de São Carlos. O LDI desenvolve e reproduz simulações para estudo do comportamento de sistemas dinâmicos e é direcionado para a capacitação de recursos humanos na área; foi criado com o objetivo capacitar profissionais nas metodologias de Dinâmica de Sistemas, Pensamento Sistêmico e Organização de Aprendizagem para o entendimento de sistemas complexos e dinâmicos.

As principais sugestões estavam relacionadas à forma de representar o sistema de produção exemplo: fluxo do sistema, existência de um laço de alimentação, estações de processamento etc.

\section{4 Construção do modelo de simulação e verificação}

Este passo é dividido em duas atividades: confecção do modelo de simulação em uma ferramenta de simulação (STELLA) e sua verificação (eliminação de erros).

\subsubsection{Programação do modelo no pacote de simulação STELLA}

A modelagem do sistema no pacote STELLA iniciou-se com modelos simples que, progressivamente, foram se tornando complexos.

Durante esta fase, foram desenvolvidas várias versões para o modelo que se desejava encontrar. A seguir, serão apresentadas algumas dessas versões preliminares, as quais deram origem ao modelo final, este sim, usado nas execuções de simulação. O modelo final será mostrado por completo (todas as camadas de modelagem), mas na explicação dos modelos intermediários será exposta somente a camada de construção do modelo.

A FIGURA 26 apresenta uma das primeiras versões do modelo. Nela, já se observa a modelagem dos fornos (estações de processamento) e filas que os 
antecedem. Esse modelo apresentou o inconveniente de não inferir o tempo de processamento, devido a problemas na estrutura. Além disso, ele não apresenta a estrutura de realimentação; a taxa de chegada é determinada apenas pela distribuição de Poisson.

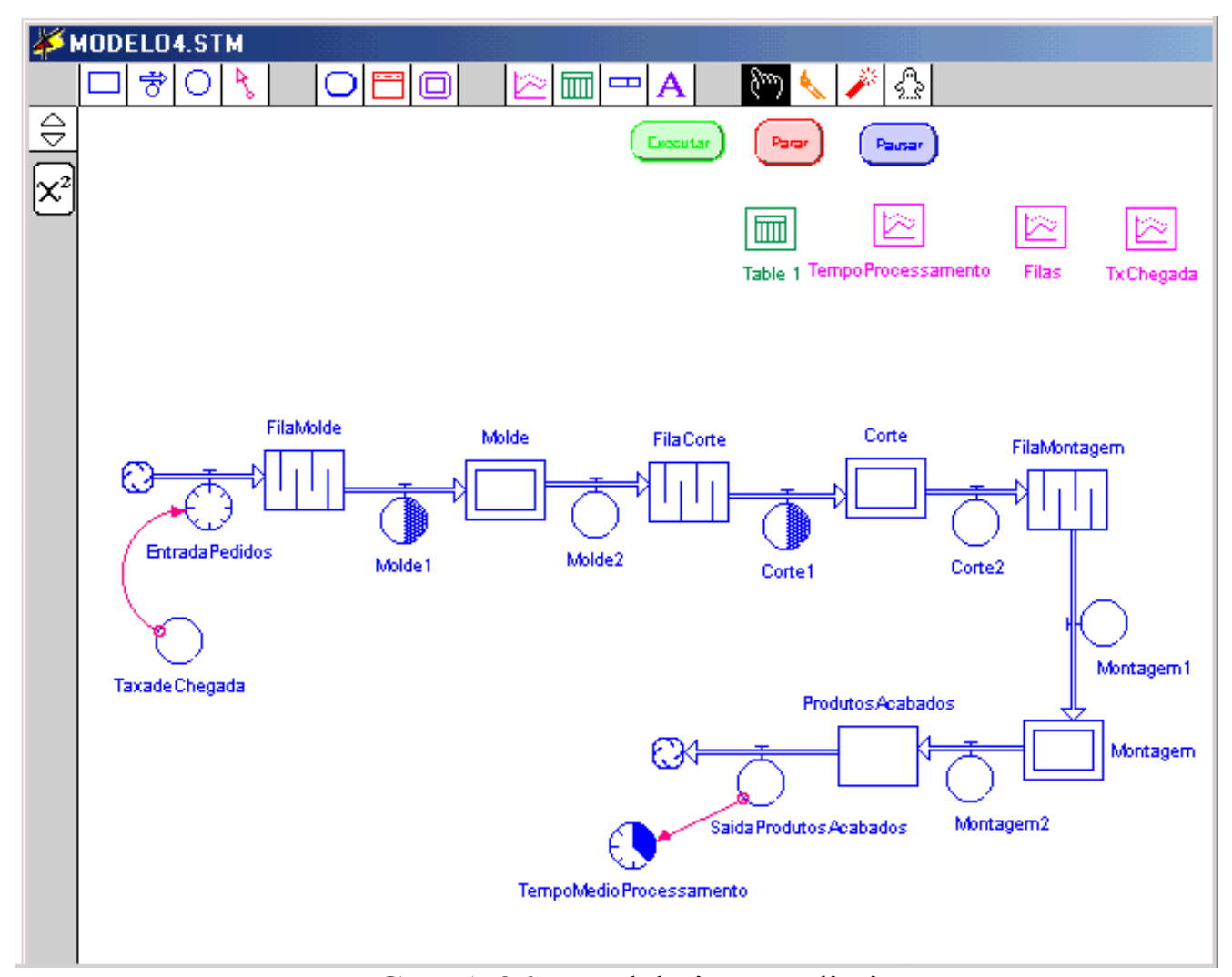

FIGURA 26 - Modelo intermediário

A FIGURA 27 mostra a tentativa de modelagem do laço de realimentação. Nessa versão, o tempo de processamento foi adequadamente modelado, porém a equação referente ao laço não estava de acordo com o que se desejava modelar.

O modelo final, usado para todas as simulações, é mostrado nas FIGURAS 28 e 29. Na FIGURA 28 apresenta-se a modelagem da camada superior, aqui chamada de painel de controle. Esta camada, como dito anteriormente, é usada para a construção de um mapa dos setores que compõem o modelo; seu objetivo é facilitar a navegação pelo usuário. A camada superior é constituída de facilitadores de navegação e de modos de observação do funcionamento do modelo. Os facilitadores de navegação utilizados foram os botões de navegação (ex. botão que leva ao modelo de simulação) e os botões de funções do programa (executar, parar, salvar, configurar 
etc.). Os modos de observação são gráficos e tabelas que podem ser visualizados enquanto ocorre a simulação. Além disso, há um quadro indicador das principais configurações do sistema e um esquema com os setores modelados (chegadas, setor de molde, setor de corte e setor de montagem).

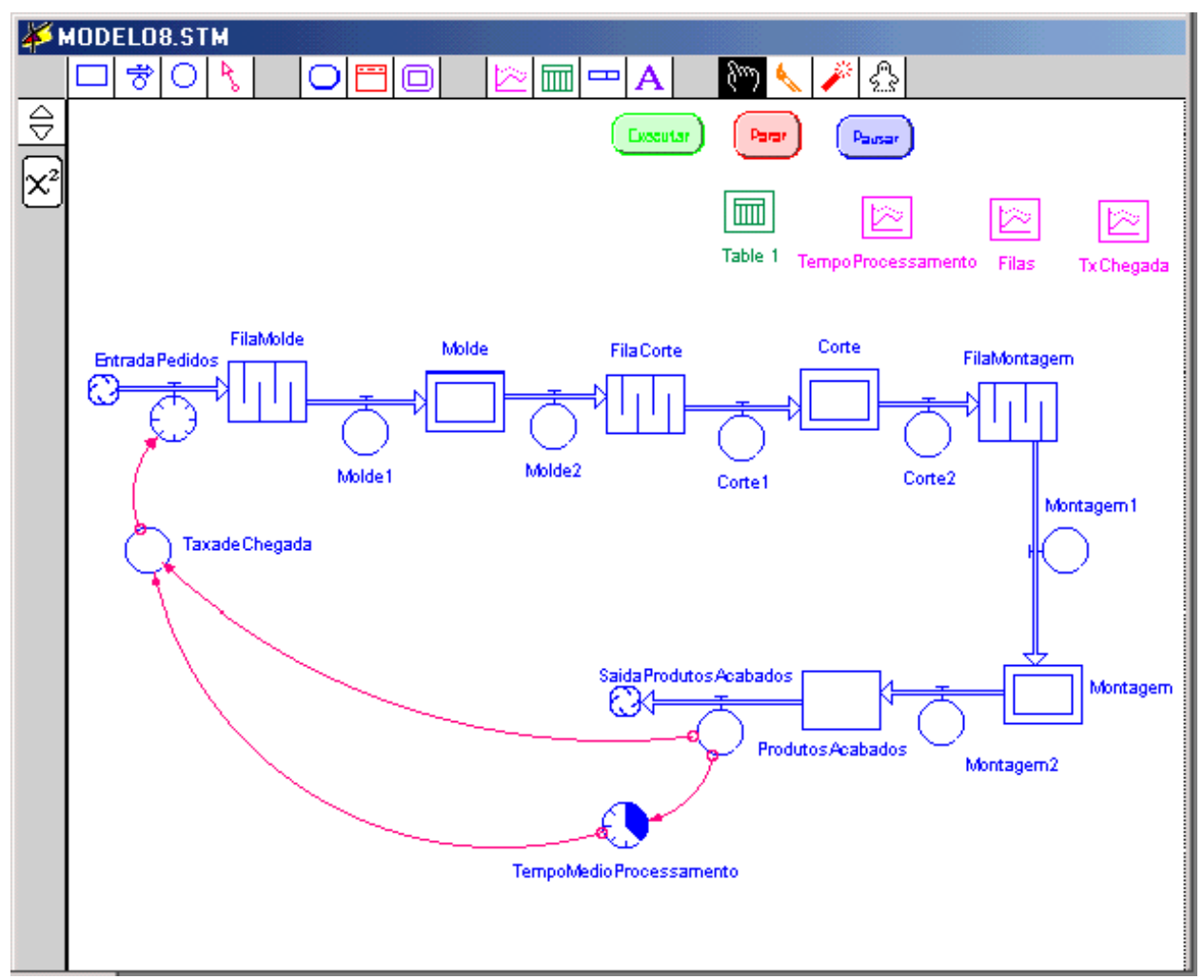

FIGURA 27 - Modelo intermediário 


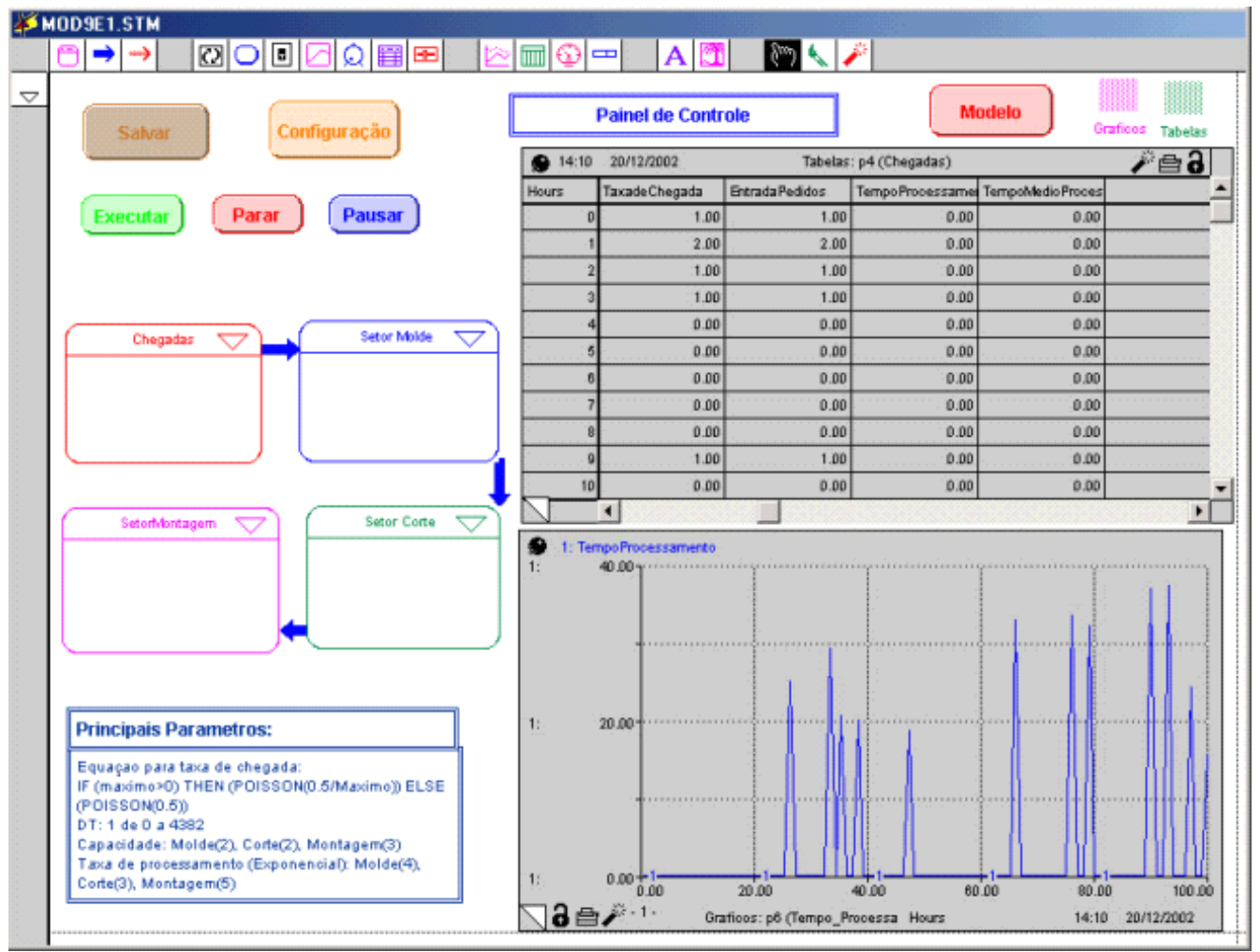

FIGURA 28 - Camada superior do modelo final

Na FIGURA 29, por sua vez, observa-se o modelo de simulação em si. Nele, há quatro setores simulados: chegadas, molde, corte e montagem. No setor "chegadas", modelou-se a entrada dos trabalhos na fábrica. Com base na literatura e em modelos similares, determinou-se que a distribuição que melhor descreve as chegadas é a de Poisson. Também foi modelado o laço de realimentação do sistema. Esse laço baseia-se no fato de que uma empresa rejeita pedidos caso haja um excesso de produtos no sistema (principalmente nos estoques em processo). Assim, a taxa de chegadas é influenciada pelo tamanho das filas; quanto maior o tamanho das filas, menor a taxa de chegadas. 


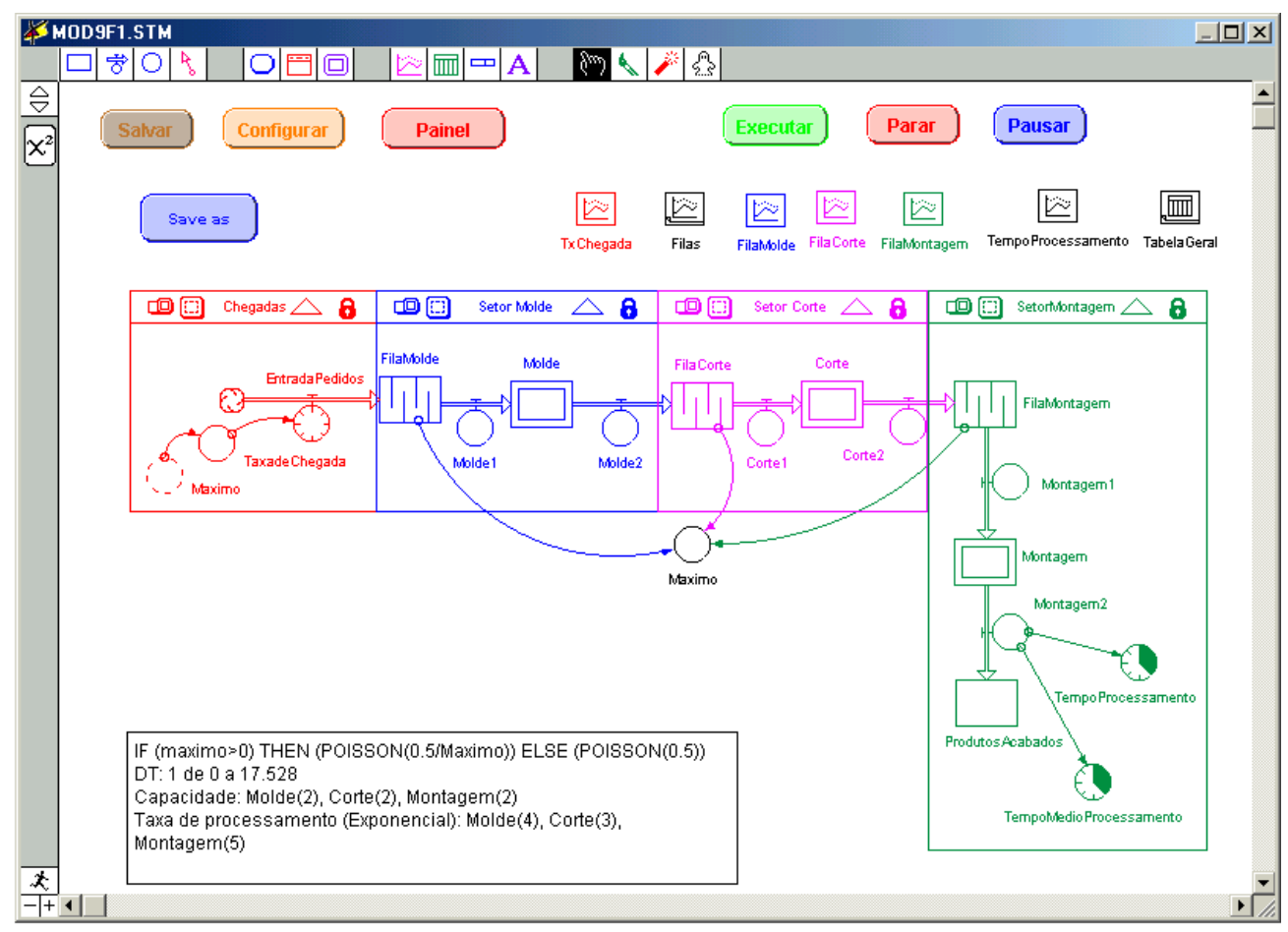

FIGURA 29 - Camada de construção do modelo final

Para modelar a chegada de trabalhos, foram utilizados os blocos de fluxo “conversor" e "conector". O bloco de fluxo contém um indicador para o início da contagem de tempo (para o cálculo do tempo de processamento e tempo médio de processamento); essa contagem é iniciada quando a peça entra no sistema e termina quando ela passa pelo fluxo "saída de produtos acabados" do setor de montagem.

Para que a taxa de chegadas fosse influenciada pelo tamanho das filas, foram utilizadas uma regra de decisão e uma função. A função "máximo" (inserida no conversor "Maximo") determina o tamanho máximo entre todas as filas. Esse valor é enviado para o conversor "Taxa de Chegadas", onde há uma equação que o utiliza para determinar a próxima taxa de chegada. A regra de decisão é: IF (Maximo $>0$ ) THEN (POISSON(0.5/Maximo) ELSE (POISSON (0.5)). Dessa maneira, sempre que o tamanho de todas as filas é zero, o simulador utiliza a taxa de chegada Poisson com média igual a 0.5 ; caso contrário utilizará a equação apresentada acima, fazendo com que a média da Poisson seja a equação 0.5/Maximo.

Os setores molde, corte e montagem contêm as estações de processamento (representadas pelos fornos) e suas respectivas filas. Essas filas fornecem a informação (número de trabalhos em fila) requerida pela função "máximo". Todas as 
filas têm capacidade infinita. Os fornos têm todos a mesma capacidade de atendimento simultâneo (duas unidades) e esperam o tempo necessário para atingir a sua capacidade máxima e começar a funcionar; além disso, possuem a distribuição exponencial negativa como taxa de atendimento. Todos os tempos de atendimento seguem a mesma distribuição, porém com tempos médios de processamento diferentes. As diferenças nos tempos de processamento são as principais fontes de gargalos no sistema.

O setor de montagem contém ainda os blocos de saída dos trabalhos; nessa parte da montagem foram alocados alguns medidores de desempenho: blocos (fluxos, estoques, conversores e conectores), os quais determinam os tempos de processamento médio e unitário.

Este modelo também apresenta botões de navegação e função do programa (salvar, configurar etc.); além disso, possui botões de atalho para tabelas e gráficos e um quadro com informações sobre os parâmetros do modelo simulado. Todos os botões estão representados na parte superior da área de trabalho.

A partir desse modelo, sessenta e quatro simulações foram realizadas, com variação na quantidade de estações de processamento (fornos) e no tempo médio de serviço. Os principais resultados obtidos serão discutidos na seção 7.11.

\subsubsection{Verificação do programa de simulação computacional}

Aqui, verificou-se se o programa era adequado para o modelo e se ele funcionava adequadamente. O propósito dessa verificação é assegurar que o modelo conceitual seja refletido adequadamente na representação computacional. BANKS et al. (1996) apresentam algumas sugestões que podem ser usadas no processo de verificação. Entre os tipos de verificação citados, utilizou-se:

- Representação no STELLA verificada por especialistas da área;

- Representação examinada através de animação, uma vez que ela torna mais fácil a visualização de erros, pois possibilita a comparação do funcionamento do modelo com o do sistema real;

- Exame das saídas do modelo, para verificar se elas são razoáveis para os diferentes tipos de parâmetros de entrada;

- Exame dos parâmetros de entrada utilizados durante a simulação, para se ter certeza de que esses não foram mudados inadvertidamente; 
- Definição precisa de cada variável usada e descrição geral da proposta de cada seção principal do modelo;

- Utilização de interface gráfica (tabelas, gráficos, animação etc.) para avaliar se o comportamento das variáveis estava correto.

\subsection{Realização de execuções piloto}

Foram realizadas diversas experimentações no modelo de simulação computacional verificado no item anterior, com o objetivo de fornecer dados para a validação do modelo programado.

\section{6 Validação do modelo programado}

A validação do modelo programado muitas vezes é realizada comparando-se os dados obtidos no modelo com os dados do sistema. Essa técnica não pôde ser usada neste trabalho, visto que o sistema simulado é fictício.

Utilizaram-se, então, algumas técnicas sugeridas por LAW \& KELTON (2000): coleta de informações e dados de alta qualidade no sistema, manutenção de um documento de suposições e desempenho para validação da saída do modelo de simulação.

\subsubsection{Coleta de informações e dados de alta qualidade no sistema}

Refere-se à coleta de toda informação existente sobre o sistema. Isso foi realizado por meio da comunicação com especialistas em simulação e no pacote de simulação anteriormente citados, da análise da teoria existente e da intuição do modelador.

\subsubsection{Validação da saída do modelo de simulação}

Pode ser feita de duas formas: pela comparação das saídas do modelo e do sistema e pela análise de especialistas. Como não há um sistema real para comparação, empregou-se mais uma vez a análise de especialistas para se determinar se os dados de saída eram coerentes com o sistema modelado. 
Novamente, os especialistas do LDI foram consultados. Esses especialistas foram escolhidos devido a sua larga experiência com o programa de simulação e com o processo de simulação em si.

Mais uma vez a entrevista realizada foi não-estruturada, a qual, devido ao seu tempo e característica, não pôde ser documentada. Sua duração foi de seis horas, com análises de modelos, gráficos, tabelas, equações, laço de realimentação entre outros.

Algumas das principais sugestões estavam relacionadas à:

- representação do laço de realimentação, particularmente a determinação da equação que materializa a realimentação do sistema;

- estabelecimento do critério de aceitação de pedidos conforme o tamanho das filas;

- representação das estações de processamento através do bloco forno com um bloco fila colocado anteriormente;

- aparência do programa em relação à formatação dos blocos (cores, tipo de letra etc.), à colocação de gráficos e tabelas, utilização de botões de atalhos etc.

\section{7 Projeto dos experimentos}

Nesta etapa, definiu-se o número de simulações realizadas a partir dos parâmetros a serem variados na simulação. Tais parâmetros foram: tempo de processamento e o número de estações de produção (molde, corte e montagem). A combinação desses fatores resultou em sessenta e quatro simulações cumpridas. A lista completa dos modelos e seus parâmetros encontram-se em anexo (Anexo 01).

Além disso, determinou-se como condição inicial da simulação um sistema de filas vazio (sem nenhum cliente).

\subsection{Execuções das simulações}

Tabelas e gráficos foram empregados para reunir os dados resultantes das simulações. Esses dados são utilizados na seção 7.11 . 
À medida que se executa a simulação, os usuários podem observar, através de gráficos e tabelas, o comportamento das principais variáveis do sistema. Durante o exercício, medidas de desempenho são calculadas (e listadas em tabelas) a partir dos dados observados.

\subsection{Análise de resultados}

Através da construção e da execução do modelo de simulação, pode-se também adquirir conhecimentos sobre o pacote de simulação STELLA, tais como:

- É fácil de entender e modelar;

- Possui flexibilidade de modelagem;

- Baseia-se na perspectiva de processos (blocos padronizados);

- Permite visualização do equacionamento do modelo (linhas de comando);

- Tem pouca interface com outros programas;

- Gerador de relatórios pouco eficiente;

- Possui geradores de variáveis aleatórias;

- Dados estão disponíveis para todas as entidades;

- Coleta das saídas realizadas de uma maneira organizada;

- Boa interface com o usuário.

Com relação à interface com outros programas, a dificuldade reside na impossibilidade de se realizar um intercâmbio de dados. Caso haja a necessidade de transferência de informações, essa deve ser feita manualmente, o que muitas vezes é ineficiente devido à complexidade dos dados e gráficos.

Já o gerador de relatórios seria mais eficiente se: gerasse gráficos mais detalhados e com melhor definição; permitisse a geração de relatórios em arquivo texto e a utilização de teclas de atalho (copiar e colar).

Os testes aqui realizados objetivaram verificar como se adquire conhecimento através da realização de simulações a respeito do sistema que se deseja estudar. Foi realizado um total de sessenta e quatro simulações, cada uma das quais apresentando uma configuração distinta para os parâmetros. A TABELA 10 traz os resultados obtidos para oito dos casos testados; o restante apresenta um padrão de 
comportamento similar, sendo por isso aqui omitido. A tabela completa, com todas as situações pesquisadas, é apresentada nos anexos.

A primeira, e mais evidente, conclusão que se pode tirar é que o critério para aceitação de novas encomendas, baseado no tamanho das filas, faz com que o número de elementos esperando em qualquer uma das três filas nunca atinja valores muito elevados (no caso aqui estudado, a maior fila observada possuía treze elementos em espera, como se pode observar na tabela). Isto indica que o critério utilizado é eficiente no propósito de manter as filas sob controle.

TABELA 10 - Resultados dos testes

\begin{tabular}{c|c|c|c|c|c|c}
\hline \multirow{2}{*}{ Modelo } & \multirow{2}{*}{$\begin{array}{c}\text { Tempo médio de } \\
\text { processamento } \\
\text { (horas) }\end{array}$} & \multirow{2}{*}{$\begin{array}{c}\text { Maior tempo de } \\
\text { processamento } \\
\text { (horas) }\end{array}$} & \multicolumn{3}{|c|}{$\begin{array}{c}\text { Tamanho máximo das } \\
\text { filas }\end{array}$} & \multirow{2}{*}{$\begin{array}{c}\text { Elementos } \\
\text { Atendidos }\end{array}$} \\
\cline { 4 - 7 } & & Molde & Corte & Montagem & \\
\hline $\mathbf{1}$ & 24,59 & 67,00 & 9 & 8 & 10 & 4660,00 \\
\hline $\mathbf{2}$ & 24,46 & 77,00 & 13 & 10 & 10 & 6614,00 \\
\hline $\mathbf{3}$ & 23,47 & 77,00 & 8 & 4 & 12 & 4838,00 \\
\hline $\mathbf{4}$ & 18,86 & 68,00 & 7 & 6 & 8 & 6042,00 \\
\hline $\mathbf{5}$ & 24,91 & 90,00 & 6 & 8 & 12 & 4850,00 \\
\hline $\mathbf{6}$ & 18,66 & 62,50 & 6 & 10 & 8 & 6672,00 \\
\hline $\mathbf{7}$ & 24,01 & 92,00 & 6 & 6 & 12 & 5092,00 \\
\hline $\mathbf{8}$ & 16,75 & 54,50 & 6 & 6 & 8 & 7284,00 \\
$\mathbf{. . .}$ & $\mathbf{\ldots}$ & $\ldots$ & $\ldots$ & $\ldots$ & $\ldots$ & $\ldots$ \\
\hline
\end{tabular}

Um segundo ponto a ser analisado é o número de elementos atendidos pelo sistema; o tamanho das filas não é aqui um fator preponderante, pois, como visto anteriormente, seu tamanho é mantido sob controle em qualquer situação, mesmo que isso implique numa drástica redução do número de elementos aceitos no sistema. Assim, em casos onde a demanda é muito elevada, pode ser interessante aumentar a capacidade de atendimento do sistema, respeitados os limites impostos para os investimentos e pelo espaço físico.

Duas maneiras de se aumentar a capacidade de atendimento do sistema foram testadas: aumentando-se o número de estações de atendimento ou diminuindo-se o tempo de processamento de cada estação (o que pode ser feito pela aquisição de máquinas mais modernas, por exemplo). Nos testes, observou-se que ambas as soluções são equivalentes; por exemplo, dobrar o número de estações produz 
aproximadamente o mesmo efeito de se diminuir pela metade seu tempo de processamento.

Pode-se observar na TABELA 10 que o aumento da capacidade de atendimento surtiu mais efeito quando este foi aplicado aos pontos de gargalo, ou seja, nos locais mais diretamente responsáveis pelas limitações do sistema. Esse é o caso, no sistema estudado, da etapa de montagem. Contudo, quando se adiciona uma estação apenas a esta etapa, transfere-se o gargalo para outro ponto do sistema, o qual será menos restritivo, porém ainda limitará a capacidade de atendimento. Tal situação é ilustrada pela configuração número dois da TABELA 10, onde se pode notar que houve um aumento considerável, em relação à primeira configuração, no número de peças processadas.

Se houver o desejo de se aumentar ainda mais a capacidade do sistema, devese tomar o novo ponto restritivo e acrescentar uma estação. Este é o caso observado na situação seis, onde se adicionou uma estação extra à etapa de molde, além daquela já acrescentada à etapa de montagem. Novamente, observa-se um aumento na capacidade e um novo deslocamento do gargalo. A situação oito revela o comportamento obtido ao se acrescentar estações extras a todas as três etapas do sistema.

Nas situações em que se adicionou uma nova estação a pontos que não os de gargalo, analisou-se duas situações distintas. No primeiro caso, em que a nova estação foi adicionada em uma etapa posterior àquela correspondente ao gargalo, não houve aumento da capacidade do sistema. Isto se deve ao fato de que, como o fator limitante está localizado em um ponto anterior à nova estação, não haverá um incremento no número de pedidos atendidos, e sim um aumento na capacidade ociosa do sistema, causando prejuízos desnecessários.

No segundo caso, onde a nova estação foi alocada em um ponto anterior àquele onde está localizado o gargalo, também não houve uma variação significativa no número de pedidos atendidos, uma vez que é o ponto de gargalo que age como limitador, a exemplo do que ocorre no caso anterior. Contudo, esta é uma situação mais complexa e potencialmente mais prejudicial à empresa; o ponto de gargalo, antes já sobrecarregado, terá agora que lidar com um número ainda maior de peças enviadas pelas etapas anteriores. Como resultado, a fila crescerá rapidamente e, 
como o critério para aceitação de novos pedidos é o tamanho máximo das filas presentes no sistema, a taxa de aceitação diminuirá de maneira acentuada. Haverá, então, uma forte flutuação na taxa de pedidos aceitos, o que não é desejável numa linha de produção, acarretando numa queda na produtividade, perda de clientes e, conseqüentemente, em prejuízos para a empresa. Tal fenômeno não pôde ser observado nos resultados obtidos para as simulações realizadas neste trabalho, pois o modelo aqui implementado é muito simples e de caráter meramente ilustrativo; modelos mais completos devem levar em conta fatores como produtividade, capacidade de planejamento, comportamento dos clientes, entre outros, a fim de que se tenha uma visão confiável do comportamento da organização frente às possíveis conjunturas encontradas na prática. Quanto mais completo e fidedigno o modelo, maior e mais confiável a aquisição de conhecimento.

Pode-se concluir então que as ações para aumento da capacidade do sistema devem ser sempre aplicadas aos pontos de restrição, e que o procedimento deve ser repetido até que se atinja a capacidade e tempo de processamento desejados, ou até que se atinja os limites de recursos financeiros e de espaço.

Nos testes preliminares, investigou-se também o papel da capacidade de atendimento simultâneo de cada estação; observou-se que sua influência no desempenho global do sistema não é muito elevada, de modo que seu estudo foi feito de forma limitada. Ao final, decidiu-se fixar seu valor em 2 para todas as estações.

Quanto ao tempo médio de processamento, verificou-se que este será tanto menor quanto melhor for o equilíbrio entre as diferentes etapas do processo. Numa situação ideal, conforme cada elemento vencesse determinada etapa, ele já deveria encontrar a próxima estação livre que, por sua vez, deveria ter acabado de atender outro elemento, de maneira a tornar mínimo seu tempo ocioso. Como tal situação, na prática, é impossível, deve-se encontrar o melhor equilíbrio possível entre cada uma das etapas. A melhor maneira de se atingir esse equilíbrio é manipular o número e a eficiência das estações até que se atinja o desempenho desejado.

No caso do estudo aqui realizado, a melhor situação verificou-se quando todas as etapas receberam uma estação adicional. É importante observar que, no caso aqui implementado, o sistema recebe tantos elementos quanto possível, ou seja, não há limites de demanda, de maneira que não haverá momentos de ociosidade. Em 
outras palavras, sempre haverá elementos suficientes para preencher toda a capacidade do sistema, de maneira que este nunca ficará ocioso. Contudo, em situações reais, quase sempre há um limite de demanda, de maneira que se deve evitar sobredimensionar o sistema, o que causaria grandes períodos de ociosidade e, como conseqüência, prejuízos.

Com relação ao tempo máximo de processamento, ou seja, o tempo máximo que determinado elemento ficará no sistema, pode-se observar que este está intimamente ligado ao comportamento do tempo médio de processamento. Contudo, os componentes aleatórios do sistema podem fazer com que haja discrepâncias entre os dois valores; por exemplo, é possível que em determinado momento uma grande quantidade de elementos adentrem o sistema e, nesse caso, haverá um congestionamento que acarretará no aumento do tempo de processamento de algumas das peças. Tal aumento será absorvido quando do cálculo da média dos tempos de processamento, porém o valor de pico se tornará irremediavelmente elevado. Assim, esta medida só é interessante quando ela for analisada em conjunto com outros parâmetros de desempenho, de maneira a se ter uma visão global do sistema.

As conclusões e observações aqui levantadas respondem por apenas uma pequena parte da análise que se poderia fazer a respeito do sistema; considerando-se que o caso aqui abordado é muito simples, pode-se concluir que a simulação oferece uma diversidade de meios e ferramentas para análise de cada ponto crítico encontrado em sistemas reais. O estudo aqui realizado buscou apenas mostrar o caminho a ser trilhado até que conclusões consistentes e importantes possam ser tiradas.

É importante observar ainda que cada caso possui particularidades que muitas vezes são imponderáveis, mas que, ao aliar-se o conhecimento pessoal do corpo técnico com o conhecimento adquirido por meio da simulação, tais peculiaridades podem ser desvendadas e abordadas de uma maneira sistemática e cuidadosa, tornando possível a solução de problemas antes considerados intratáveis. A própria extração de dados relevantes em meio a um extenso conjunto de dados é uma valiosa fonte de conhecimento, pois, em última análise, isso exigirá um esforço por parte do 
usuário ou analista para entender o funcionamento de sua organização e quais variáveis influenciarão de maneira significativa seu desempenho no futuro.

\section{10 Documentação e implementação}

Os dois últimos passos de um estudo de simulação são a documentação e a implementação. O primeiro refere-se à sua documentação, bem como dos resultados obtidos. Neste estudo, a documentação do desenvolvimento dos passos da simulação foi feita em relatórios parciais e em um relatório final (aqui descrito). Além disso, os modelos, em si, são registros do desenvolvimento das simulações.

Com relação à implementação do projeto de simulação, nota-se que suas principais restrições e condicionantes relacionam-se, geralmente, a aspectos ambientais, humanos, políticos e/ou computacionais. Por isso, há uma grande vantagem em se envolver gerentes e funcionários, ligados ao sistema modelado, na confecção e execução do estudo de simulação.

\section{11 Considerações sobre a aquisição do conhecimento}

Os principais conhecimentos adquiridos sobre o sistema foram:

- O critério de aceitação de novas encomendas, baseado no tamanho das filas, faz com que o número de elementos esperando em qualquer uma das três filas nunca atinja valores muito elevados.

- O aumento da capacidade de atendimento surtiu mais efeito quando este foi aplicado aos pontos de gargalo, ou seja, nos locais mais diretamente responsáveis pelas limitações do sistema. O principal gargalo do sistema é a montagem, isto se deve ao fato dessa estação ter o maior tempo de processamento. Contudo, quando se adiciona uma estação apenas a esta etapa, transfere-se o gargalo para outro ponto do sistema (estação com o maior tempo de processamento), que será menos restritivo, porém ainda limitará a capacidade de atendimento. 
- A ampliação da capacidade de uma estação que não é gargalo causa ociosidade a esta estação, além disso, faz aumentar a quantidade de clientes na fila e, conseqüentemente, crescer o tempo de processamento dos trabalhos.

- As duas maneiras de se aumentar a capacidade de atendimento do sistema (aumento do número de estações de atendimento ou diminuição do tempo de processamento de cada estação; o que pode ser feito pela aquisição de máquinas mais modernas, por exemplo) levam a soluções equivalentes; dobrar o número de estações produz aproximadamente o mesmo efeito de se diminuir pela metade seu tempo de processamento.

- As ações para aumento da capacidade do sistema devem ser sempre aplicadas aos pontos de restrição, e que o procedimento deve ser repetido até que se atinja a capacidade e tempo de processamento desejados, ou até que se atinja os limites de recursos financeiros e de espaço físico.

- Quanto ao tempo médio de processamento, verificou-se que este será tanto menor quanto melhor for o equilíbrio entre as diferentes etapas do processo. A melhor maneira de se atingir esse equilíbrio é manipular o número e a eficiência das estações até que se atinja o desempenho desejado. No caso do sistema estudado, a melhor situação verificou-se quando todas as etapas receberam uma estação adicional.

É importante observar que cada pessoa, ao estudar o sistema e utilizar seu conhecimento e visão pessoal, pode retirar das simulações conhecimentos diferentes. Por essa razão é aconselhável que mais de uma pessoa realize os estudos de simulação. 


\section{CONCLUSÃO}

As organizações vêm enfrentando uma competitividade crescente, devido a fatores como globalização, exigência e sofisticação dos clientes, avanços tecnológicos etc. Para enfrentar adequadamente e tirar proveito dessa situação, as organizações necessitam de profissionais capacitados que as auxiliem a transformar os desafios ambientais em oportunidades de negócios.

Esses profissionais têm que tomar decisões rápidas e eficazes em uma nova ordem mundial gerada pela revolução da informação. Nessa nova sociedade, o principal recurso estratégico é o conhecimento; nela, a informação simples não garante o diferencial competitivo. Assim, para assegurar lucro por um longo prazo, as organizações precisam aprender a criar e gerenciar o conhecimento a fim de obter vantagens reais.

Os investimentos em novas tecnologias (produto, processo, técnicas administrativas) são altos e arriscados, porém essenciais para a sobrevivência das organizações. O uso de recursos que garantam a eficácia desses investimentos e minimizem riscos é muito importante. Um desses recursos é a simulações computacional.

Além disso, o conhecimento e conjunto de suposições dos profissionais a respeito do ambiente de negócios e dos fatores críticos para seu sucesso é a base para o sucesso de uma organização. Assim sendo, os tomadores de decisão precisam se adaptar à nova realidade; para isso, precisam de ferramentas que possibilitem o teste de novos cenários antes que mudanças possam ocorrer.

Adquirir novos conhecimentos não é apenas uma questão de instruir-se com outros ou com suas obras, mas também aprender através da prática, da experimentação. Esta última pode ser representada pela simulação de sistemas; nela, o conhecimento a respeito de um sistema é adquirido através da análise de diversos cenários. 
O objetivo principal desta pesquisa foi demonstrar a aplicação prática da simulação, em particular daquela baseada na metodologia de Dinâmica de Sistemas, como um método de aquisição de conhecimento. Para tanto, um problema de dimensionamento de fila em uma fábrica foi estudado, por meio do pacote de simulação Stella.

Todos os objetivos propostos foram atingidos: uma aplicação prática da simulação computacional foi realizada; uma revisão bibliográfica sobre a simulação e sobre aquisição de conhecimento individual foi apresentada; e sugestões, sobre a forma de utilização da ferramenta de simulação para a aquisição do conhecimento, foram descritas durante o texto.

Cabe ressaltar que o conhecimento que aqui se buscou está relacionado apenas com o sistema de produção que foi simulado. Apesar de se supor natural a aquisição de conhecimentos a partir da utilização do pacote e dos passos de simulação, esse tipo de conhecimento não foi analisado.

Nesta ocasião, o ponto principal da simulação não é encontrar a resposta a algum problema do sistema, mas sim a inspeção das características comportamentais do sistema, o entendimento dos efeitos de cada mudança etc. O desafio era saber se a simulação é uma ferramenta eficiente, através da qual os tomadores de decisão poderiam adquirir conhecimento tanto sobre o sistema em que estão inseridos, quanto sobre seus subsistemas e ambiente.

Diversas vantagens da simulação puderam ser visualizadas através desse trabalho. A principal delas reside no fato de que ela permite às organizações experimentar regras de decisão alternativas dentro dos limites de um laboratório severamente controlado, sem interrupções das operações do sistema real. Outra grande vantagem observada refere-se à capacidade do modelo de simulação de comprimir o tempo e o espaço, permitindo a tomadores de decisão conhecer, em pouco tempo, as conseqüências de longo prazo concernentes às suas ações e ao sistema como um todo.

A simulação também pode ser usada na educação e treinamento de profissionais. Ela ajuda os administradores a enxergar as causas implícitas dos problemas a partir dos sintomas superficiais. Além disso, permite a reorganização das percepções em uma imagem mais clara e coerente da dinâmica dos sistemas. 
Além disso, dois dos maiores benefícios obtidos pelo usuário do modelo ao aplicar a simulação a um sistema de produção são, primeiro, uma melhor visão sistêmica do efeito que alterações locais terão sobre o desempenho global do sistema e, segundo, a possibilidade de uma reflexão sobre os diversos aspectos de um sistema de produção. Adicionalmente, sua aplicação ao projeto e avaliação de sistemas de produção traz benefícios como: maior eficiência na utilização de recursos, redução de estoque em processo, maior velocidade e confiabilidade de entrega, menores custos operacionais etc.

Deve-se ressaltar que, para ser uma ferramenta útil, a simulação deve ser utilizada corretamente: os passos do estudo devem ser seguidos sistematicamente, os dados devem ser analisados com cuidado e a implementação deve ser conduzida corretamente. Se tais cuidados forem negligenciados, erros advindos de uma simulação incorreta causarão danos e prejuízos ao sistema real.

Outra observação refere-se ao crescimento da confiabilidade da simulação à medida que é realizada por mais de uma pessoa; o trabalho em equipe conduz a um maior conhecimento e experiências, além de tornar menos freqüentes erros de interpretação e de tratamento estatístico.

A simulação computacional mostrou-se útil na criação de novos conceitos a respeito das relações entre os elementos do sistema estudado e adequada para a análise de diferentes cenários e políticas operacionais, além de auxiliar de maneira eficiente na aquisição de conhecimento individual sobre o sistema de produção simulado.

Tais afirmações podem ser observadas através da maneira como a simulação da fábrica de componentes plásticos foi capaz de transformar um problema não estruturado em uma fonte poderosa de conhecimento. As idéias para melhoria do sistema foram traduzidas em mudanças específicas na política e estrutura das estações de processamento (variações no número de estações e variações no tempo de processamento). Essas mudanças, e seus efeitos, permitiram a aquisição de conhecimento sobre o sistema.

Assim sendo, conclui-se que a simulação computacional é uma ferramenta muito útil na aquisição de conhecimentos sobre o sistema estudado. Isso porque proporciona a superação de algumas das dificuldades com as quais os tomadores de 
decisão se confrontam nas organizações, dificuldades estas que vêm crescendo em quantidade e complexidade de maneira cada vez mais severa num ambiente altamente mutável. 


\section{ANEXOS}

ANEXO 01 - LISTA DOS MODELOS SIMULADOS E SEUS PARÂMETROS

ANEXO 02 - RESULTADOS DAS SIMULAÇÕES 
ANEXO 1

LISTA DOS MODELOS SIMULADOS E SEUS PARÂMETROS 


\section{LISTA DOS MODELOS SIMULADOS E SEUS PARÂMETROS}

\begin{tabular}{|c|c|c|c|c|c|c|c|}
\hline \multirow[b]{2}{*}{ Modelo } & \multirow[b]{2}{*}{ Taxa de Chegada } & \multicolumn{3}{|c|}{ Tempo de processamento } & \multicolumn{3}{|c|}{ Número de estações } \\
\hline & & Molde & Corte & Montagem & Molde & Corte & Montagem \\
\hline 1 & 0,5 & 4 & 3 & 5 & 1 & 1 & 1 \\
\hline 2 & 0,5 & 4 & 3 & 5 & 1 & 1 & 2 \\
\hline 3 & 0,5 & 4 & 3 & 5 & 1 & 2 & 1 \\
\hline 4 & 0,5 & 4 & 3 & 5 & 1 & 2 & 2 \\
\hline 5 & 0,5 & 4 & 3 & 5 & 2 & 1 & 1 \\
\hline 6 & 0,5 & 4 & 3 & 5 & 2 & 1 & 2 \\
\hline 7 & 0,5 & 4 & 3 & 5 & 2 & 2 & 1 \\
\hline 8 & 0,5 & 4 & 3 & 5 & 2 & 2 & 2 \\
\hline 9 & 0,5 & 4 & 3 & 2,5 & 1 & 1 & 1 \\
\hline 10 & 0,5 & 4 & 3 & 2,5 & 1 & 1 & 2 \\
\hline 11 & 0,5 & 4 & 3 & 2,5 & 1 & 2 & 1 \\
\hline 12 & 0,5 & 4 & 3 & 2,5 & 1 & 2 & 2 \\
\hline 13 & 0,5 & 4 & 3 & 2,5 & 2 & 1 & 1 \\
\hline 14 & 0,5 & 4 & 3 & 2,5 & 2 & 1 & 2 \\
\hline 15 & 0,5 & 4 & 3 & 2,5 & 2 & 2 & 1 \\
\hline 16 & 0,5 & 4 & 3 & 2,5 & 2 & 2 & 2 \\
\hline 17 & 0,5 & 4 & 1,5 & 5 & 1 & 1 & 1 \\
\hline 18 & 0,5 & 4 & 1,5 & 5 & 1 & 1 & 2 \\
\hline 19 & 0,5 & 4 & 1,5 & 5 & 1 & 2 & 1 \\
\hline 20 & 0,5 & 4 & 1,5 & 5 & 1 & 2 & 2 \\
\hline 21 & 0,5 & 4 & 1,5 & 5 & 2 & 1 & 1 \\
\hline 22 & 0,5 & 4 & 1,5 & 5 & 2 & 1 & 2 \\
\hline 23 & 0,5 & 4 & 1,5 & 5 & 2 & 2 & 1 \\
\hline 24 & 0,5 & 4 & 1,5 & 5 & 2 & 2 & 2 \\
\hline 25 & 0,5 & 4 & 1,5 & 2,5 & 1 & 1 & 1 \\
\hline 26 & 0,5 & 4 & 1,5 & 2,5 & 1 & 1 & 2 \\
\hline 27 & 0,5 & 4 & 1,5 & 2,5 & 1 & 2 & 1 \\
\hline 28 & 0,5 & 4 & 1,5 & 2,5 & 1 & 2 & 2 \\
\hline 29 & 0,5 & 4 & 1,5 & 2,5 & 2 & 1 & 1 \\
\hline 30 & 0,5 & 4 & 1,5 & 2,5 & 2 & 1 & 2 \\
\hline 31 & 0,5 & 4 & 1,5 & 2,5 & 2 & 2 & 1 \\
\hline 32 & 0,5 & 4 & 1,5 & 2,5 & 2 & 2 & 2 \\
\hline 33 & 0,5 & 2 & 3 & 5 & 1 & 1 & 1 \\
\hline
\end{tabular}




\begin{tabular}{|c|c|c|c|c|c|c|c|}
\hline \multirow[b]{2}{*}{ Modelo } & \multirow[b]{2}{*}{ Taxa de Chegada } & \multicolumn{3}{|c|}{ Tempo de processamento } & \multicolumn{3}{|c|}{ Número de estações } \\
\hline & & Molde & Corte & Montagem & Molde & Corte & Montagem \\
\hline 34 & 0,5 & 2 & 3 & 5 & 1 & 1 & 2 \\
\hline 35 & 0,5 & 2 & 3 & 5 & 1 & 2 & 1 \\
\hline 36 & 0,5 & 2 & 3 & 5 & 1 & 2 & 2 \\
\hline 37 & 0,5 & 2 & 3 & 5 & 2 & 1 & 1 \\
\hline 38 & 0,5 & 2 & 3 & 5 & 2 & 1 & 2 \\
\hline 39 & 0,5 & 2 & 3 & 5 & 2 & 2 & 1 \\
\hline 40 & 0,5 & 2 & 3 & 5 & 2 & 2 & 2 \\
\hline & & & & & & & \\
\hline 41 & 0,5 & 2 & 3 & 2,5 & 1 & 1 & 1 \\
\hline 42 & 0,5 & 2 & 3 & 2,5 & 1 & 1 & 2 \\
\hline 43 & 0,5 & 2 & 3 & 2,5 & 1 & 2 & 1 \\
\hline 44 & 0,5 & 2 & 3 & 2,5 & 1 & 2 & 2 \\
\hline 45 & 0,5 & 2 & 3 & 2,5 & 2 & 1 & 1 \\
\hline 46 & 0,5 & 2 & 3 & 2,5 & 2 & 1 & 2 \\
\hline 47 & 0,5 & 2 & 3 & 2,5 & 2 & 2 & 1 \\
\hline 48 & 0,5 & 2 & 3 & 2,5 & 2 & 2 & 2 \\
\hline 49 & 0,5 & 2 & 1,5 & 5 & 1 & 1 & 1 \\
\hline 50 & 0,5 & 2 & 1,5 & 5 & 1 & 1 & 2 \\
\hline 51 & 0,5 & 2 & 1,5 & 5 & 1 & 2 & 1 \\
\hline 52 & 0,5 & 2 & 1,5 & 5 & 1 & 2 & 2 \\
\hline 53 & 0,5 & 2 & 1,5 & 5 & 2 & 1 & 1 \\
\hline 54 & 0,5 & 2 & 1,5 & 5 & 2 & 1 & 2 \\
\hline 55 & 0,5 & 2 & 1,5 & 5 & 2 & 2 & 1 \\
\hline 56 & 0,5 & 2 & 1,5 & 5 & 2 & 2 & 2 \\
\hline & & & & & & & \\
\hline 57 & 0,5 & 2 & 1,5 & 2,5 & 1 & 1 & 1 \\
\hline 58 & 0,5 & 2 & 1,5 & 2,5 & 1 & 1 & 2 \\
\hline 59 & 0,5 & 2 & 1,5 & 2,5 & 1 & 2 & 1 \\
\hline 60 & 0,5 & 2 & 1,5 & 2,5 & 1 & 2 & 2 \\
\hline 61 & 0,5 & 2 & 1,5 & 2,5 & 2 & 1 & 1 \\
\hline 62 & 0,5 & 2 & 1,5 & 2,5 & 2 & 1 & 2 \\
\hline 63 & 0,5 & 2 & 1,5 & 2,5 & 2 & 2 & 1 \\
\hline 64 & 0,5 & 2 & 1,5 & 2,5 & 2 & 2 & 2 \\
\hline
\end{tabular}


ANEXO 02

RESULTADOS DAS SIMULAÇÕES 


\section{RESULTADOS DAS SIMULAÇÕES}

\begin{tabular}{|c|c|c|c|c|c|c|}
\hline \multirow{2}{*}{ Modelo } & \multirow{2}{*}{$\begin{array}{l}\text { Tempo médio de } \\
\text { processamento }\end{array}$} & \multirow{2}{*}{$\begin{array}{l}\text { Maior tempo de } \\
\text { processamento }\end{array}$} & \multicolumn{3}{|c|}{ Tamanho das filas } & \multirow{2}{*}{$\begin{array}{l}\text { Elementos } \\
\text { Atendidos }\end{array}$} \\
\hline & & & Molde & Corte & Montagem & \\
\hline 1 & 24,59 & 67,00 & 9 & 8 & 10 & 4660 \\
\hline 2 & 24,46 & 77,00 & 13 & 10 & 10 & 6614 \\
\hline 3 & 23,47 & 77,00 & 8 & 4 & 12 & 4838 \\
\hline 4 & 18,86 & 68,00 & 7 & 6 & 8 & 6042 \\
\hline 5 & 24,91 & 90,00 & 6 & 8 & 12 & 4850 \\
\hline 6 & 18,66 & 62,50 & 6 & 10 & 8 & 6672 \\
\hline 7 & 24,01 & 92,00 & 6 & 6 & 12 & 5092 \\
\hline 8 & 16,75 & 54,50 & 6 & 6 & 8 & 7284 \\
\hline 9 & 18,56 & 51,00 & 10 & 8 & 8 & 5408 \\
\hline 10 & 21,00 & 70,50 & 11 & 10 & 4 & 6720 \\
\hline 11 & 17,48 & 58,50 & 8 & 4 & 8 & 5798 \\
\hline 12 & 16,00 & 52,00 & 11 & 4 & 6 & 6214 \\
\hline 13 & 17,07 & 61,00 & 6 & 10 & 8 & 6154 \\
\hline 14 & 15,76 & 58,00 & 6 & 10 & 4 & 6590 \\
\hline 15 & 15,72 & 78,00 & 5 & 6 & 10 & 6728 \\
\hline 16 & 13,41 & 49,00 & 7 & 6 & 6 & 7804 \\
\hline 17 & 22,53 & 80,50 & 9 & 6 & 10 & 4800 \\
\hline 18 & 21,15 & 55,00 & 11 & 6 & 10 & 7060 \\
\hline 19 & 22,39 & 90,00 & 8 & 2 & 10 & 4800 \\
\hline 20 & 18,03 & 55,50 & 10 & 4 & 8 & 5862 \\
\hline 21 & 22,46 & 74,00 & 6 & 8 & 12 & 5074 \\
\hline 22 & 15,37 & 54,50 & 6 & 6 & 10 & 7164 \\
\hline 23 & 21,56 & 83,00 & 6 & 4 & 12 & 5222 \\
\hline 24 & 15,01 & 70,00 & 5 & 4 & 10 & 7468 \\
\hline 25 & 15,79 & 50,50 & 9 & 8 & 8 & 5670 \\
\hline 26 & 17,68 & 67,50 & 13 & 6 & 6 & 7432 \\
\hline 27 & 15,76 & 56,50 & 8 & 2 & 8 & 5754 \\
\hline 28 & 14,20 & 57,50 & 7 & 2 & 6 & 6172 \\
\hline 29 & 14,11 & 46,00 & 7 & 8 & 8 & 6748 \\
\hline 30 & 12,43 & 40,00 & 6 & 6 & 6 & 7538 \\
\hline 31 & 13,52 & 55,50 & 7 & 4 & 10 & 6892 \\
\hline
\end{tabular}




\begin{tabular}{|c|c|c|c|c|c|c|}
\hline \multirow{2}{*}{ Modelo } & \multirow{2}{*}{$\begin{array}{l}\text { Tempo médio de } \\
\text { processamento }\end{array}$} & \multirow{2}{*}{$\begin{array}{l}\text { Maior tempo de } \\
\text { processamento }\end{array}$} & \multicolumn{3}{|c|}{ Tamanho das filas } & \multirow{2}{*}{$\begin{array}{l}\text { Elementos } \\
\text { Atendidos }\end{array}$} \\
\hline & & & Molde & Corte & Montagem & \\
\hline 32 & 11,74 & 41,00 & 7 & 6 & 6 & 8010 \\
\hline 33 & 20,92 & 65,50 & 7 & 8 & 10 & 4980 \\
\hline 34 & 19,53 & 56,00 & 9 & 10 & 10 & 7944 \\
\hline 35 & 20,84 & 85,00 & 6 & 4 & 14 & 5166 \\
\hline 36 & 14,43 & 50,50 & 6 & 6 & 8 & 7206 \\
\hline 37 & 22,22 & 110,00 & 5 & 8 & 12 & 5048 \\
\hline 38 & 16,85 & 57,00 & 5 & 8 & 8 & 6560 \\
\hline 39 & 20,73 & 101,00 & 4 & 6 & 10 & 5370 \\
\hline 40 & 15,05 & 62,50 & 5 & 6 & 10 & 7460 \\
\hline 41 & 14,22 & 38,50 & 6 & 8 & 10 & 6158 \\
\hline 42 & 15,89 & 53,00 & 9 & 12 & 8 & 8478 \\
\hline 43 & 13,14 & 46,50 & 6 & 6 & 8 & 6738 \\
\hline 44 & 11,18 & 35,50 & 6 & 6 & 4 & 7706 \\
\hline 45 & 14,99 & 50,00 & 6 & 10 & 8 & 6292 \\
\hline 46 & 13,69 & 57,00 & 4 & 8 & 6 & 6762 \\
\hline 47 & 13,22 & 54,50 & 5 & 6 & 10 & 7020 \\
\hline 48 & 11,24 & 41,00 & 5 & 6 & 6 & 8272 \\
\hline 49 & 18,98 & 80,50 & 6 & 8 & 10 & 5226 \\
\hline 50 & 15,23 & 52,00 & 9 & 10 & 14 & 9410 \\
\hline 51 & 18,91 & 68,00 & 6 & 2 & 10 & 5224 \\
\hline 52 & 13,12 & 60,50 & 6 & 4 & 8 & 7146 \\
\hline 53 & 19,63 & 130,00 & 7 & 8 & 10 & 5318 \\
\hline 54 & 13,61 & 57,50 & 4 & 6 & 8 & 7480 \\
\hline 55 & 19,25 & 71,50 & 4 & 4 & 12 & 5432 \\
\hline 56 & 13,16 & 52,50 & 6 & 4 & 10 & 7702 \\
\hline 57 & 11,53 & 39,00 & 6 & 8 & 10 & 6770 \\
\hline 58 & 11,61 & 34,50 & 11 & 8 & 8 & 10524 \\
\hline 59 & 11,29 & 37,50 & 6 & 4 & 8 & 6900 \\
\hline 60 & 9,83 & 32,50 & 7 & 4 & 8 & 7664 \\
\hline 61 & 12,03 & 47,50 & 5 & 10 & 10 & 6988 \\
\hline 62 & 10,15 & 41,50 & 5 & 6 & 6 & 8042 \\
\hline 63 & 11,58 & 47,00 & 7 & 4 & 10 & 7298 \\
\hline 64 & 9,32 & 41,00 & 5 & 4 & 6 & 8408 \\
\hline
\end{tabular}




\section{REFERÊNCIAS BIBLIOGRÁFICAS}

ACKOFF, Russell L.; SASIENI, Maurice W. Pesquisa operacional. Rio de Janeiro: Livros Técnicos e Científicos, 1977.

ANDERSEN, D. F.; RICHARDSON G. P. Toward a pedagogy of system dynamics. In: LEGASTO JR, A. A.; FORRESTER, J.W.; LYNEIS, J.M. (eds.). System Dynamics. Amsterdam: North-Holland Publishing Company, 1980.

ANDERSSON, C.; KARLSSON, L. A system dynamics simulation study of a software development process. Lund, Suécia, 2001. Disponível em: $<$ http://www.telecom.lth.se/SERG/Master/5419.pdf > . Acesso em: 16 maio 2002.

ARANTES, T. F. Pesquisa bibliográfica nas ciências biomédicas. São Paulo: Faculdade de Odontologia - USP. Revista n.XIII, 1971.

ARAÚJO, V. M. R. H.. Sistemas de informação: nova abordagem teórico-conceitual. Ciência da Informação, Brasília, v. 24, n. 1, p. 54-76, jan./abr. 1995.

BANKS, J. Selecting simulation software. In: WINTER SIMULATION CONFERENCE, 1991, New York. Proceedings... New York: Association for Computing Machinery, 2000. p. 15-20.

BANKS, J.; CARSON II, J.S.; NELSON, B.L. Discrete-event system simulation. 2. ed. New Jersey: Prentice Hall, 1996.

BARBOSA, W. do V. Tempos pós-modernos. In: LYOTARD, J-F. O pós-moderno. Rio de Janeiro: J. Olympio, 1986. p. vii-xviii. 
BARTON, R. F. A primer on simulation and gaming. Englewood Cliffs, New Jersey: Prentice-Hall, 1970.

BATEMAN, R. E. et al. System improvement using simulation. Orem, Utah: Promodel Corporation, 1997.

BERTALANFFY, L.V. Teoria geral dos sistemas. Petrópolis : Vozes, 1977.

BUFFA, E.S. Administração da produção. Rio de Janeiro: Livros Técnicos e Científicos, 1972.

BUFFA, E.S.; DYER J.S. Management science/operations research model formulation and solution methods. New York: John Wiley \& Sons, 1977.

CAPRA, F. Das partes para o todo: pensamento sistêmico em ecologia e educação. Em: http://www.eps.ufsc.br/disciplinas/fialho/consciencia/congresso/CAPRA.html. Acesso em: 12 dezembro 2001.

CASSANDRAS, C.G.; LAFORTUNE, S. Introduction to discrete event systems. Boston: Kluwer Academic Publishers, 1999.

CHECKLAND, P. Systems thinking, systems practice. New York: John Wiley, 1981.

CHURCHMAN, C.W. The systems approach. New York: Dell Publ., 1968.

COVER, J. Introduction to System Dynamics. Powersim Press, 1996.

CREMA, R. Abordagem holística: integração do método analítico e sintético. In: BRANDÃO, D.M.S.; CREMA, R. (Orgs.). O novo paradigma holístico: ciência, filosofia, arte e mística. São Paulo: Summus, 1991. 
DAVENPORT, T. H.; PRUSAK, L. Conhecimento empresarial: como as organizações gerenciam o seu capital intelectual. 3. ed. Rio de Janeiro: Campus, 1998.

DEATON, M. L.; WINEBRAKE, J.J. Dynamic modeling of environmental systems. Springer-Verlag, 2000.

DIBELLA, A. J.; NEVIS, E. C. Como as organizações aprendem: uma estratégia integrada voltada para a construção de capacidade de aprendizagem. São Paulo: Educator, 1999.

DRUCKER, P. F. Sociedade pós-capitalista. 2. ed. São Paulo: Pioneira, 1994.

ECKER, J.G.; KUPFERSCHMID, M. Introduction to operations research. New York: John Wiley \& Sons, 1988.

EHRLICH, Pierre Jacques. Pesquisa operacional: curso introdutório. 5. ed. São Paulo: Atlas, 1985.

ELLENRIEDER, Alberto von. Pesquisa operacional. Rio de Janeiro: Almeida Neves Editores Ltda, 1971.

EMSHOFF James R.; SISSON, Roger L. Design and use of computer simulation models. New York: MacMillan, 1970.

EVANS, George W; WALLACE, Graham F.; SUTHERLAND, Georgia L. Simulation using digital computers. Englewood Cliffs, N.J.: Prentice-Hall, 1967.

FACHIN, O. Fundamentos de metodologia. 3. ed. São Paulo: Saraiva, 2001.

FERRARI, A. T. Metodologia da ciência. 3. ed. Rio de Janeiro: Kennedy, 1974. 
FLEURY, A.C.; FLEURY, M.T.L. Aprendizagem e Inovação Organizacional: as experiências de Japão, Coréia e Brasil. São Paulo: Atlas, 1995.

FORRESTER, J.W. Industrial Dynamics. Portland: Productivity Press, 1961.

FORRESTER, J.W. Urban Dynamics. Cambridge, Mass.: M.I.T. Press, 1969.

FORRESTER, J.W. World Dynamics. Cambridge, Mass.: Wright-Allen Press, 1971.

GALLAHER, E. J. Biological system dynamics: from personal discovery to universal application. Simulation, 66:4, p. 243-257. 1996.

GEUS, A. The living company. Boston: Harvard Business School Press, 1997.

HARRELL, C; TUMAY, K. Simulation made easy: a manager's guide. Norcross: Engineering \& Management Press, 1995.

HERMANN, C. C.; MAGEE J.F. Operations research for management. In: BURSK, E.C.; CHAPMAN, J.F. (Eds). New decision-making tools for managers. New York: The Mentor Executive Library, 1963.

HIGH PERFORMANCE SYSTEM. STELLA research. Hanover: High Performance System, 1997.

HILLIER, F.S.; LIEBERMAN, G.J. Introdução à pesquisa operacional. São Paulo: Editora da Universidade de São Paulo, 1988.

JOHNSON-LAIRD, P. N. Mental models. Cambridge: Cambridge University Press, 1983. 
KELTON, W. D., SADOWSKI, R. P., SADOWSKI, D. A. Simulation with Arena. New York: McGraw-Hill, 1998.

KHEIR, N.A. (Ed.) Systems modeling and computer simulation. 2. ed. New York: Marcel Dekker, 1996.

KITTEL, C. The nature and development of operations research. Science, p. 105$150,1947$.

KLEIN, D.A. A gestão estratégica do capital intelectual: recursos para a economia baseada em conhecimento. Rio de Janeiro: Qualitymark, 1998.

LABORATÓRIO DE DINÂMICA INDUSTRIAL. Disponível em: $<$ http://www.proex.ufscar.br/textos/dinamicaindustrial.doc $>$ Acesso em: 22 setembro 2002.

LANDES, David S. A riqueza e a pobreza das nações: por que algumas são tão ricas e outras são tão pobres. 6. ed. Rio de Janeiro: Campus, 1998.

LAW, A. M.; KELTON, W. D. Simulation modeling and analysis. 3. ed. Boston: McGraw-Hill, 2000.

LEGASTO JR, A. A.; FORRESTER, J.W.; LYNEIS, J.M. (eds.). System Dynamics. Amsterdam: North-Holland Publishing Company, 1980.

LEGASTO JR, A. A.; MACIARIELLO, J. System dynamics: a critical review. In: LEGASTO JR, A. A.; FORRESTER, J.W.; LYNEIS, J.M. (eds.). System Dynamics. Amsterdam: North-Holland Publishing Company, 1980.

LEPIKSON, H. A. SOMA - Sistema Orgânico de Manufatura Autônoma: uma nova abordagem distribuída para o gerenciamento do chão de fábrica. 1998. $273 \mathrm{f}$. Tese (Doutorado) - Universidade Federal de Santa Catarina, Florianópolis. 
MACHLINE, Claude et al. Manual de administração da produção. 3. ed. v.2. Rio de Janeiro: Ed. da Fundação Getúlio Vargas, 1975.

MACULAN, A. M. As novas estratégias tecnológicas das multinacionais do setor de telecomunicações. Revista de Economia Política, v. 3, n. 2. 1992.

MEDEIROS, Otoniel Marcelino. Pesquisa operacional. Revista da ETFRN. Natal, ano 12, v.2, p.53-60, 2000.

MEIER, R. C; NEWELL, W.T.; PAZER, H. L. Simulation in business and economics. New Jersey: Prentice Hall, 1969.

MIRSHAWKA, Victor. Elementos da pesquisa operacional. São Paulo: Nobel, 1977.

MORECROFT, J.D.W; STERMAN, J.D. (ed.). Modeling for learning organizations. Portland: Productivity Press, 1994.

MUSSELMAN, K.J. Guidelines for simulation project success. In: WINTER SIMULATION CONFERENCE, 1993, Los Angeles, California . Proceedings... Los Angeles, p. 58-64.

NAYLOR, T.H. Computer simulation experiments with models of economic systems. New York: John Wiley \& Sons, 1971.

NAYLOR, T.H. et al. Técnicas de simulação em computadores. São Paulo: Editora Vozes, 1971.

NONAKA, I.; TAKEUCHI, H. Criação do conhecimento na empresa: como empresas japonesas geram a dinâmica da inovação. Rio de Janeiro: Campus, 1997. 
POLANYI, M. The tacit dimension. Londres: Routledge \& Kegan Paul, 1966.

RAPOPORT, A. Aspectos matemáticos da análise geral dos sistemas. In: BERTAlAnfFY, L. V. et al. Teoria dos sistemas. Rio de Janeiro: Fundação Getúlio Vargas, 1976.

ROBERTS, Nancy et al. (Ed.). Introduction to computer simulation: the system dynamics approach. Reading, Mass.: Addison-Wesley, 1983.

RORTY, R. A filosofia e o espírito da natureza. Lisboa: Publicações Dom Quixote, 1988

SALIBY, E. Repensando a simulação: a amostragem descritiva. São Paulo: Atlas, 1989.

SANTOS, J. F. dos. O que é pós-moderno. 8. ed. São Paulo: Brasiliense, 1990.

SELLITTO, M. A. Uma aplicação da programação linear em serviços:

aumentando o ganho em transportes. Disponível em: $<$ http://www.intercorpconsultoria.com.br/materia.asp? $\operatorname{cod}$ not $=755 \& \operatorname{cod}$ area $=3 \& \mathrm{~m}=\mathrm{s}>$ Acesso em: 17 março 2002.

SENGE, P. M. A quinta disciplina. São Paulo: Best Seller, 1990.

SENGE, P. M.; STERMAN, J. D. Systems thinking and organizational learning: acting locally and thinking globally in the organization of the future. In: MORECROFT, J.D.W; STERMAN, J.D. (ed.). Modeling for learning organizations. Portland: Productivity Press, 1994.

SHAMBLIN, James E.; STEVENS Jr., G.T. Operations research: a fundamental approach. New York: McGraw-Hill, 1974. 
SHANNON, R.E. Systems simulation: the art and science. Englewood Cliffs, N. J.: Prentice-Hall, 1975.

SHIMIZU, T. Simulação em computador digital. São Paulo: Editora Edgard Blücher, 1975.

SILVA, E. L. da; MENEZES, E. M. Metodologia da pesquisa e elaboração de dissertação. 2. ed. revisada. Florianópolis: Laboratório de Ensino à Distancia, 2001. SOARES, Luiz Fernando Gomes. Modelagem e simulação discreta de sistemas. São Paulo: IME - USP, 1990.

STARR, P. J. Modeling issues and decision in system dynamics. In: LEGASTO JR, A. A.; FORRESTER, J.W.; LYNEIS, J.M. (eds.). System Dynamics. Amsterdam: North-Holland Publishing Company, 1980.

TERRA, J.C.C. Gestão do conhecimento: aspectos conceituais e estudo exploratório sobre as práticas de empresas brasileiras. 1999. 293 f. Tese (Doutorado em Engenharia de Produção) - Escola Politécnica, Universidade de São Paulo, São Paulo.

THUROW, L. C. O futuro do capitalismo: como as forças econômicas de hoje moldam o mundo de amanhã. Rio de Janeiro: Rocco, 1997.

TRIPODI, T. et al. Análise da pesquisa social: diretrizes para o uso da pesquisa em serviço social e em ciências sociais. Rio de Janeiro: Francisco Alves, 1981.

VILLELA, P.R.C. Modelagem e simulação da dinâmica de sistemas: conceito e prática. In: WORKSHOP DA SOCIEDADE BRASILEIRA DE INFORMÁTICA APLICADA À AGROPECUÁRIA E AGROINDÚSTRIA, 2., 2000, Campinas. Disponível em: < http://www.sbiagro.org.br/iiwork>Acesso em: 09 agosto 2002. 
WAGNER, H. M. Principles of operations research: with applications to managerial decisions. 2.ed. New Jersey: Prentice Hall, 1975.

WATSON, H.J.; BLACKSTONE Jr., J. H. Computer simulation. 2. ed. New York: John Wiley \& Sons, 1981. 